Supporting information for Inhibitory Effects of Phenylpropanoid Derivatives from Oenanthe javanica on Antigen-stimulated Degranulation in RBL-2H3 Cells

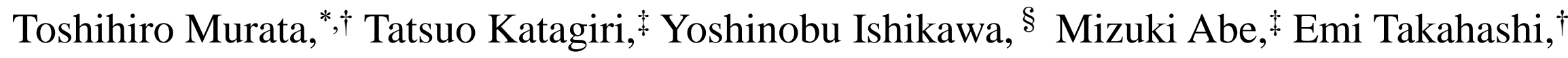
Ruka Iwahana, ${ }^{\dagger}$ Yuko Sakamoto, ${ }^{\dagger}$ and Kenroh Sasaki ${ }^{\dagger}$

${ }^{\dagger}$ Department of Pharmacognosy, Tohoku Medical and Pharmaceutical University, Aoba-ku, Sendai 981-8558, Japan

${ }^{\ddagger}$ Graduate School of Medicine and Pharmaceutical Science, University of Toyama, 2630, Sugitani, Toyama 930-0194, Japan

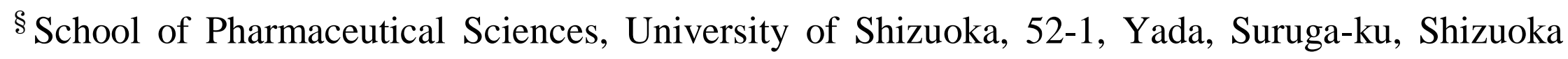
422-8526, Japan

*Corresponding author. Tel: +8122727 0086. Fax: +81227270220.

E-mail address: murata-t@tohoku-mpu.ac.jp 


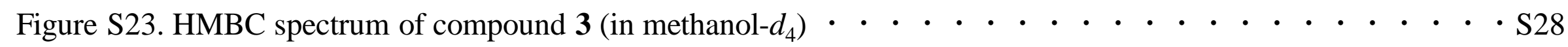

Figure S24. ${ }^{1} \mathrm{H}$ NMR spectrum of compound 3a (in methanol- $\left.d_{4}\right) \cdot$ • • • • • • • • • • • • • • • • • • S29

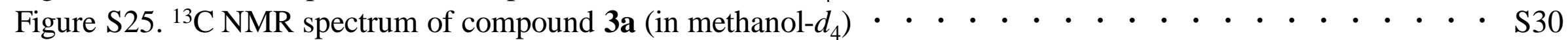

Figure S26. ${ }^{1} \mathrm{H}-{ }^{1} \mathrm{H}$ COSY spectrum of compound $3 \mathbf{3}$ (in methanol- $\left.d_{4}\right) \cdot$ • • • • • • • • • • • • • • • • • • S31

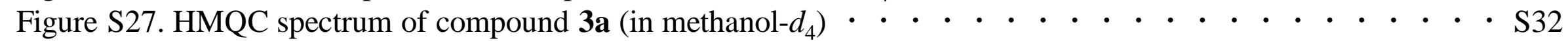

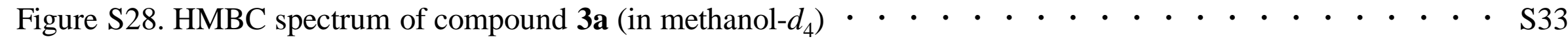

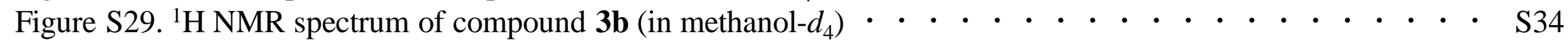

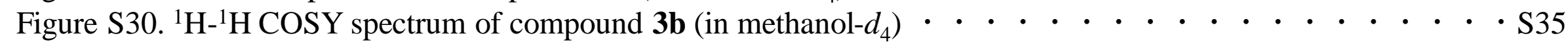

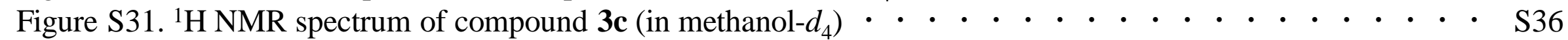

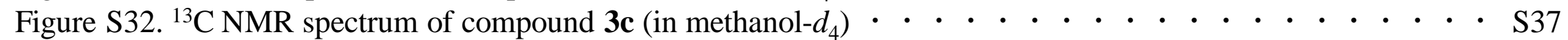

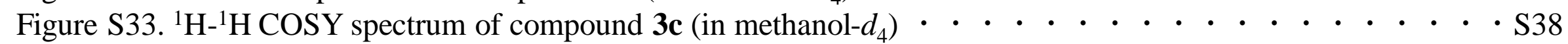

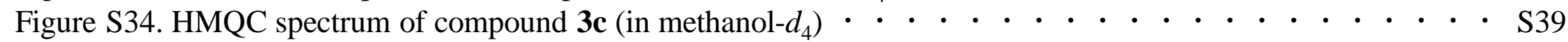

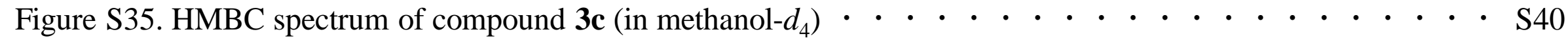

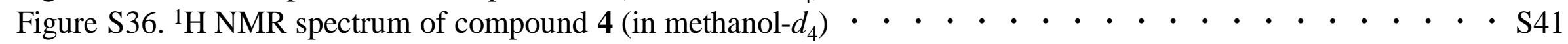

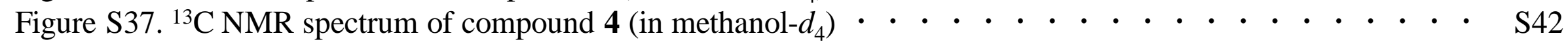

Figure S38. ${ }^{1} \mathrm{H}-{ }^{1} \mathrm{H}$ COSY spectrum of compound 4 (in methanol- $\left.d_{4}\right) \cdot$ • • • • • • • • • • • • • • • • • S43

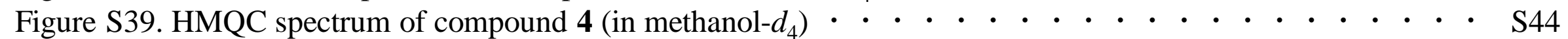

Figure S40. HMBC spectrum of compound 4 (in methanol- $\left.d_{4}\right) \cdot$ • • • • • • • • • • • • • • • • • • • S45

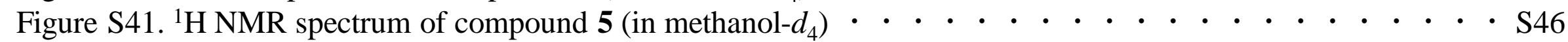

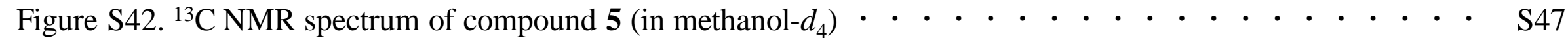

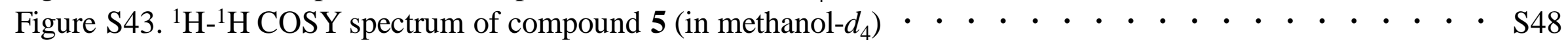

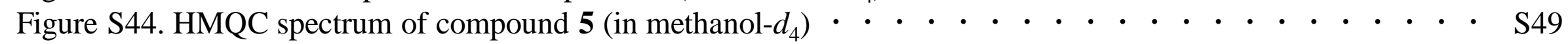

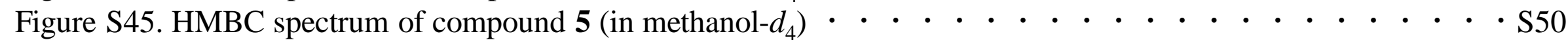

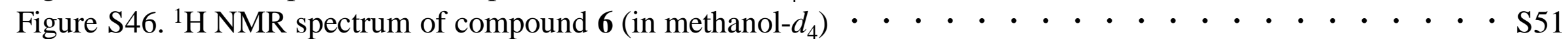

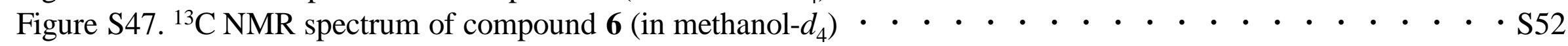

Figure S48. ${ }^{1} \mathrm{H}-{ }^{1} \mathrm{H}$ COSY spectrum of compound 6 (in methanol- $\left.d_{4}\right) \cdot$ • • • • • • • • • • • • • • • • • • S53

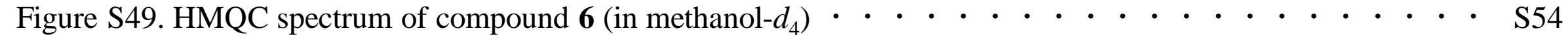

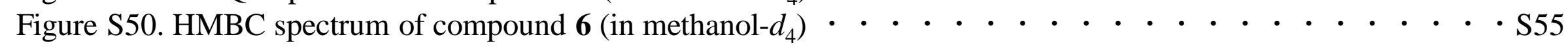


Figure S51. ${ }^{1} \mathrm{H}$ NMR spectrum for NOE of compound 6 (in methanol- $d_{4}, 270 \mathrm{MHz}$ ) • • • • • • • • • S56

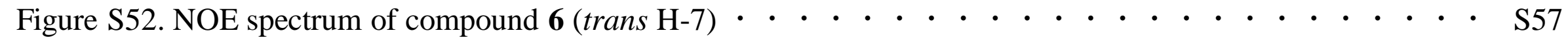
Figure S53. NOE spectrum of compound 6 (cis H-2 and 6) • • • • • • • • • • • • • • • • • • • • • • S58

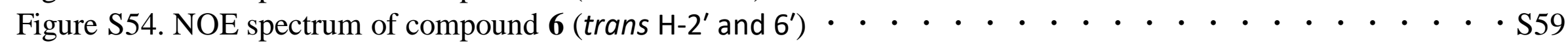

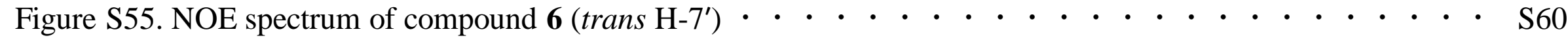

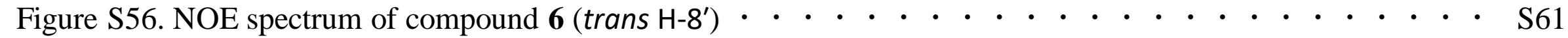

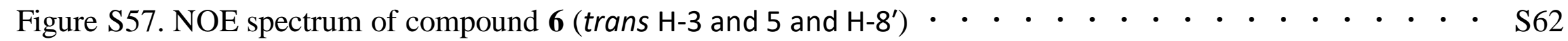

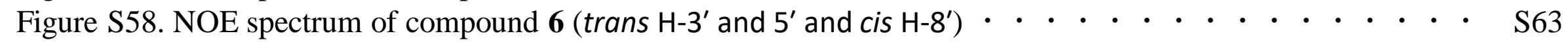

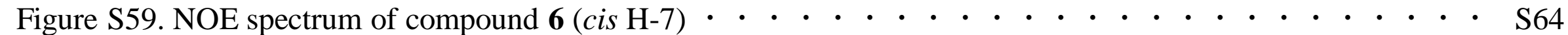
Figure S60. NOE spectrum of compound $6\left(\right.$ cis $\left.\mathrm{H}-7^{\prime}\right)$ ・ • • • • • • • • • • • • • • • • • • • • • • • S65

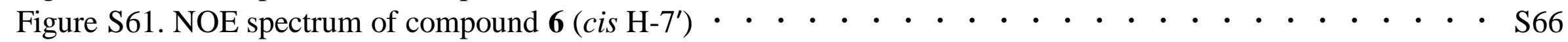

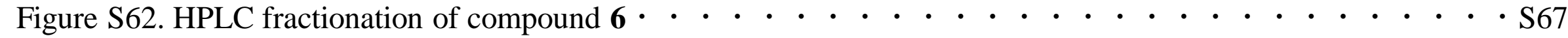



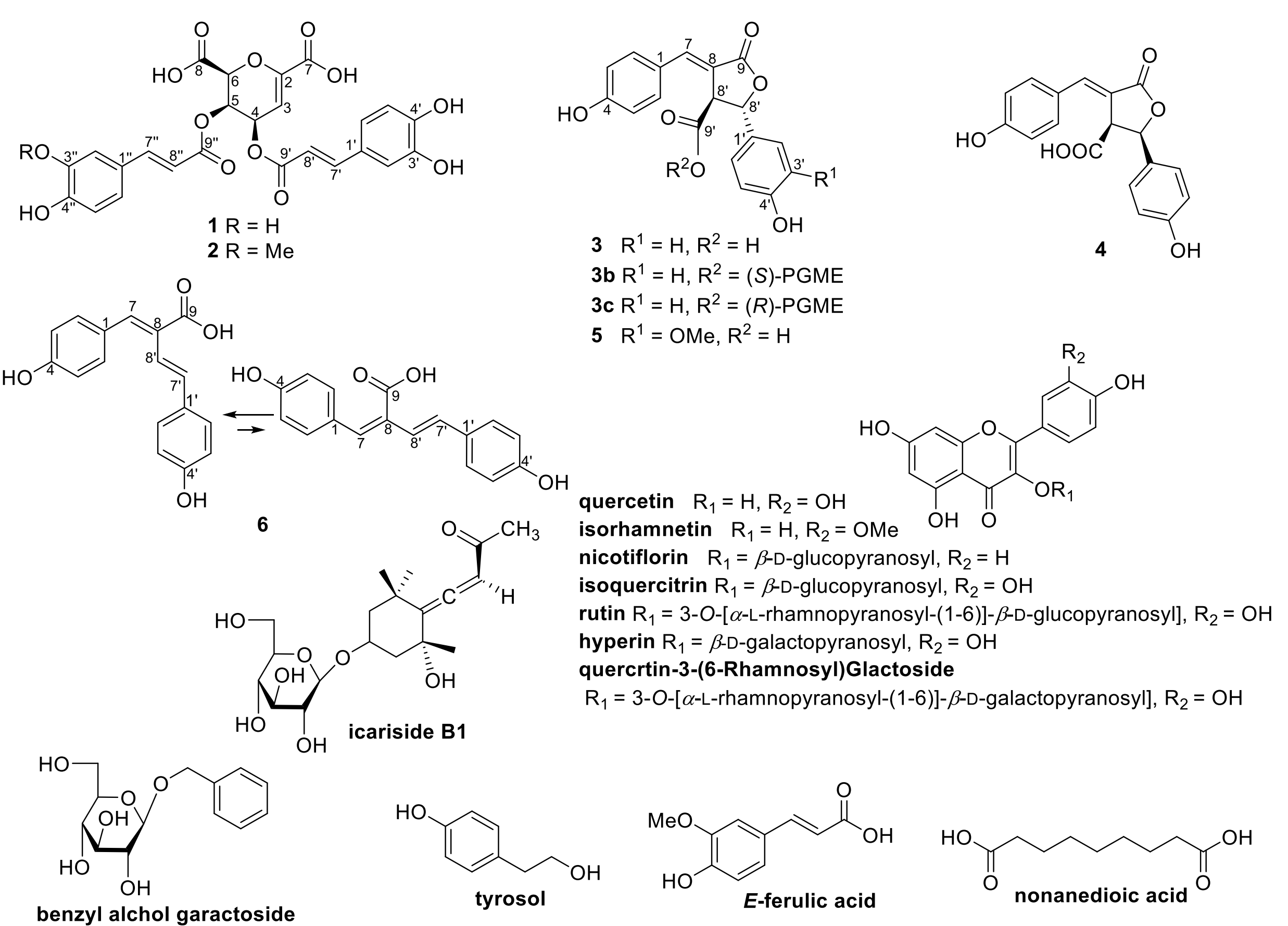<smiles>CCC(Cl)(Cl)C(Cl)(Cl)Cl</smiles><smiles>O=C(O)CCCCCCCC(=O)O</smiles>

Figure S1. Structures of 1-6, 3b, 3c, and known compounds isolated form Oenanthe javanica 

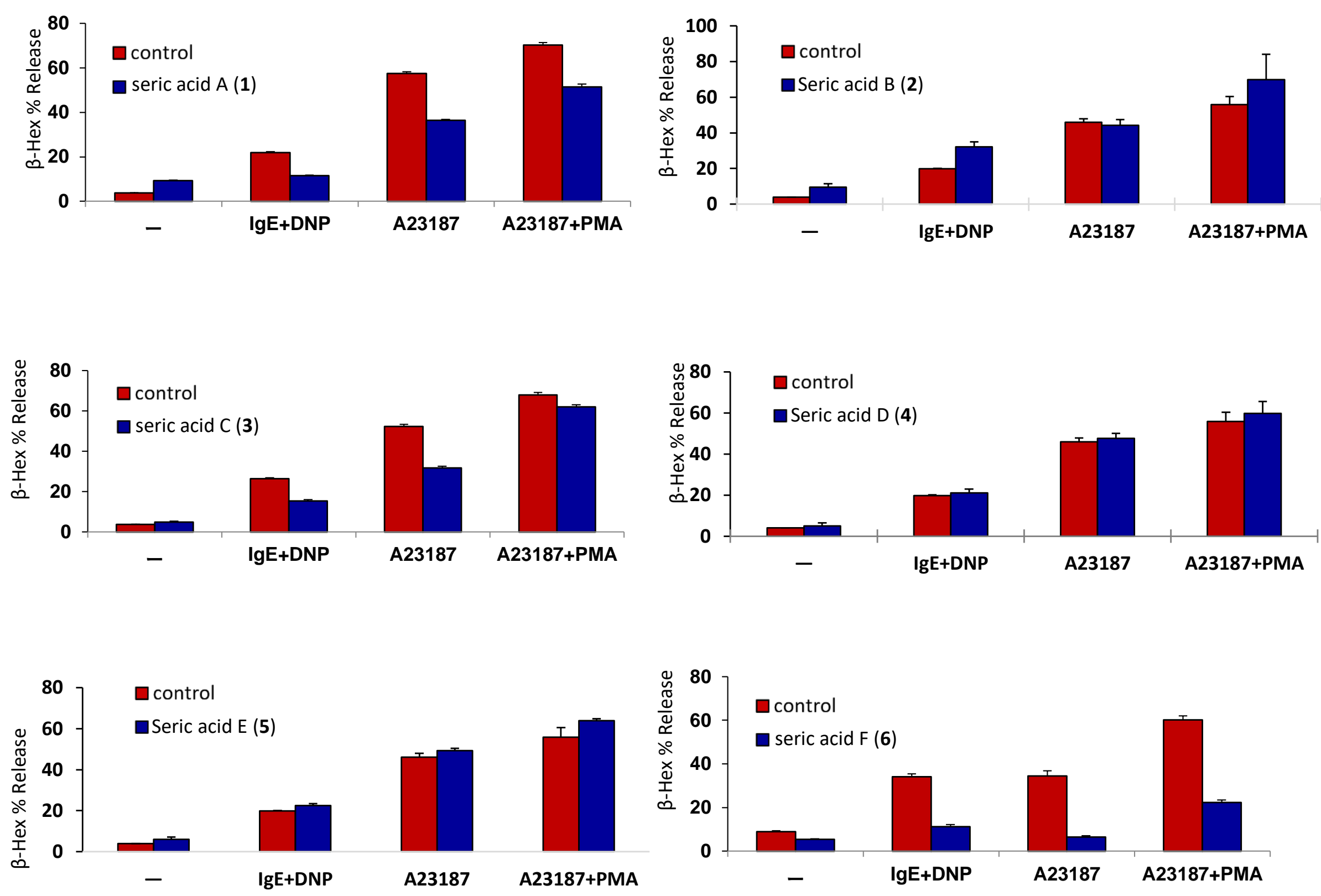

Figure S2. $\beta$-Hexosaminidase release (\%) by $\lg E+D N P, A 23187$, and $A 23183+P M A$ stimulated degradation in RBL-2H3 cells treated with compounds $\mathbf{1 - 6}$ and known compounds isolated form Oenanthe javanica. 

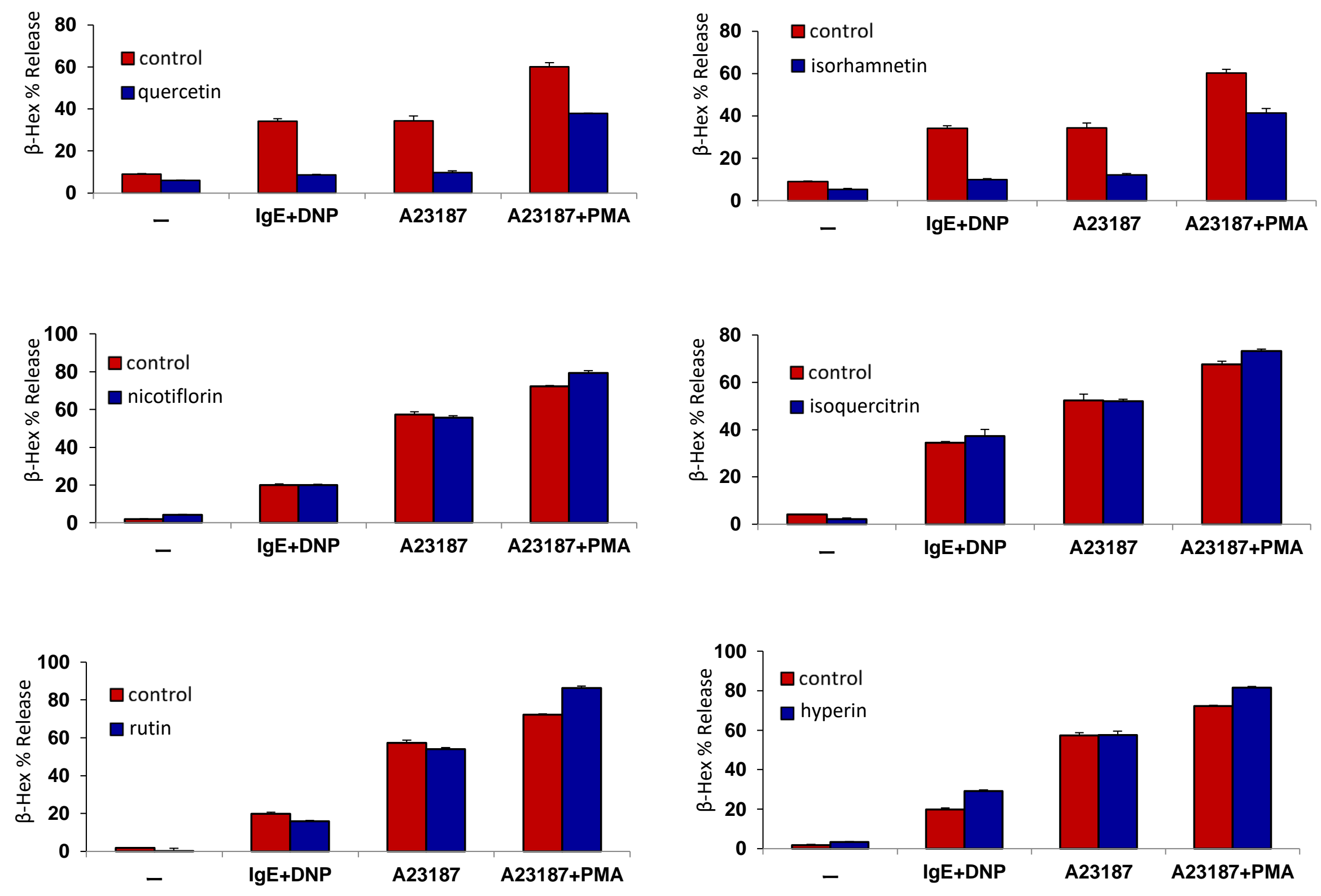

Figure S2. Continued. 

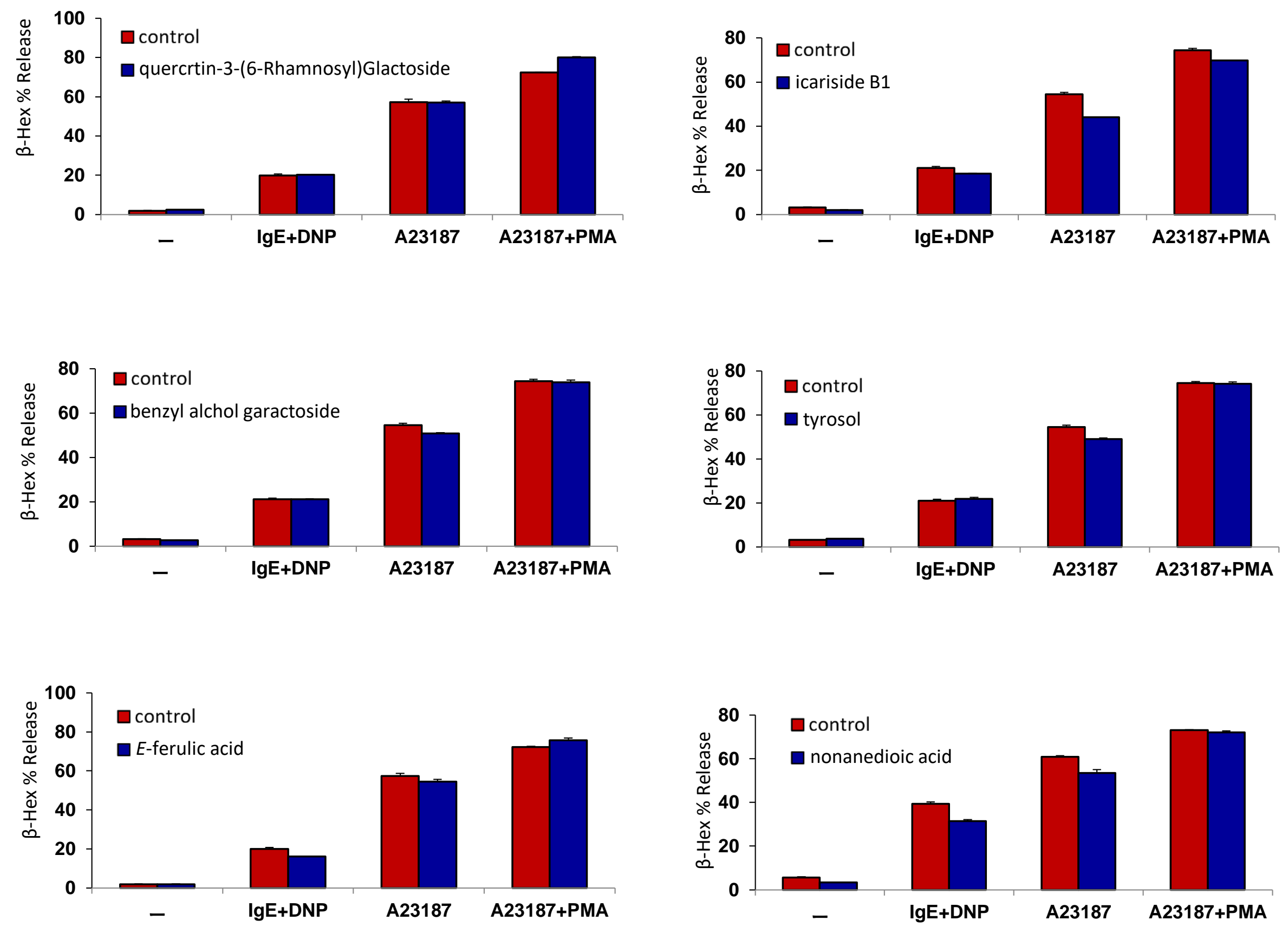

Figure S2. Continued. 


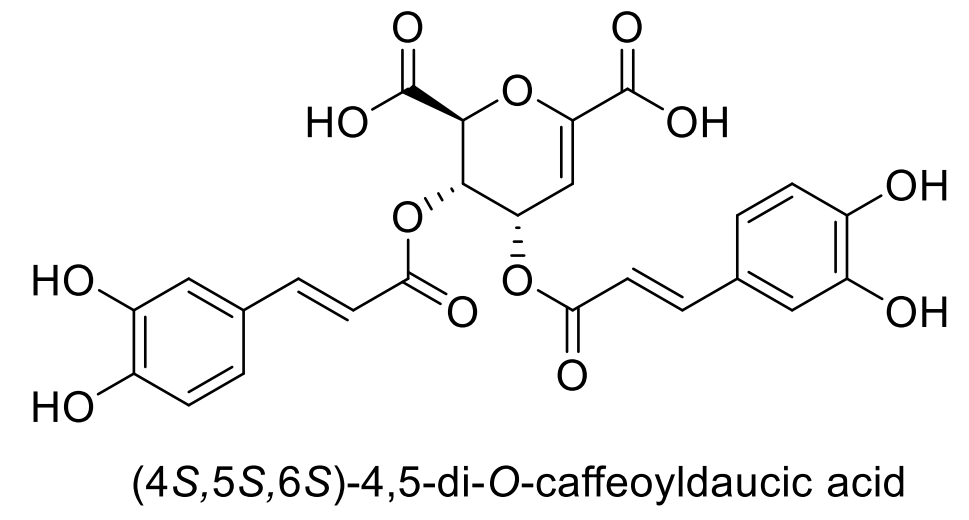<smiles>CC(C)(C)O[Ga]O[Ge]</smiles>

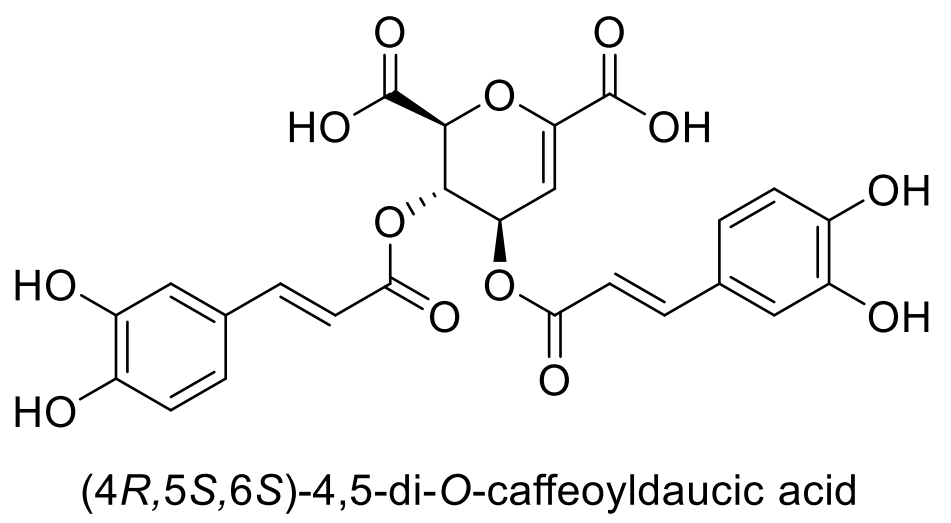

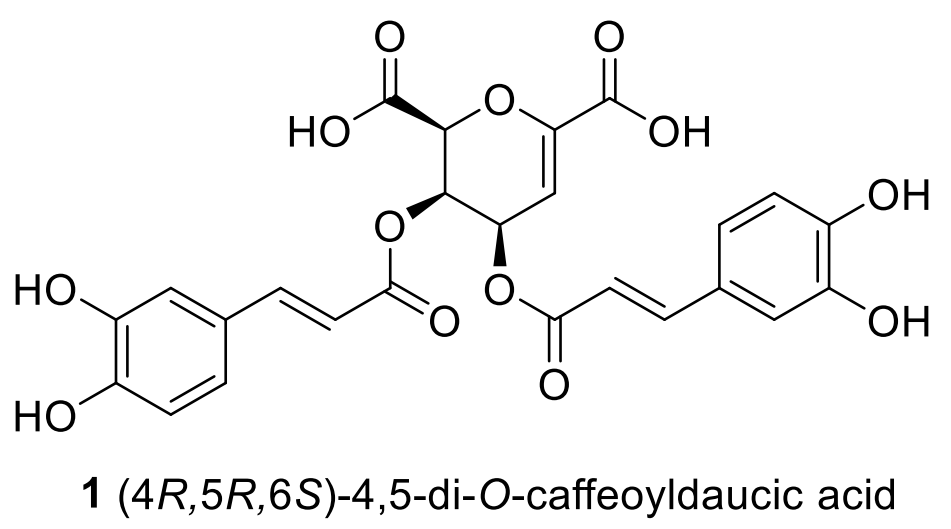

Figure S3. Structures of related compounds of $\mathbf{1}$ 
Table S1.

NMR spectroscopic data for $\mathbf{3}, \mathbf{3 a}$, and reported compounds with the same planar structure

\begin{tabular}{|c|c|c|c|c|c|c|c|c|c|}
\hline \multirow[b]{2}{*}{ position } & \multicolumn{2}{|r|}{$\mathbf{3}^{a}$} & \multicolumn{3}{|c|}{$3 \mathbf{a}^{a}$} & \multicolumn{2}{|c|}{ Reported values ${ }^{a, b}$} & \multicolumn{2}{|c|}{ Reported values $^{a, c}$} \\
\hline & $\delta_{\mathrm{C}}$ & $\delta_{\mathrm{H}}(J$ in $\mathrm{Hz})$ & $\delta_{\mathrm{C}}$ & $\delta_{\mathrm{H}}(J$ in $\mathrm{Hz})$ & $\begin{array}{l}\text { HMBC } \\
\text { (H to } \mathrm{C} \text { ) }\end{array}$ & $\delta_{\mathrm{C}}$ & $\delta_{\mathrm{H}}(J$ in $\mathrm{Hz})$ & $\delta_{\mathrm{C}}$ & $\delta_{\mathrm{H}}(J$ in $\mathrm{Hz})$ \\
\hline 1 & 126.3 & & 127.1 & & & 125.5 & & 126.8 & \\
\hline 2 & 133.9 & $7.51, \mathrm{~d}(8.5)$ & 133.9 & $7.57, \mathrm{~d}(8.5)$ & $3,4,6,7$ & 133.0 & $7.57, \mathrm{~d}(9.0)$ & 134.0 & $7.56, \mathrm{~d}(8.5)$ \\
\hline 3 & 116.9 & $6.84, \mathrm{~d}(8.5)$ & 116.7 & $6.81, \mathrm{~d}(8.5)$ & $1,4,5$ & 114.1 & $6.80, \mathrm{~d}(9.0)$ & 116.6 & $6.81, \mathrm{~d}(8.5)$ \\
\hline 4 & 161.6 & & 161.0 & & & 158.2 & & 159.0 & \\
\hline 5 & 116.9 & $6.84, \mathrm{~d}(8.5)$ & 116.7 & $6.81, \mathrm{~d}(8.5)$ & $1,3,4$ & 114.1 & $6.80, \mathrm{~d}(9.0)$ & 116.6 & $6.81, \mathrm{~d}(8.5)$ \\
\hline 6 & 133.9 & $7.51, \mathrm{~d}(8.5)$ & 133.9 & $7.57, \mathrm{~d}(8.5)$ & $2,4,5,7$ & 133.0 & $7.57, \mathrm{~d}(9.0)$ & 133.0 & $7.56, \mathrm{~d}(8.5)$ \\
\hline 7 & 141.6 & $7.65, \mathrm{~d}(2.0)$ & 139.8 & $7.56, \mathrm{~d}(2.5)$ & $2,6,8,9,8^{\prime}$ & 138.0 & $7.55, \mathrm{~d}(1.5)$ & 140.2 & $7.57, \mathrm{~d}(1.0)$ \\
\hline 8 & 120.1 & & 123.2 & & & 126.2 & & 122.2 & \\
\hline 9 & 174.0 & & 175.3 & & & 175.0 & & 174.9 & \\
\hline $1^{\prime}$ & 131.9 & & 133.1 & & & 125.5 & & 128.0 & \\
\hline $2^{\prime}$ & 128.0 & $7.14, \mathrm{~d}(8.5)$ & 128.0 & $7.14, \mathrm{~d}(8.5)$ & $3^{\prime}, 4^{\prime}, 6^{\prime}, 7^{\prime}$ & 126.2 & $7.14, \mathrm{~d}(8.5)$ & missing & $7.12, \mathrm{~d}(8.5)$ \\
\hline $3^{\prime}$ & 116.7 & $6.79, \mathrm{~d}(8.5)$ & 116.5 & $6.75, \mathrm{~d}(8.5)$ & $1^{\prime}, 4^{\prime}, 5^{\prime}$ & 115.0 & $6.71, \mathrm{~d}(8.5)$ & 116.8 & $6.76, d(8.5)$ \\
\hline $4^{\prime}$ & 159.3 & & 158.9 & & & 160.0 & & 161.2 & \\
\hline $5^{\prime}$ & 116.7 & $6.79, \mathrm{~d}(8.5)$ & 116.5 & $6.75, \mathrm{~d}(8.5)$ & $1^{\prime}, 3^{\prime}, 4^{\prime}$ & 115.0 & $6.71, \mathrm{~d}(8.5)$ & 116.8 & $6.76, \mathrm{~d}(8.5)$ \\
\hline $6^{\prime}$ & 128.0 & $7.14, \mathrm{~d}(8.5)$ & 128.0 & $7.14, \mathrm{~d}(8.5)$ & $2^{\prime}, 4^{\prime}, 5^{\prime}, 7^{\prime}$ & 126.2 & $7.14, \mathrm{~d}(8.5)$ & missing & $7.12, \mathrm{~d}(8.5)$ \\
\hline $7^{\prime}$ & 82.7 & $5.70, \mathrm{~d}(2.5)$ & 84.6 & $5.64, \mathrm{~d}(3.0)$ & $8,9,1^{\prime}, 2^{\prime}, 6^{\prime}, 9$ & 83.2 & $5.62, \mathrm{~d}(2.6)$ & 84.0 & $5.68, \mathrm{~d}(2.6)$ \\
\hline $8^{\prime}$ & 54.6 & $4.16, \mathrm{dd}(2.5,2.0)$ & 58.3 & $3.94, \mathrm{dd}(3.0,2.5)$ & $7,8,9,9^{\prime}$ & 57.8 & $3.82, \mathrm{dd}(2.6,2.5)$ & 57.1 & $4.00, \mathrm{dd}(2.6,2.5)$ \\
\hline $9^{\prime}$ & 173.7 & & 177.6 & & & 178.2 & & 178.1 & \\
\hline
\end{tabular}

${ }^{a}$ In methanol- $d_{4}$ solution.

${ }^{b}$ J. Nat. Prod. 2004, 67, 1588-1590

${ }^{c}$ Synth. Commun. 2005, 35, 1231-1238 
Table S2.

The calculated NMR data of expected stereoisomers of compound 1 and experimental NMR data for 1 and 1a

\begin{tabular}{|c|c|c|c|c|c|c|c|}
\hline & $4 S, 5 S, 6 S^{\text {a }}$ & $4 R, 5 S, 6 S^{b}$ & $4 S, 5 R, 6 S^{\mathrm{c}}$ & $4 R, 5 R, 6 S^{\mathrm{d}}$ & $\mathbf{1}^{\mathrm{e}}$ & $1 \mathrm{a}^{\mathrm{e}}$ & $4 R, 5 R, 6 S$ Na salt ${ }^{f}$ \\
\hline position & $\delta$ & $\delta$ & $\delta$ & $\delta$ & $\delta$ & $\delta$ & $\delta$ \\
\hline $\mathrm{C}-2$ & 144.2 & 143.2 & 144.3 & 147.1 & 146.9 & 150.2 & 150.6 \\
\hline $\mathrm{C}-3$ & 115.9 & 117.0 & 116.7 & 112.2 & 109.1 & 103.7 & 108.3 \\
\hline C-4 & 64.6 & 69.5 & 64.5 & 64.9 & 66.2 & 65.9 & 67.9 \\
\hline $\mathrm{C}-5$ & 65.8 & 66.4 & 67.7 & 63.5 & 65.2 & 67.9 & 69.7 \\
\hline C-6 & 76.1 & 77.1 & 72.9 & 75.7 & 76.2 & 77.6 & 78.2 \\
\hline $\mathrm{C}-7$ & 162.9 & 164.1 & 164.6 & 164.5 & 164.6 & 169.0 & 173.7 \\
\hline $\mathrm{C}-8$ & 170.7 & 172.2 & 174.0 & 171.0 & 170.1 & 173.3 & 180.2 \\
\hline C-1' & 126.6 & 126.6 & 126.9 & 126.9 & 127.5 & 126.7 & 127.5 \\
\hline C-2' & 121.1 & 121.0 & 120.8 & 112.7 & 114.9 & 114.6 & 112.1 \\
\hline C-3' & 144.0 & 144.5 & 144.5 & 145.3 & 146.0 & 147.8 & 145.4 \\
\hline C-4' & 146.5 & 146.9 & 146.9 & 148.2 & 149.9 & 151.7 & 147.5 \\
\hline C-5' & 115.6 & 115.5 & 115.6 & 114.7 & 116.5 & 116.6 & 114.4 \\
\hline C-6' & 119.1 & 119.5 & 119.9 & 127.9 & 123.5 & 123.4 & 127.6 \\
\hline C-7' & 151.3 & 151.1 & 151.4 & 150.1 & 148.5 & 147.5 & 148.9 \\
\hline C-8' & 112.5 & 112.5 & 111.3 & 111.7 & 114.0 & 114.1 & 113.9 \\
\hline C-9' & 169.7 & 170.1 & 169.8 & 167.9 & 167.8 & 168.3 & 168.4 \\
\hline C-1" & 127.6 & 127.0 & 126.5 & 126.9 & 127.6 & 126.7 & 127.4 \\
\hline C-2" & 121.0 & 120.9 & 111.8 & 112.7 & 115.2 & 114.5 & 112.2 \\
\hline C-3" & 144.4 & 144.8 & 143.8 & 145.3 & 146.9 & 148.0 & 145.1 \\
\hline C-4" & 147.2 & 147.4 & 149.7 & 148.3 & 149.8 & 151.5 & 148.0 \\
\hline C-5" & 115.7 & 115.5 & 115.3 & 114.8 & 116.6 & 116.5 & 115.3 \\
\hline C-6" & 119.3 & 119.9 & 129.7 & 128.8 & 123.6 & 123.8 & 128.5 \\
\hline C-7" & 151.4 & 150.5 & 151.5 & 150.7 & 148.0 & 147.6 & 151.3 \\
\hline C-8" & 112.1 & 112.9 & 111.4 & 112.4 & 114.1 & 113.9 & 113.6 \\
\hline C-9" & 170.1 & 167.6 & 169.6 & 167.1 & 167.9 & 168.4 & 172.3 \\
\hline $\mathbf{M A E}^{\mathrm{g}}$ & 2.47 & 2.71 & 2.48 & 1.68 & & & \\
\hline $\mathrm{H}-2$ & 6.52 & 6.39 & 6.51 & 5.94 & 6.01 & 5.70 & 6.37 \\
\hline H-3 & 5.82 & 6.46 & 6.11 & 6.35 & 5.98 & 6.05 & 6.08 \\
\hline H-4 & 5.73 & 5.38 & 5.72 & 5.94 & 5.98 & 5.94 & 5.71 \\
\hline H-5 & 5.61 & 5.45 & 4.76 & 5.47 & 5.13 & 4.65 & 4.93 \\
\hline H-2' & 7.14 & 7.18 & 7.15 & 7.56 & 7.04 & 6.98 & 7.50 \\
\hline H-5' & 7.00 & 6.99 & 6.96 & 6.95 & 6.76 & 6.70 & 6.89 \\
\hline H-6' & 7.63 & 7.52 & 7.57 & 6.88 & 6.91 & 6.84 & 6.83 \\
\hline H-7' & 7.85 & 7.86 & 7.88 & 7.70 & 7.54 & 7.44 & 7.66 \\
\hline H-8' & 6.56 & 6.58 & 6.51 & 6.35 & 6.31 & 6.08 & 6.33 \\
\hline H-2" & 7.17 & 7.53 & 7.09 & 7.48 & 7.00 & 6.95 & 7.43 \\
\hline H-5" & 7.00 & 6.99 & 7.02 & 6.99 & 6.68 & 6.61 & 7.02 \\
\hline H-6" & 7.57 & 7.20 & 7.50 & 7.17 & 6.81 & 6.71 & 7.17 \\
\hline H-7" & 7.88 & 7.87 & 7.76 & 7.87 & 7.49 & 7.49 & 8.00 \\
\hline H-8" & 6.55 & 6.46 & 6.32 & 6.18 & 6.16 & 6.21 & 6.29 \\
\hline $\mathbf{M A E}^{\mathrm{g}}$ & 0.360 & 0.375 & 0.308 & 0.235 & & & \\
\hline
\end{tabular}

Calculation data of ${ }^{\mathrm{a}}(4 S, 5 S, 6 S)$-4,5-di- $O$-caffeoyldaucic acid, ${ }^{\mathrm{b}}(4 R, 5 S, 6 S)$-4,5-di- $O$-caffeoyldaucic acid, ${ }^{\mathrm{c}}(4 S, 5 R, 6 S)$ 4,5-di- $O$-caffeoyldaucic acid, ${ }^{\mathrm{d}}(4 R, 5 R, 6 S)-4,5$-di- $O$-caffeoyldaucic acid. ${ }^{\mathrm{e}}$ In methanol- $d_{4}$ solution. ${ }^{\mathrm{f}} \mathrm{Calculation}$ data of $(4 R, 5 R, 6 S)$-4,5-di- $O$-caffeoyldaucic acid disodium salt. ${ }^{\mathrm{g}}$ The mean absolute error (MAE) value between each calulated data and experimental data of compound $\mathbf{1}$. 
Table S3.

The calculated NMR data of $\mathbf{3}$ and disodium salt of $\mathbf{3}$ and experimental NMR data for $\mathbf{3}$ and $\mathbf{3 a}$

\begin{tabular}{|c|c|c|c|c|}
\hline & $\mathbf{3}^{a}$ & $\mathbf{3 a}^{a}$ & neutrality $^{\mathrm{b}}$ & Na salt ${ }^{\mathrm{c}}$ \\
\hline position & $\delta$ & $\delta$ & $\delta$ & $\delta$ \\
\hline $\mathrm{C}-1$ & 126.3 & 127.1 & 125.2 & 126.0 \\
\hline $\mathrm{C}-2$ & 133.9 & 133.9 & 135.6 & 136.1 \\
\hline C-3 & 116.9 & 116.7 & 115.8 & 115.0 \\
\hline C-4 & 161.6 & 161.0 & 160.9 & 160.1 \\
\hline C-5 & 116.9 & 116.7 & 115.8 & 115.0 \\
\hline C-6 & 133.9 & 133.9 & 135.6 & 136.1 \\
\hline $\mathrm{C}-7$ & 141.6 & 139.8 & 144.9 & 141.9 \\
\hline C-8 & 120.1 & 123.2 & 116.9 & 121.7 \\
\hline C-9 & 174.0 & 175.3 & 175.3 & 175.6 \\
\hline C-1' & 131.9 & 133.1 & 134.5 & 134.2 \\
\hline C-2' & 128.0 & 128.0 & 126.2 & 125.8 \\
\hline C-3' & 116.7 & 116.5 & 114.9 & 114.3 \\
\hline C-4' & 159.3 & 158.9 & 156.9 & 156.6 \\
\hline$C-5^{\prime}$ & 116.7 & 116.5 & 114.9 & 114.3 \\
\hline C-6' & 128.0 & 128.0 & 126.2 & 125.8 \\
\hline C-7' & 82.7 & 84.6 & 80.5 & 81.5 \\
\hline C-8' & 54.6 & 58.3 & 55.0 & 59.8 \\
\hline C-9' & 173.7 & 177.6 & 176.7 & 185.4 \\
\hline $\mathrm{H}-2$ & 7.51 & 7.57 & 7.64 & 8.23 \\
\hline $\mathrm{H}-3$ & 6.84 & 6.81 & 7.06 & 7.00 \\
\hline H-5 & 6.84 & 6.81 & 7.06 & 7.00 \\
\hline H-6 & 7.51 & 7.57 & 7.64 & 8.23 \\
\hline $\mathrm{H}-7$ & 7.65 & 7.56 & 7.88 & 7.65 \\
\hline H-2' & 7.14 & 7.14 & 7.51 & 7.31 \\
\hline H-3' & 6.79 & 6.75 & 7.01 & 6.94 \\
\hline H-5' & 6.79 & 6.75 & 7.01 & 6.94 \\
\hline H-6' & 7.14 & 7.14 & 7.51 & 7.31 \\
\hline H-7' & 5.70 & 5.64 & 5.84 & 6.04 \\
\hline H-8' & 4.16 & 3.94 & 4.35 & 4.01 \\
\hline
\end{tabular}

${ }^{a}$ In methanol- $d_{4}$ solution. Calculation data of ${ }^{\mathrm{b}}$ compound $\mathbf{3}$ and cdisodium salt of $\mathbf{3}$. 


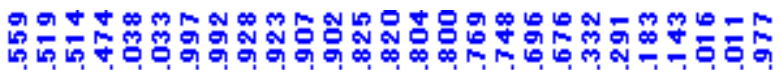
MMMMM

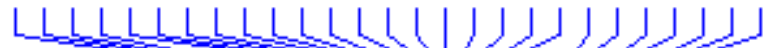
Tा<smiles>O=C(/C=C/c1ccc(O)c(O)c1)O[C@H]1C=C(C(=O)O)O[C@H](C(=O)O)[C@H]1OC(=O)/C=C/c1ccc(O)c(O)c1</smiles>
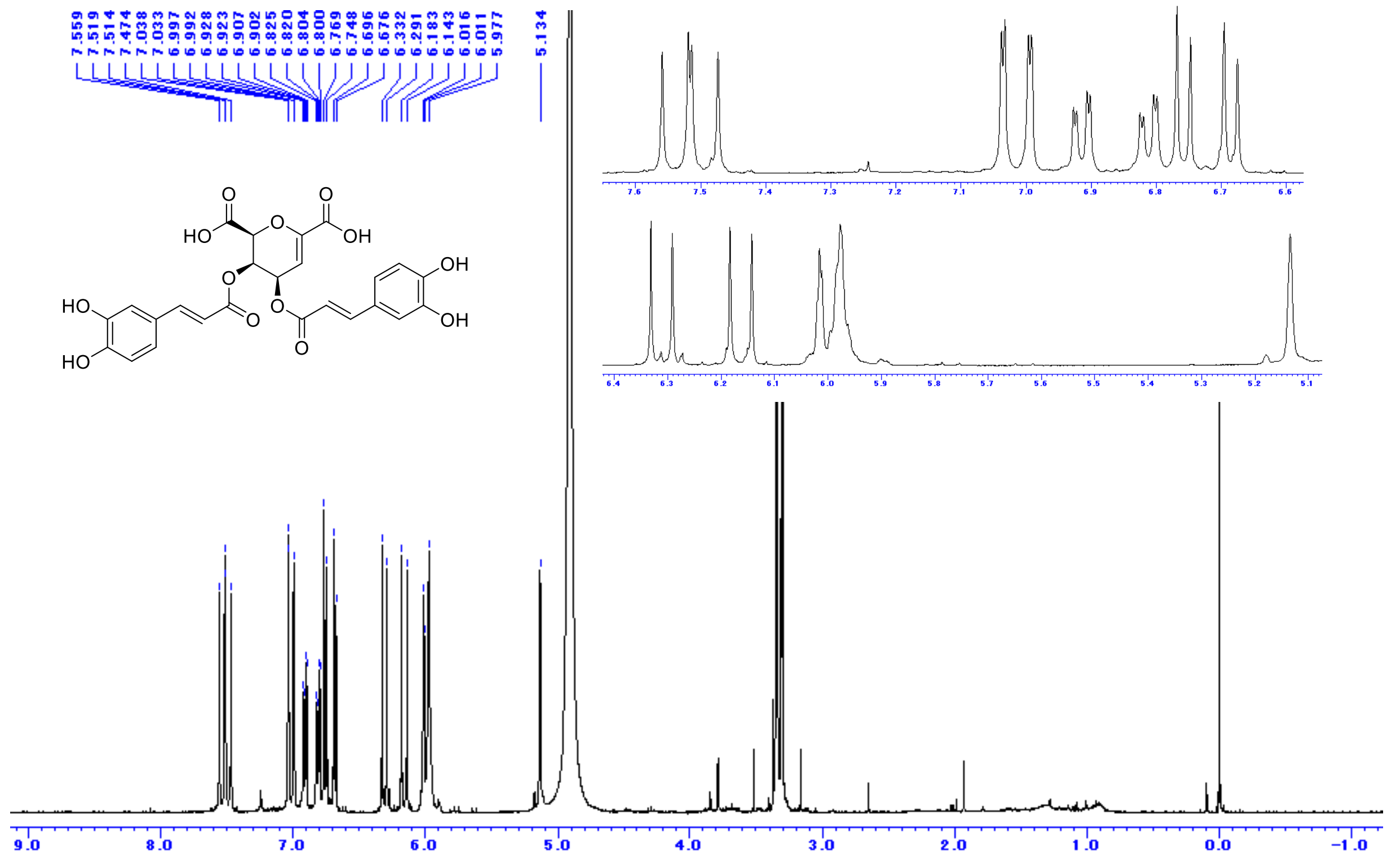

Figure S4. ${ }^{1} \mathrm{H}$ NMR spectrum of compound 1 (in methanol- $d_{4}$ ) 

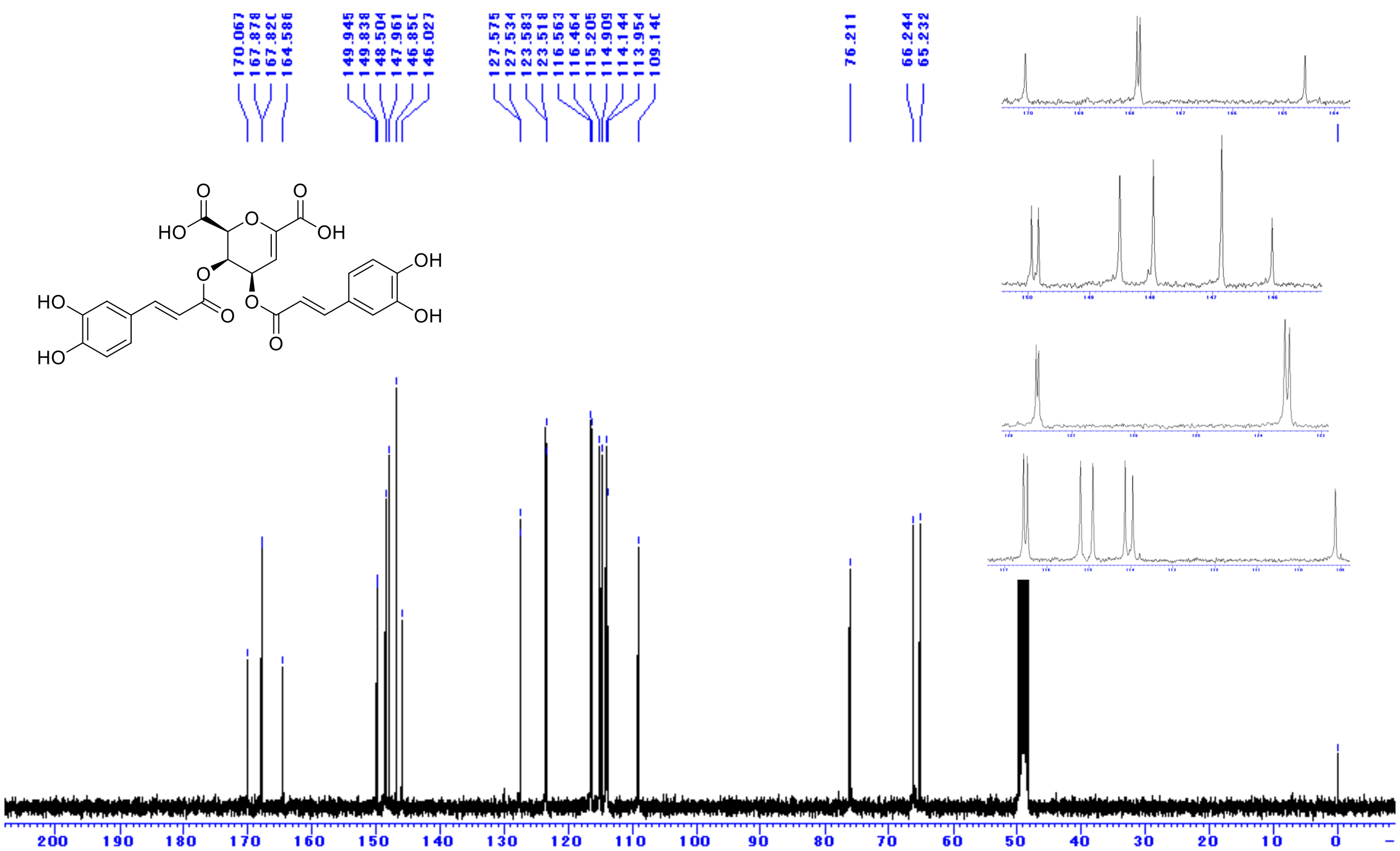

Figure S5. ${ }^{13} \mathrm{C}$ NMR spectrum of compound 1 (in methanol- $d_{4}$ ) 


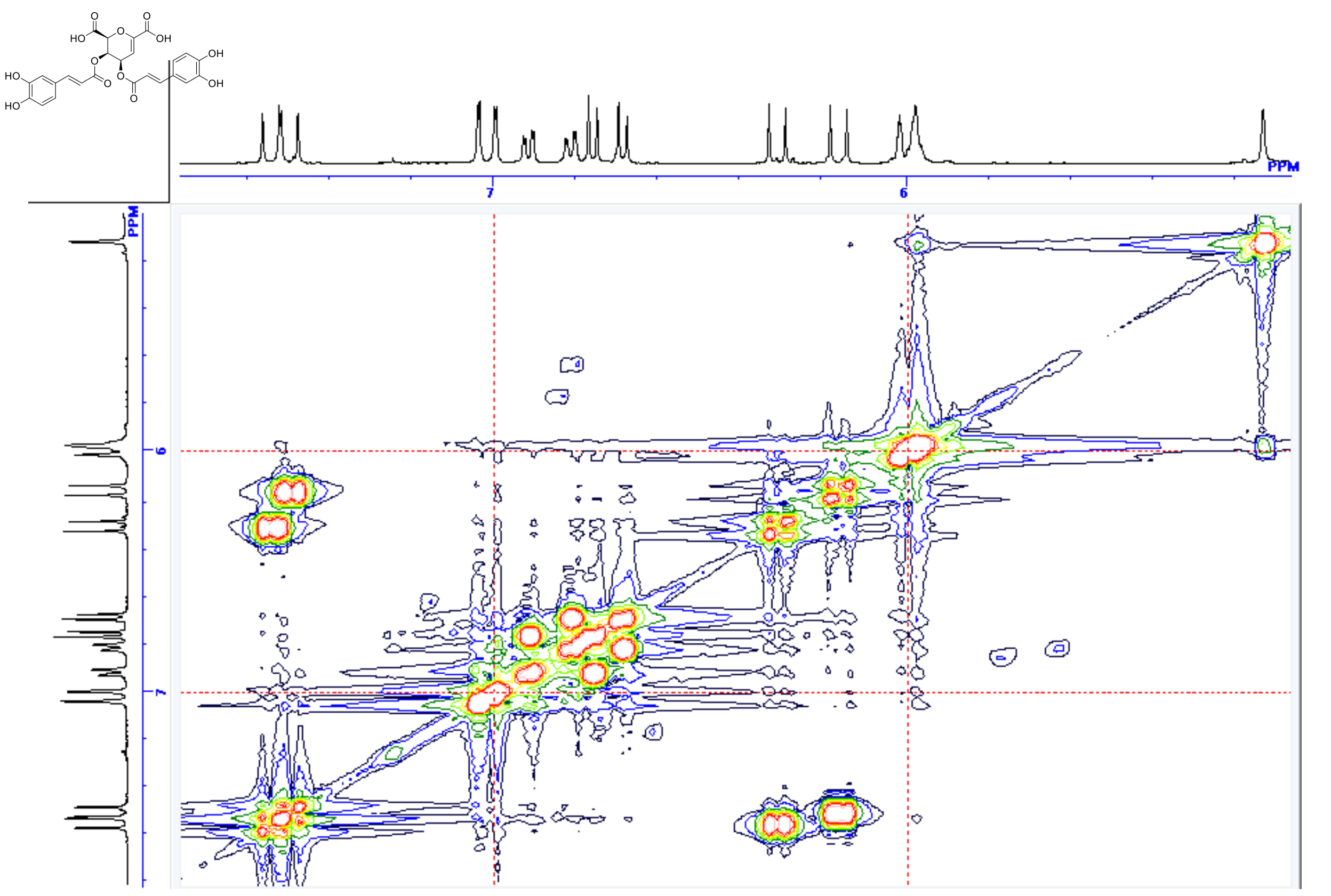

Figure S6. ${ }^{1} \mathrm{H}-{ }^{1} \mathrm{H}$ COSY spectrum of compound 1 (in methanol- $d_{4}$ ) 


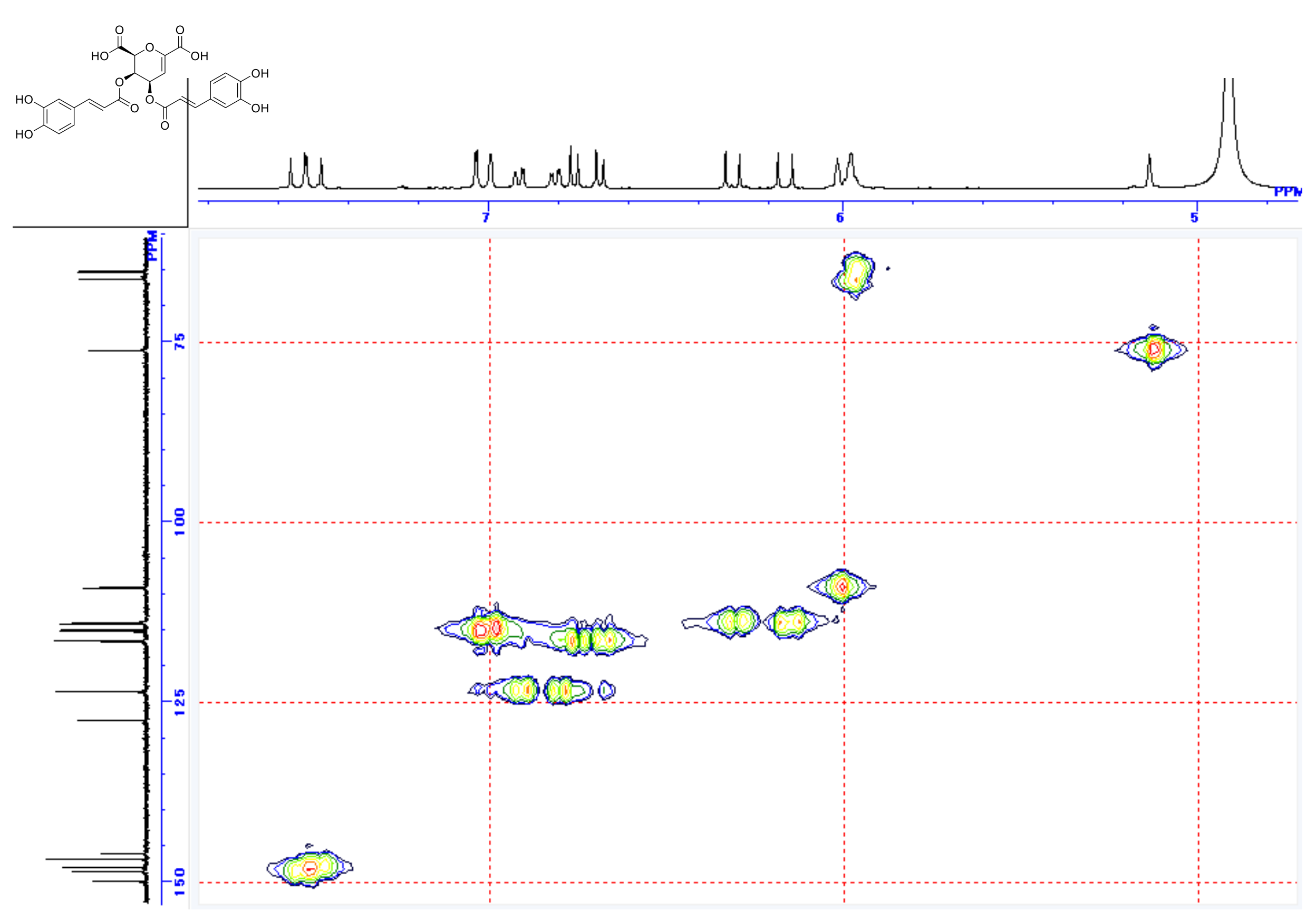

Figure S7. HMQC spectrum of compound 1 (in methanol- $d_{4}$ ) 


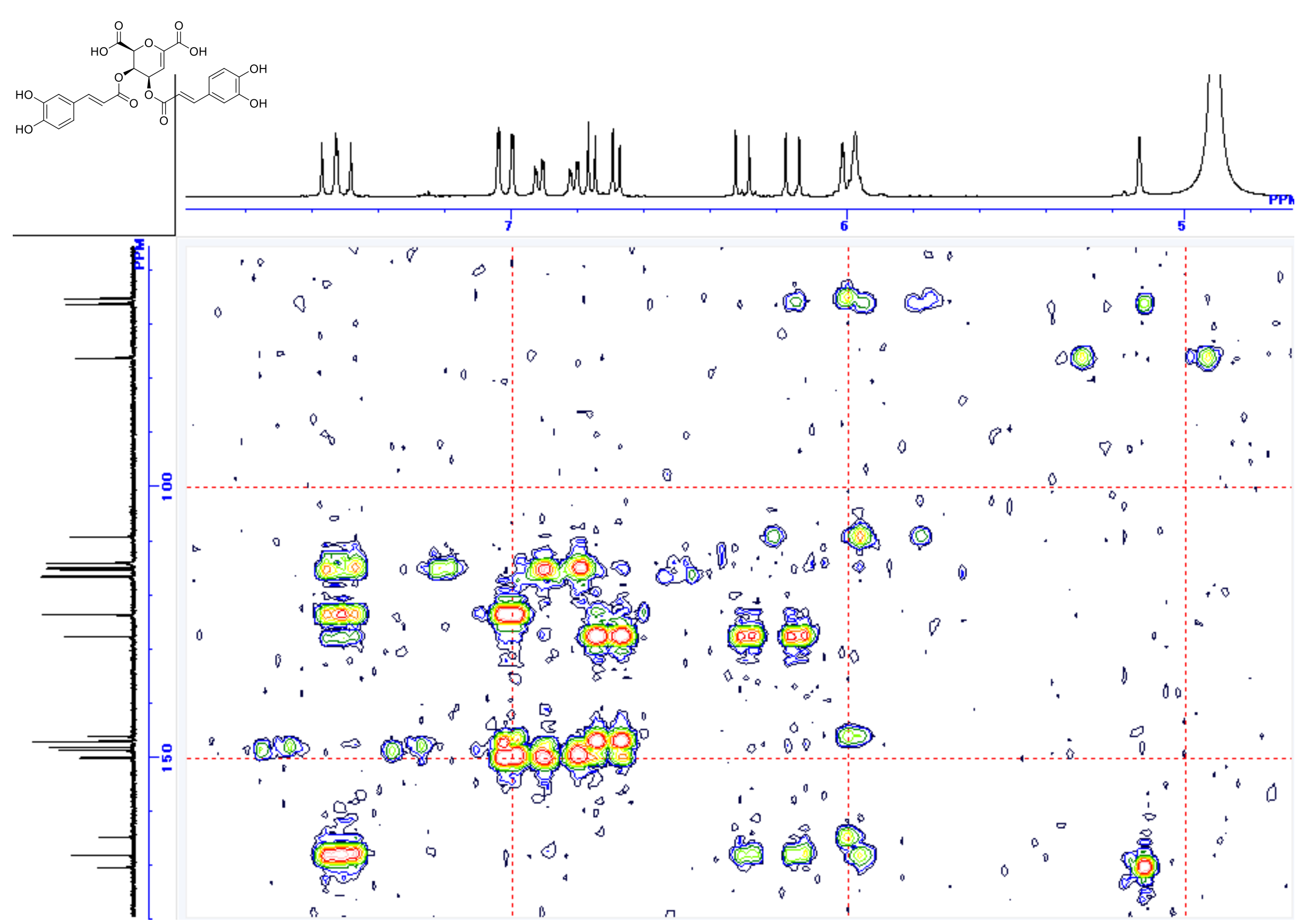

Figure S8. HMBC spectrum of compound 1 (in methanol- $d_{4}$ ) 


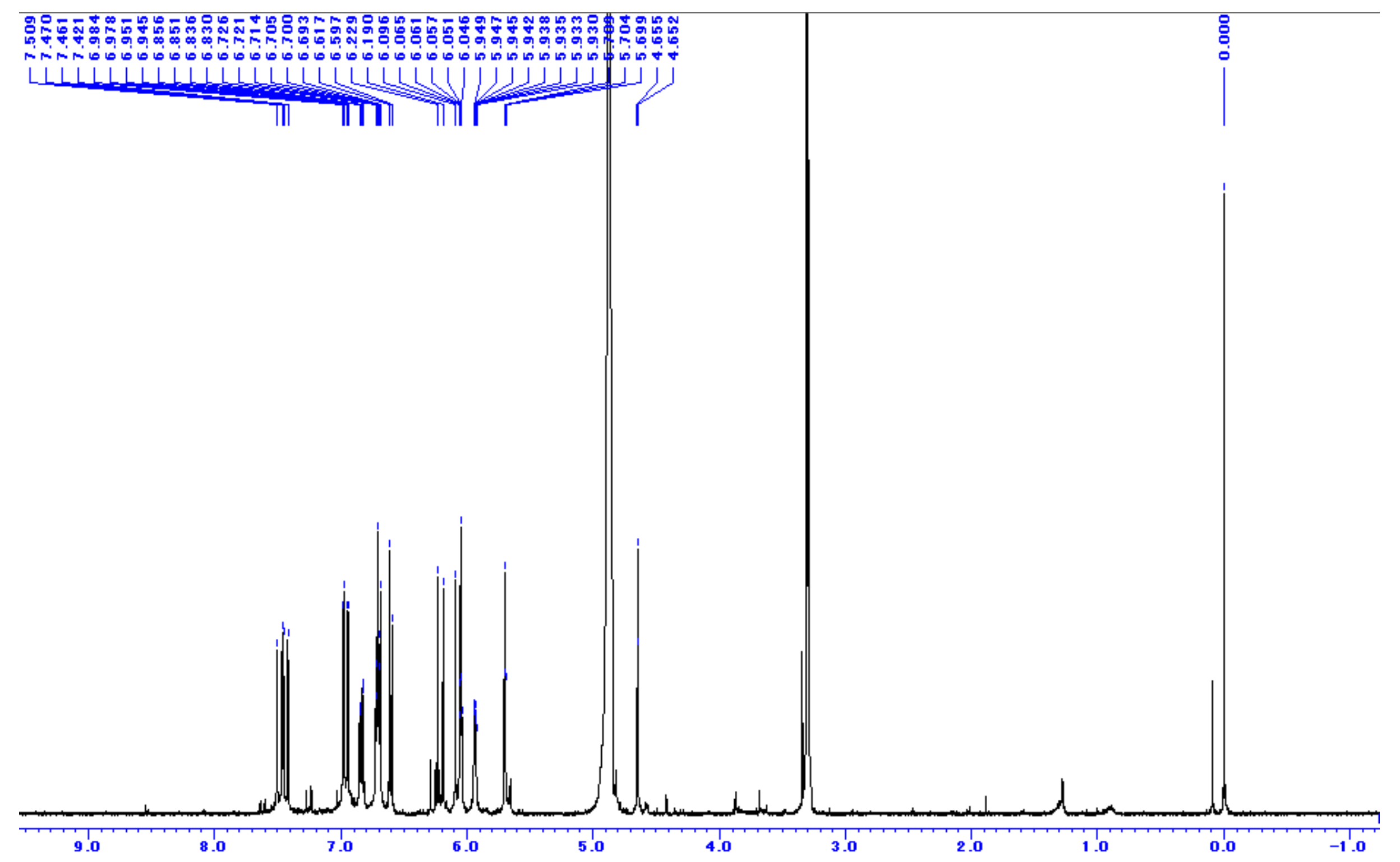

Figure S9. ${ }^{1} \mathrm{H}$ NMR spectrum of compound 1a (in methanol- $d_{4}$ ) 
1a: a sodium salt of $\mathbf{1}$

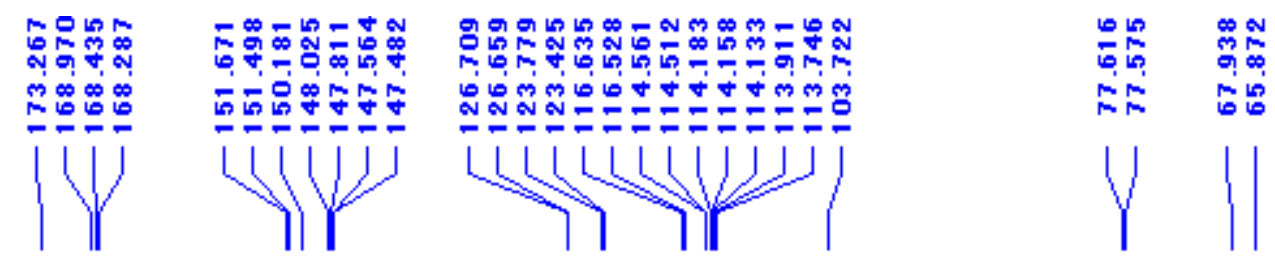

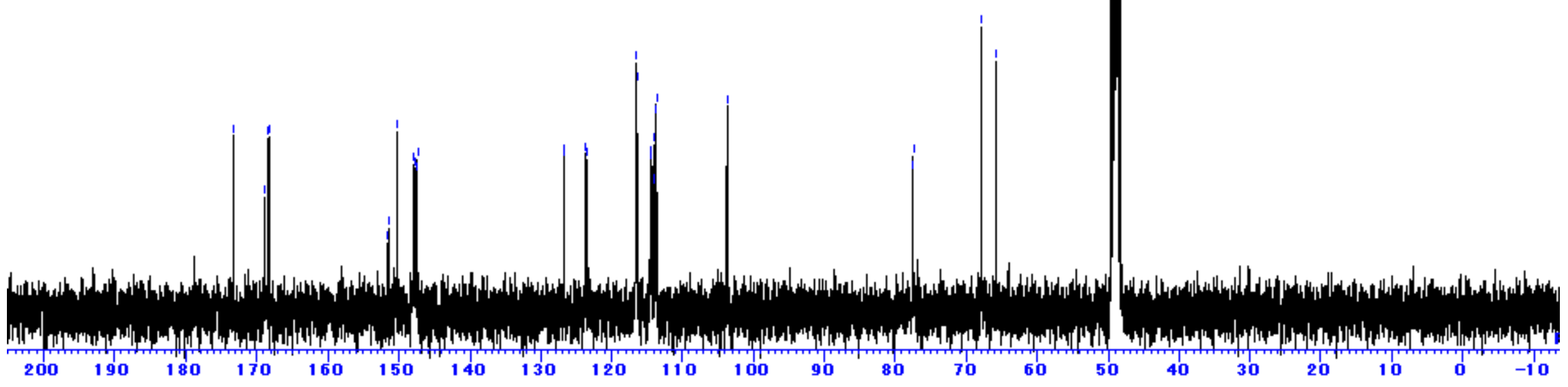

Figure S10. ${ }^{13} \mathrm{C}$ NMR spectrum of compound 1a (in methanol- $d_{4}$ ) 
1a: a sodium salt of $\mathbf{1}$

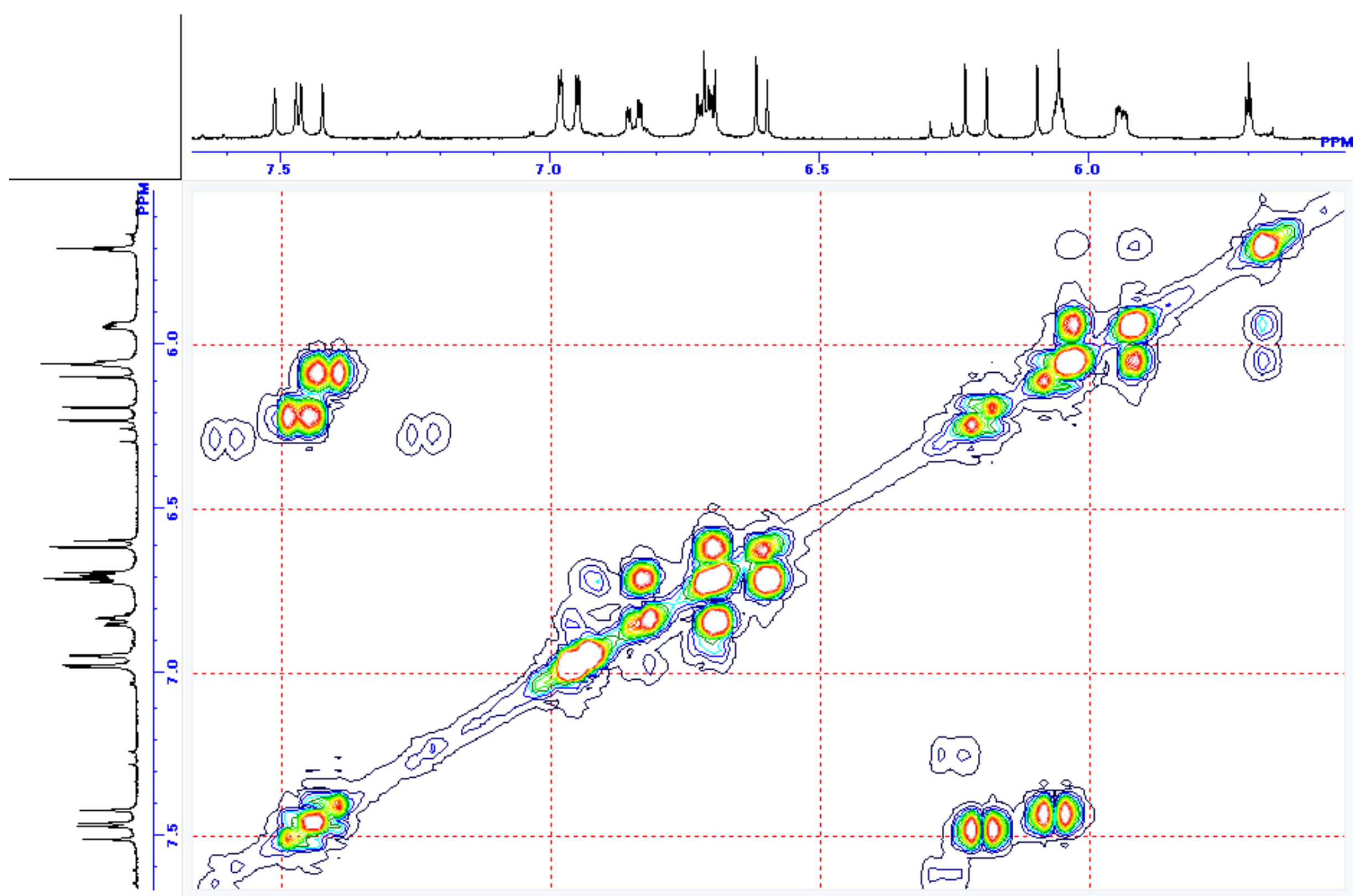

Figure S11. ${ }^{1} \mathrm{H}-{ }^{1} \mathrm{H}$ COSY spectrum of compound $\mathbf{1 a}$ (in methanol- $d_{4}$ ) 
Ia: a sodium salt of $\mathbf{1}$

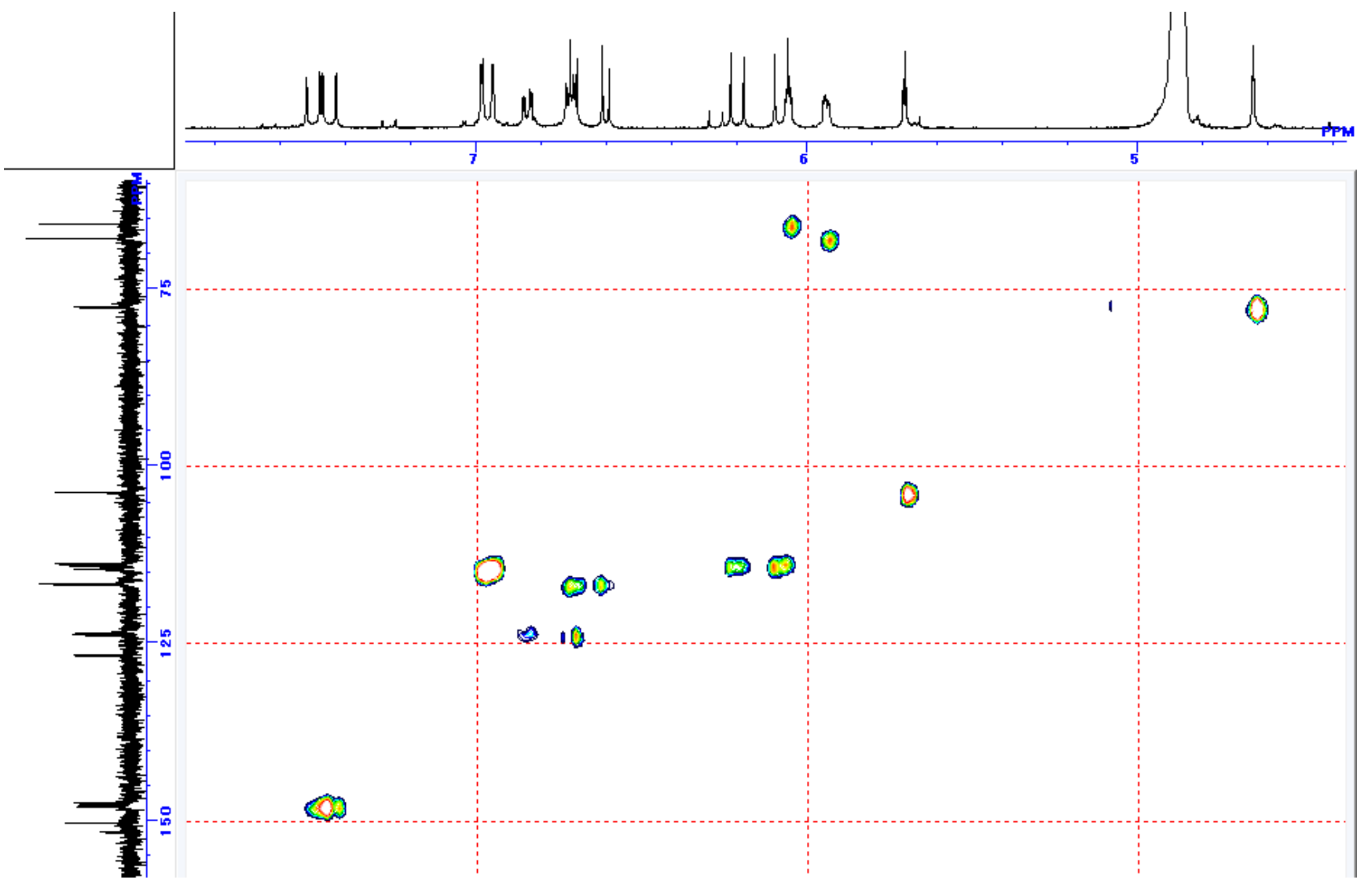

Figure S12. HMQC spectrum of compound la (in methanol- $d_{4}$ )

S17 
1a: a sodium salt of $\mathbf{1}$

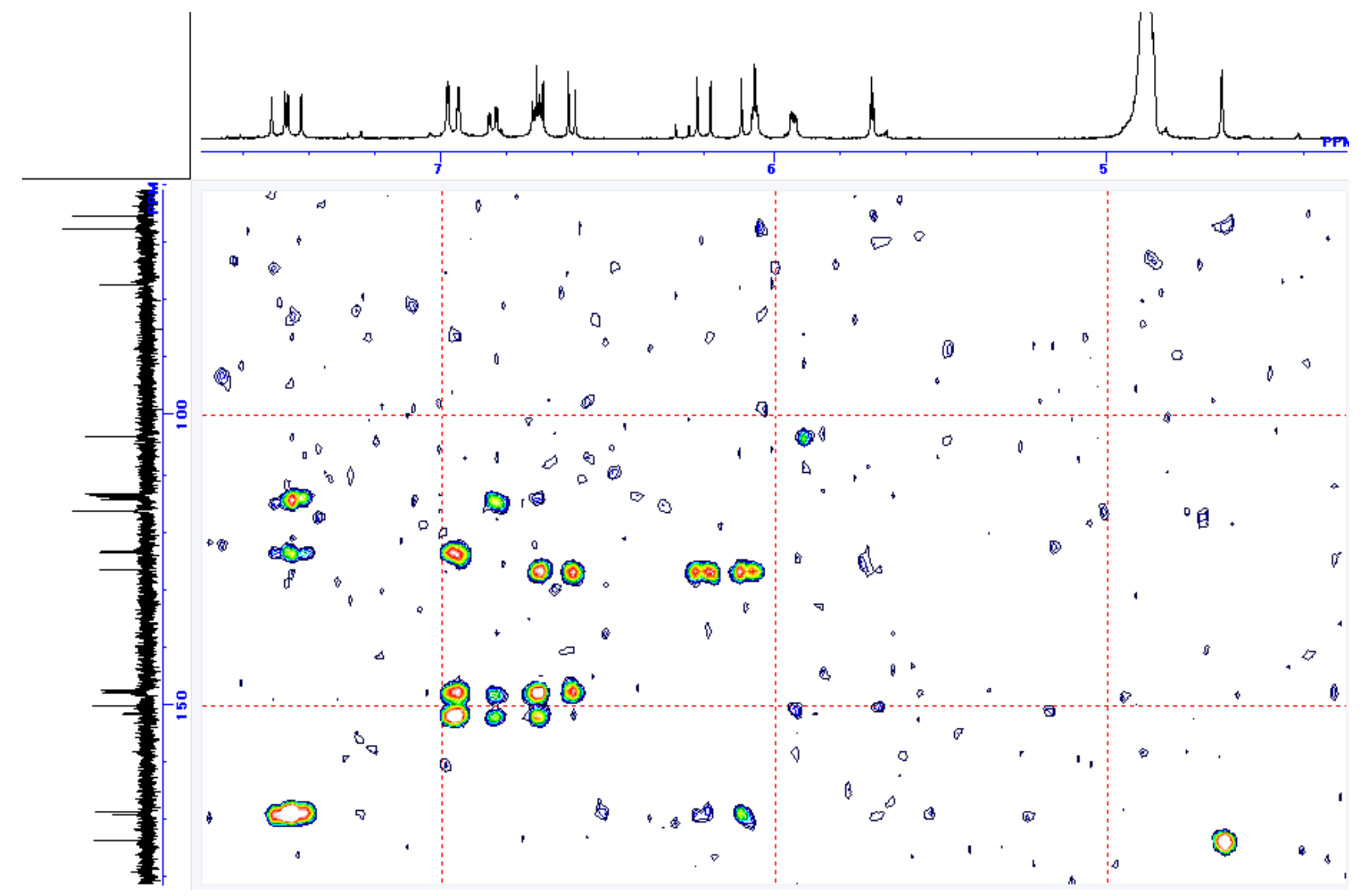

Figure S13. HMBC spectrum of compound 1a (in methanol- $d_{4}$ ) 


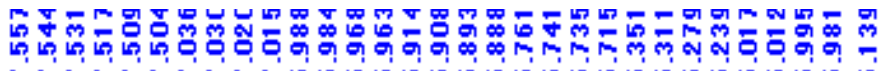

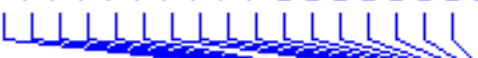

1

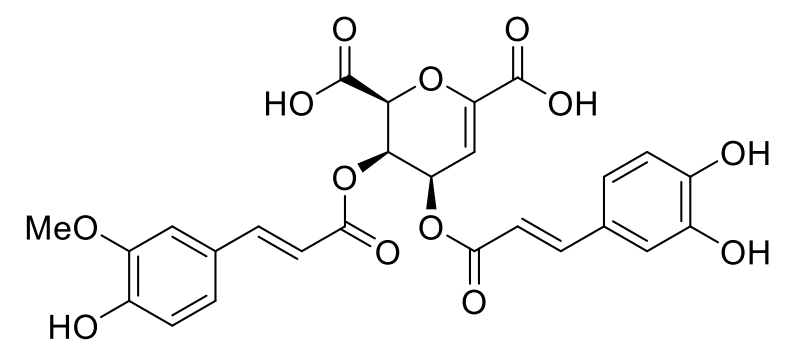

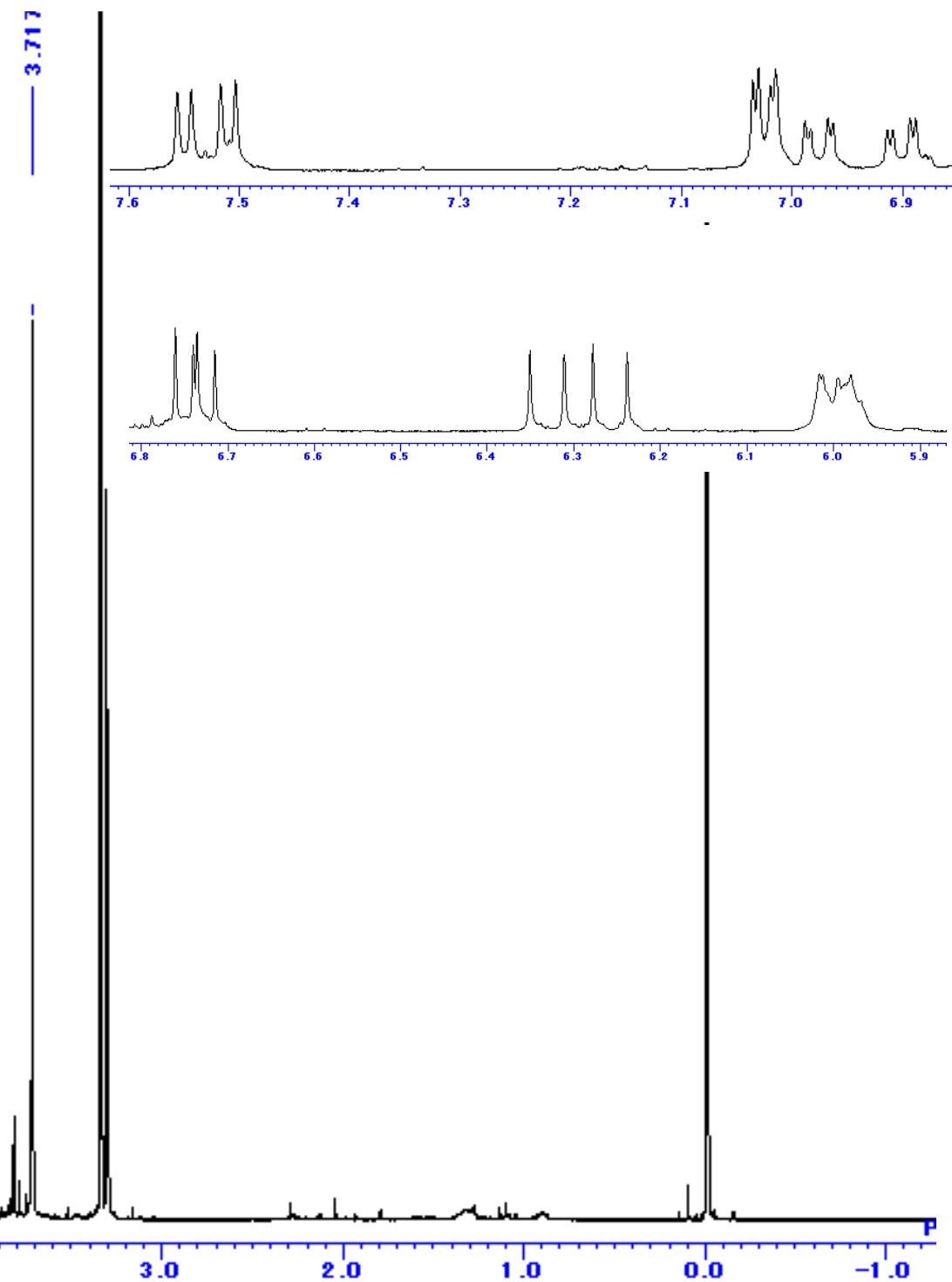

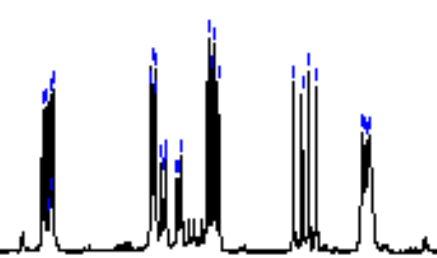

6.0

5.0

\begin{abstract}
(1)
\end{abstract}
Figure S14. ${ }^{1} \mathrm{H}$ NMR spectrum of compound 2 (in methanol- $d_{4}$ ) 

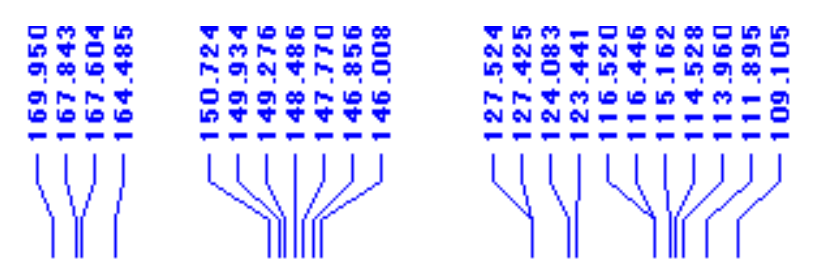

$$
\text { | }
$$<smiles>COc1cc(/C=C/C(=O)O[C@H]2C(OC(=O)/C=C/c3ccc(O)c(O)c3)C=C(C(=O)O)OC2C(=O)O)ccc1O</smiles>

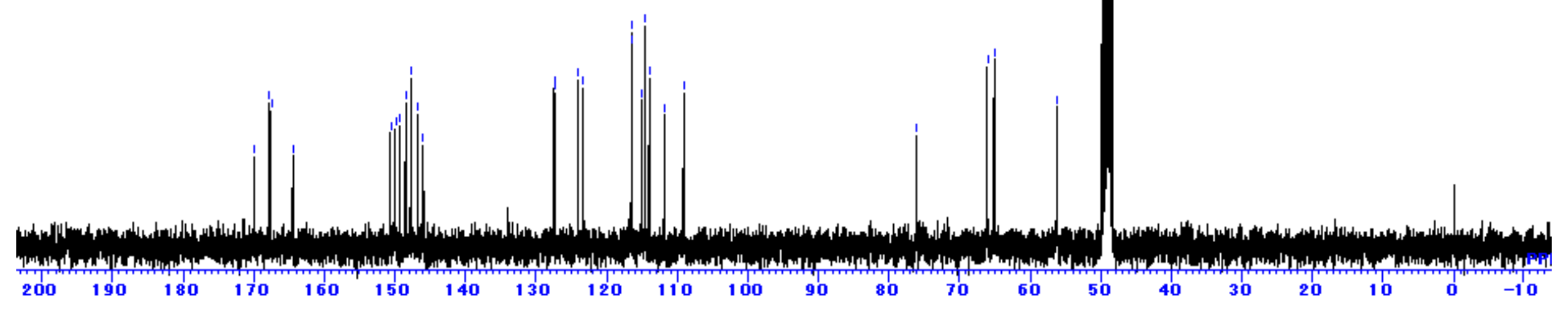

Figure S15. ${ }^{13} \mathrm{C}$ NMR spectrum of compound 2 (in methanol- $d_{4}$ ) 


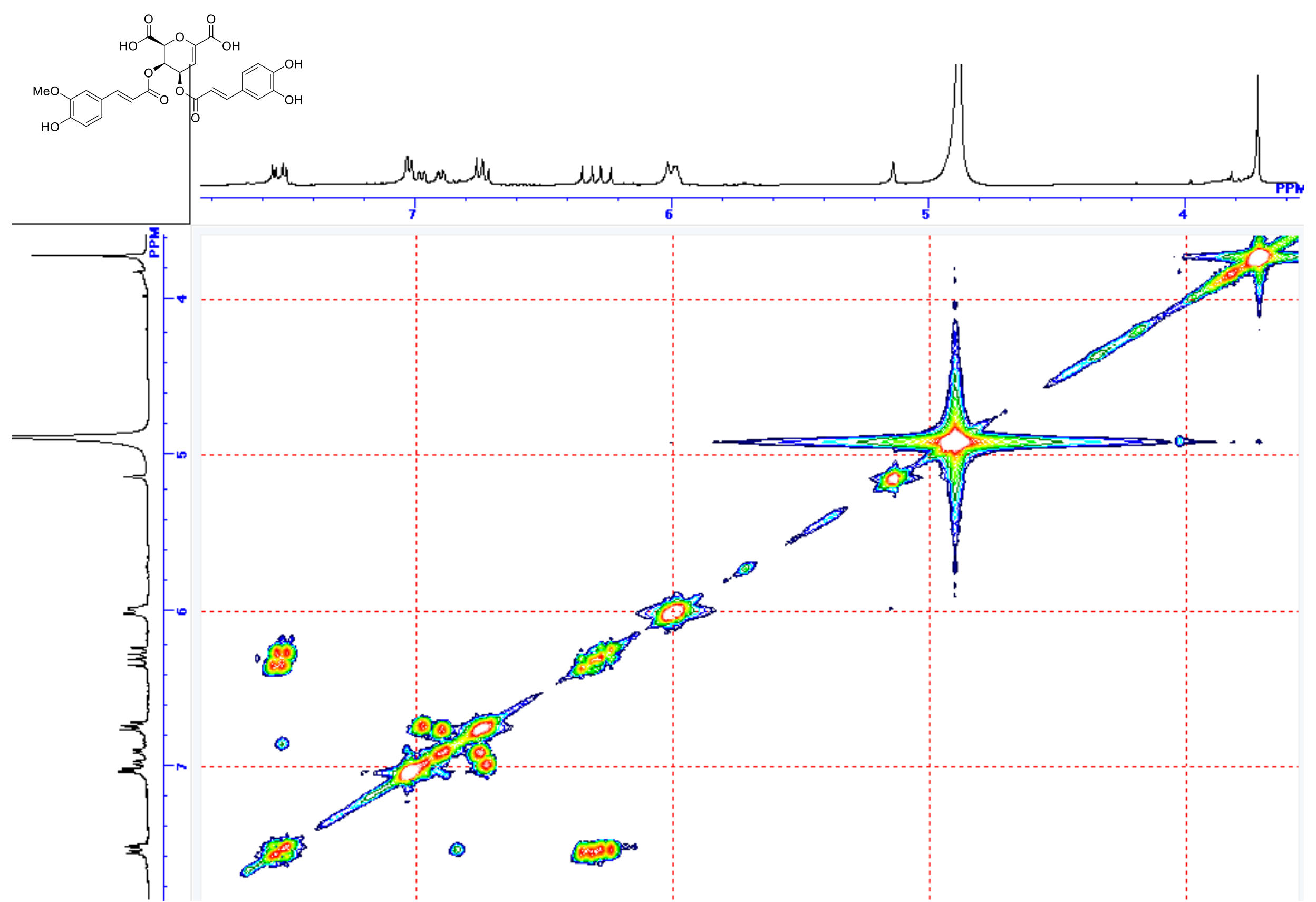

Figure S16. ${ }^{1} \mathrm{H}^{-1} \mathrm{H}$ COSY spectrum of compound 2 (in methanol- $d_{4}$ ) 


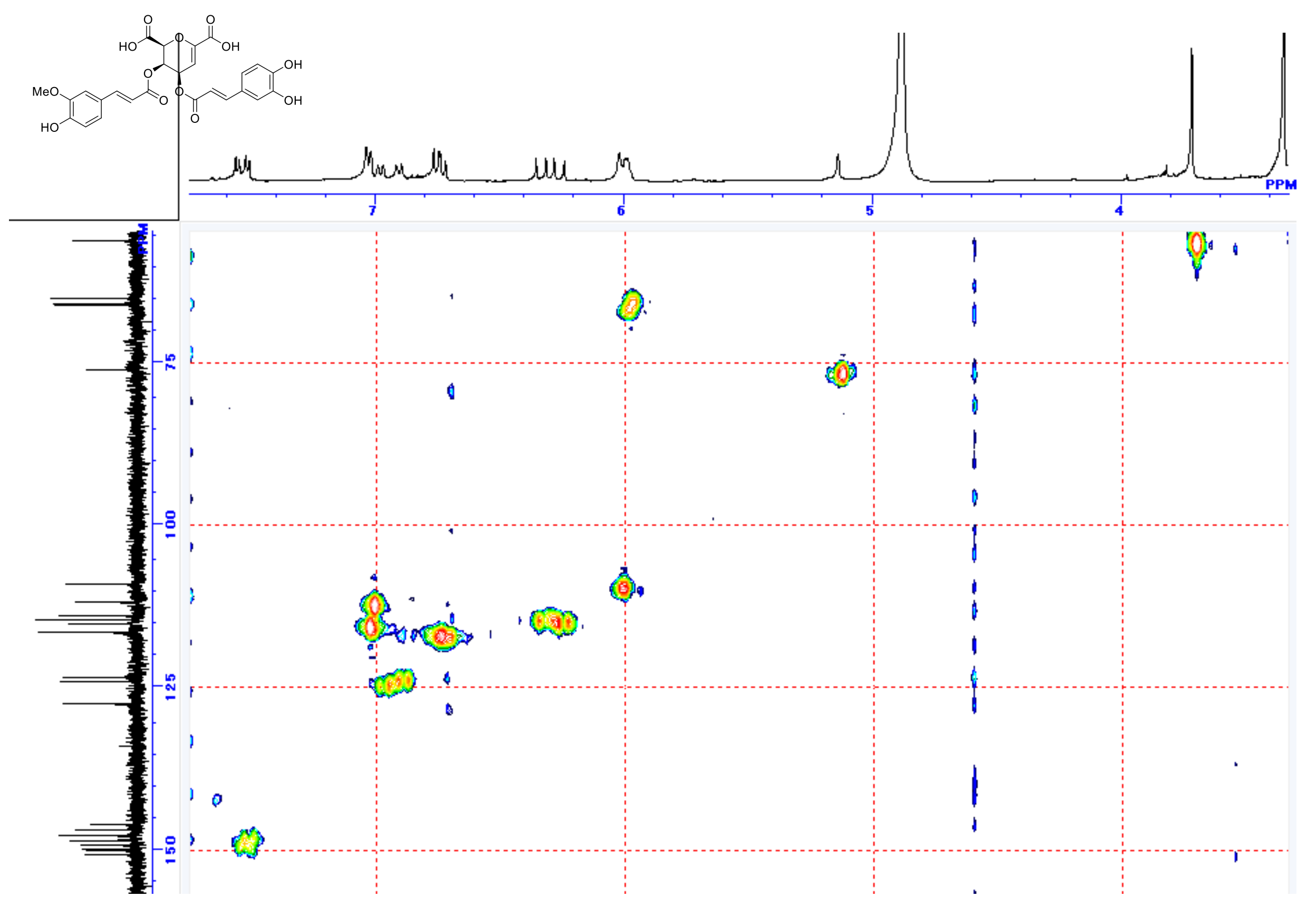

Figure S17. HMQC spectrum of compound 2 (in methanol- $d_{4}$ ) 


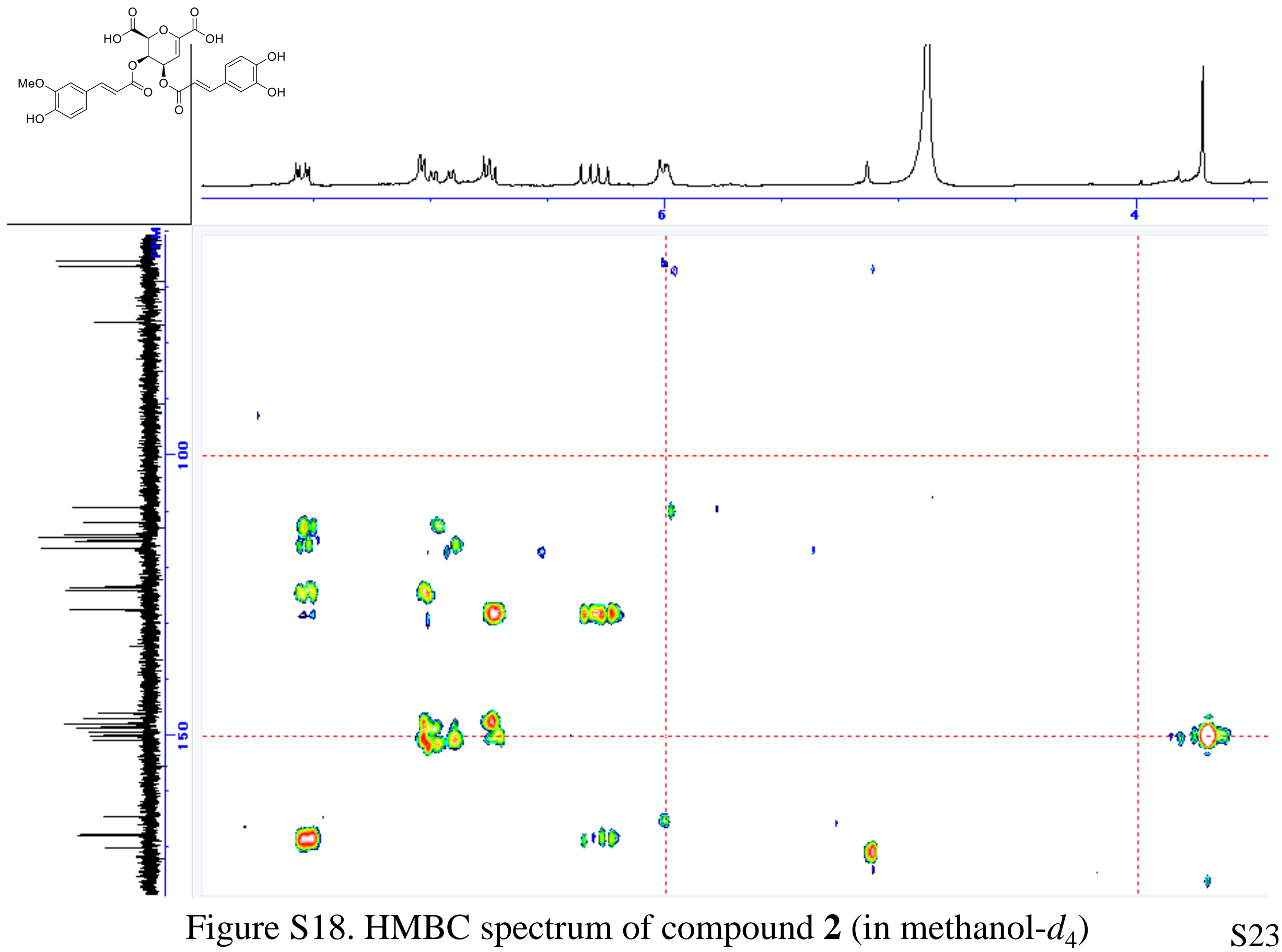




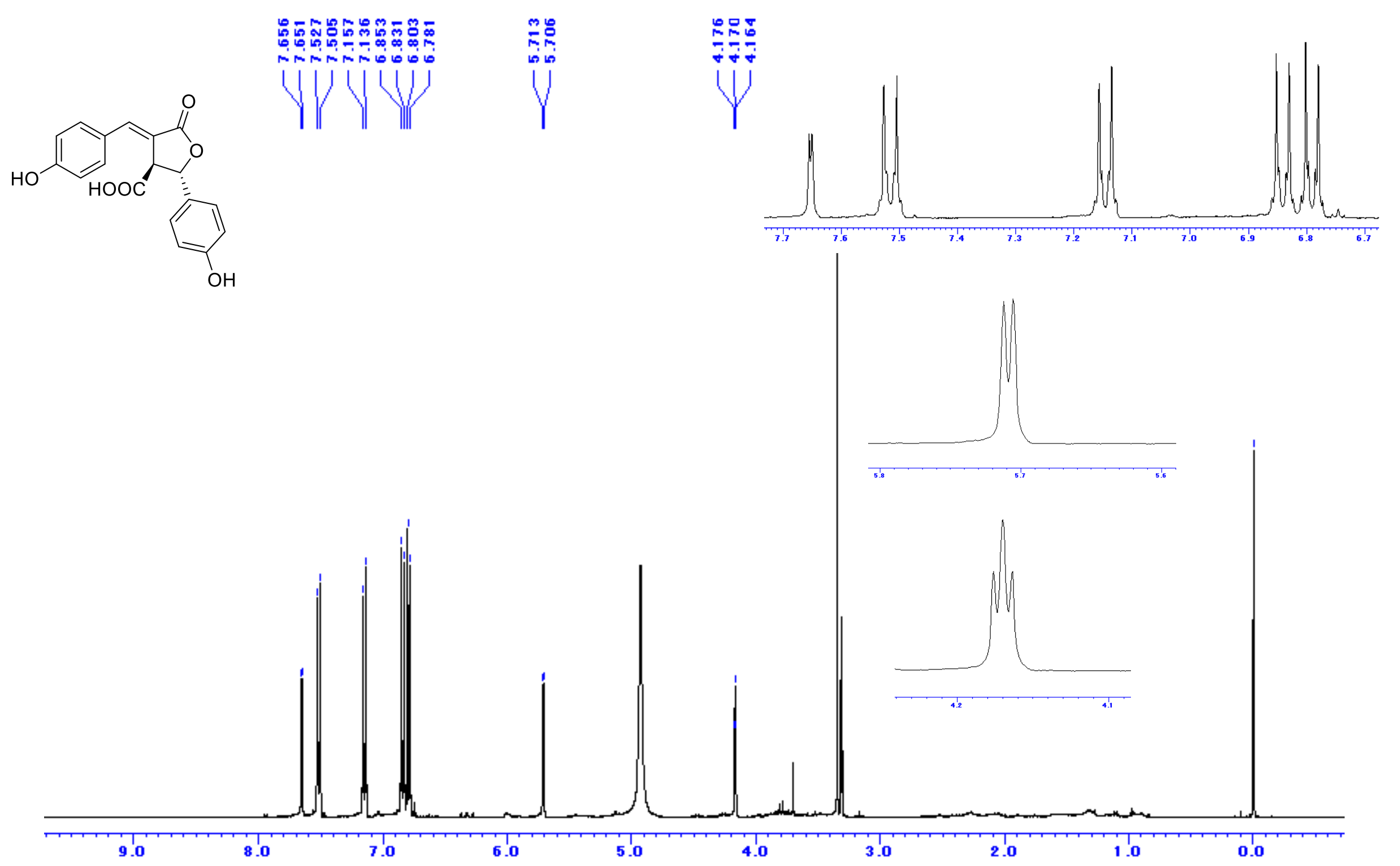

Figure S19. ${ }^{1} \mathrm{H}$ NMR spectrum of compound $\mathbf{3}$ (in methanol- $d_{4}$ ) 

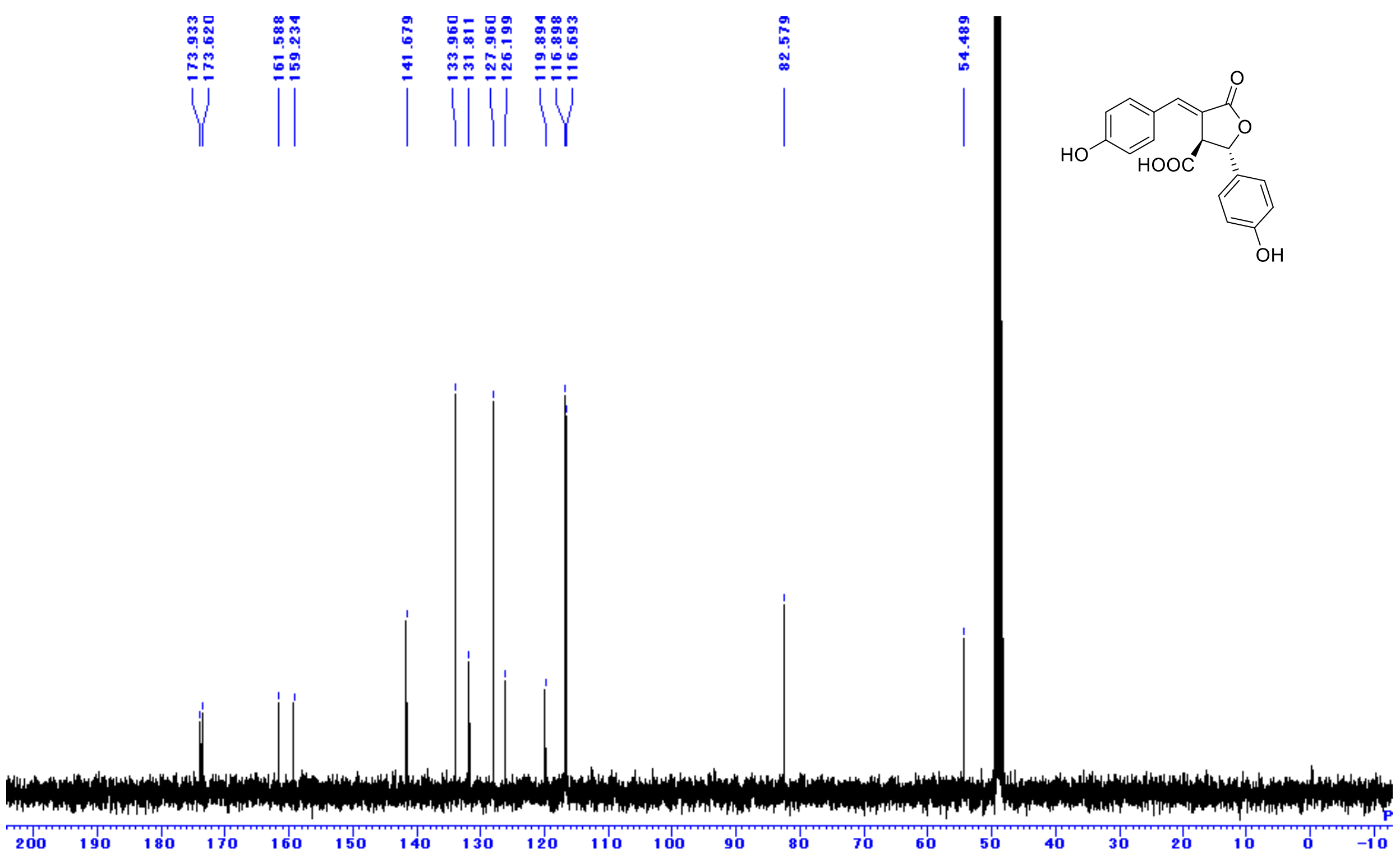

Figure S20. ${ }^{13} \mathrm{C}$ NMR spectrum of compound $\mathbf{3}$ (in methanol- $d_{4}$ ) 


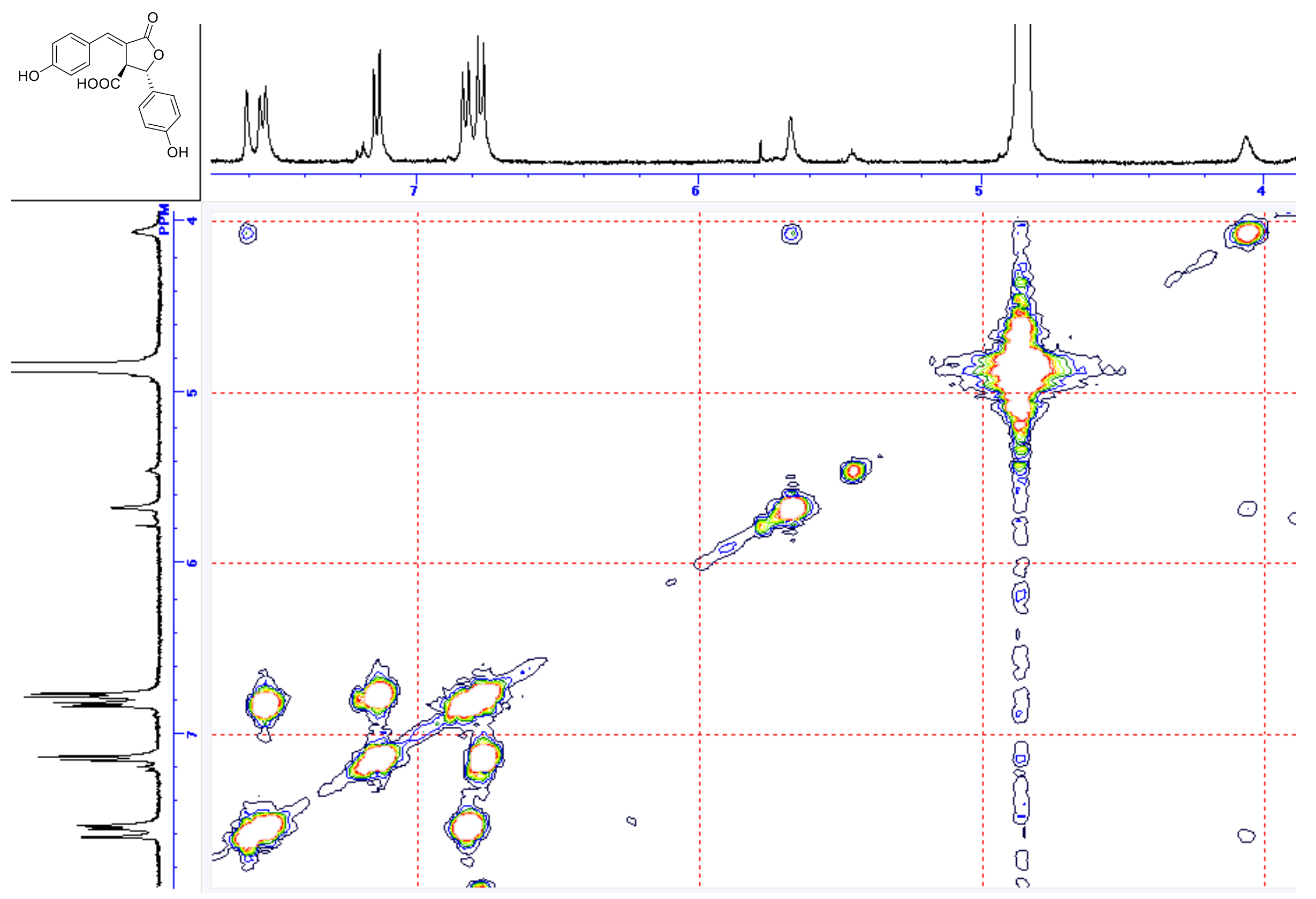

Figure S21. ${ }^{1} \mathrm{H}^{-1} \mathrm{H}$ COSY spectrum of compound 3 (in methanol- $d_{4}$ ) 


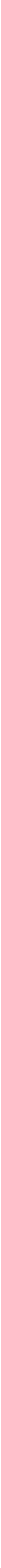

Figure S22. HMQC spectrum of compound $\mathbf{3}$ (in methanol- $d_{4}$ ) 


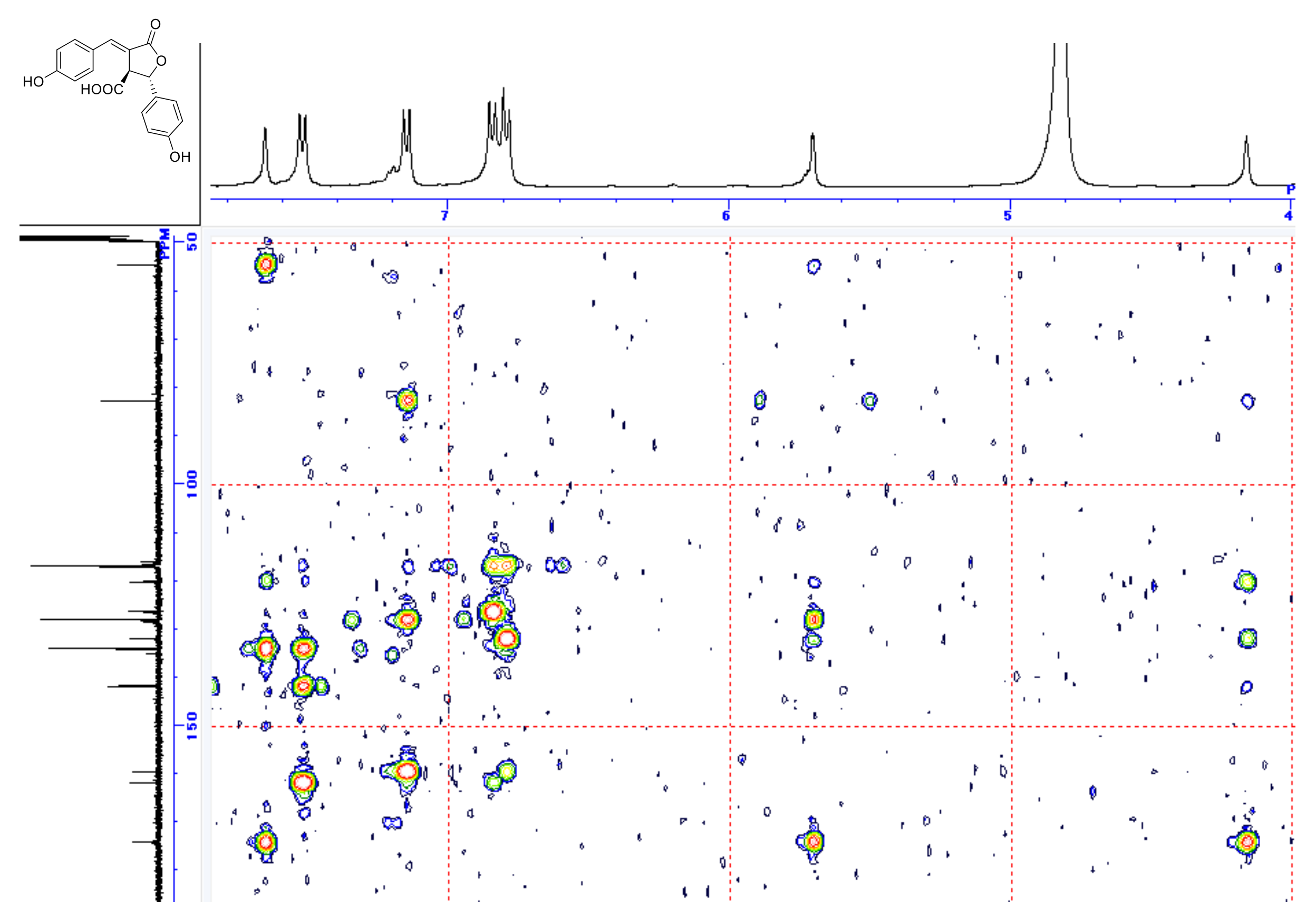

Figure S23. HMBC spectrum of compound 3 (in methanol- $d_{4}$ ) $\quad$ S28 
3a: a sodium salt of $\mathbf{3}$

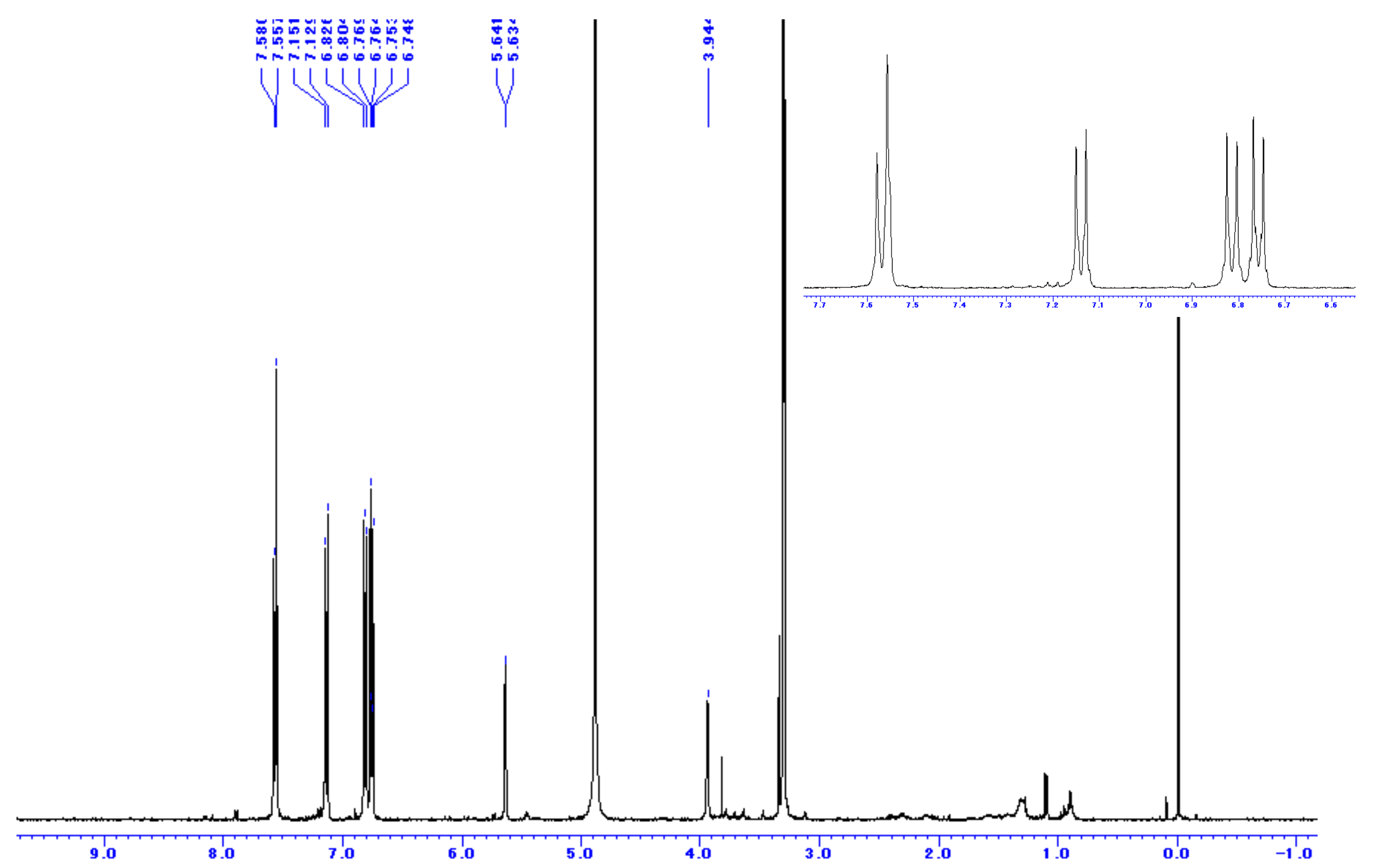

Figure S24. ${ }^{1} \mathrm{H}$ NMR spectrum of compound 3a (in methanol- $d_{4}$ ) 
3a: a sodium salt of $\mathbf{3}$
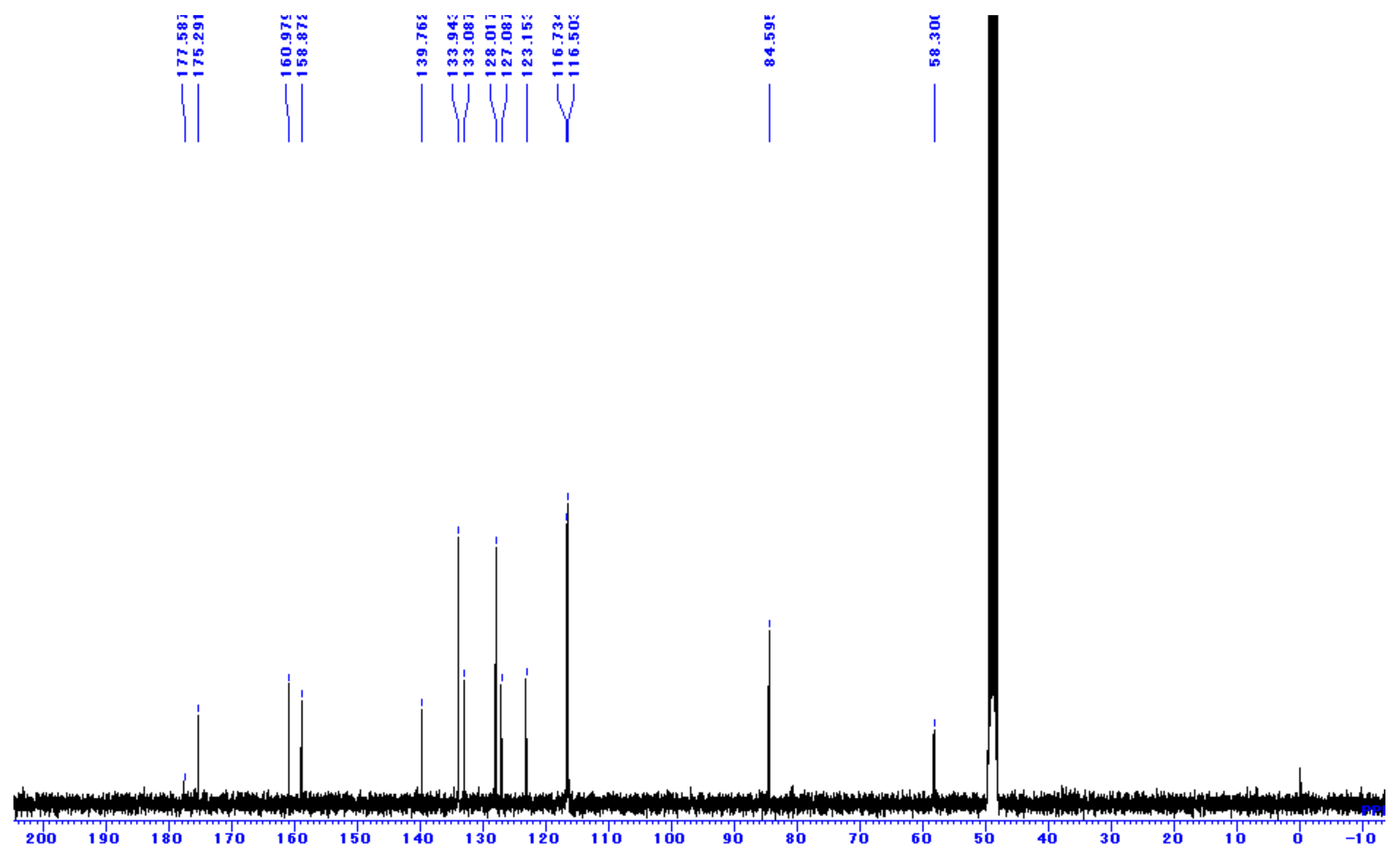

Figure S25. ${ }^{13} \mathrm{C}$ NMR spectrum of compound 3a (in methanol- $d_{4}$ ) 
3a: a sodium salt of $\mathbf{3}$

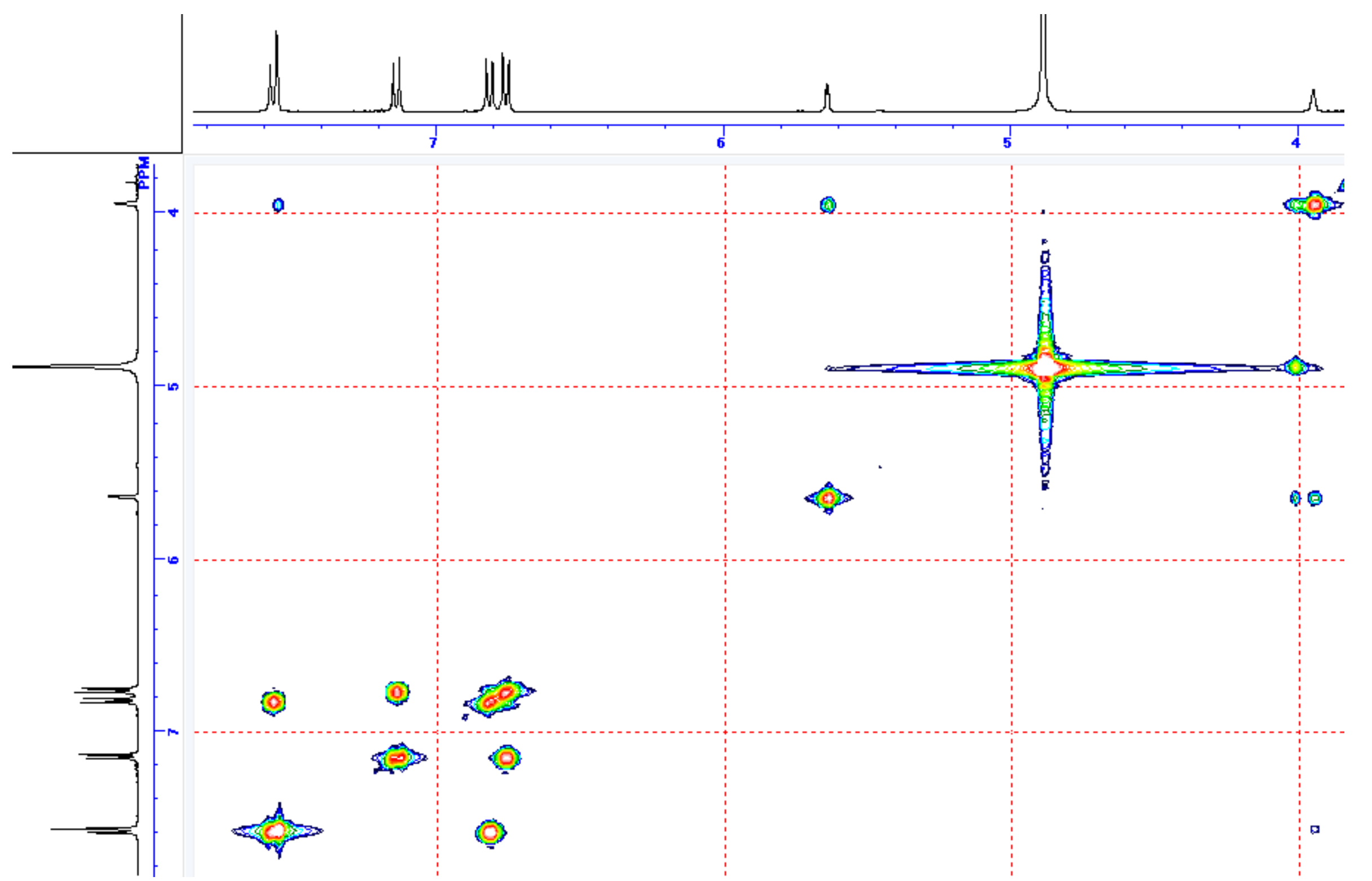

Figure S26. ${ }^{1} \mathrm{H}^{1}{ }^{1} \mathrm{H}$ COSY spectrum of compound 3a (in methanol- $d_{4}$ ) 
3a: a sodium salt of $\mathbf{3}$

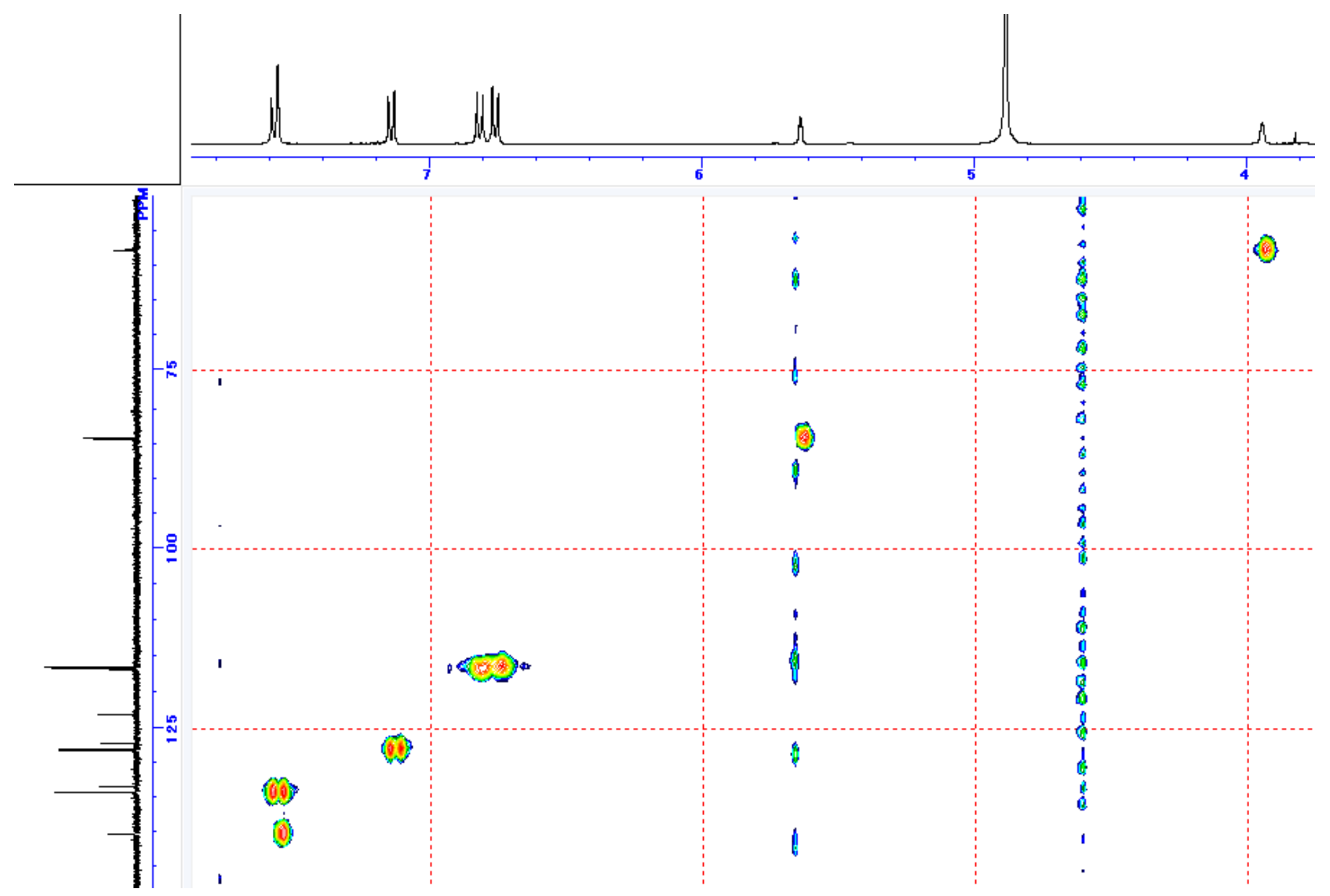

Figure S27. HMQC spectrum of compound 3a (in methanol- $d_{4}$ ) 
3a: a sodium salt of $\mathbf{3}$

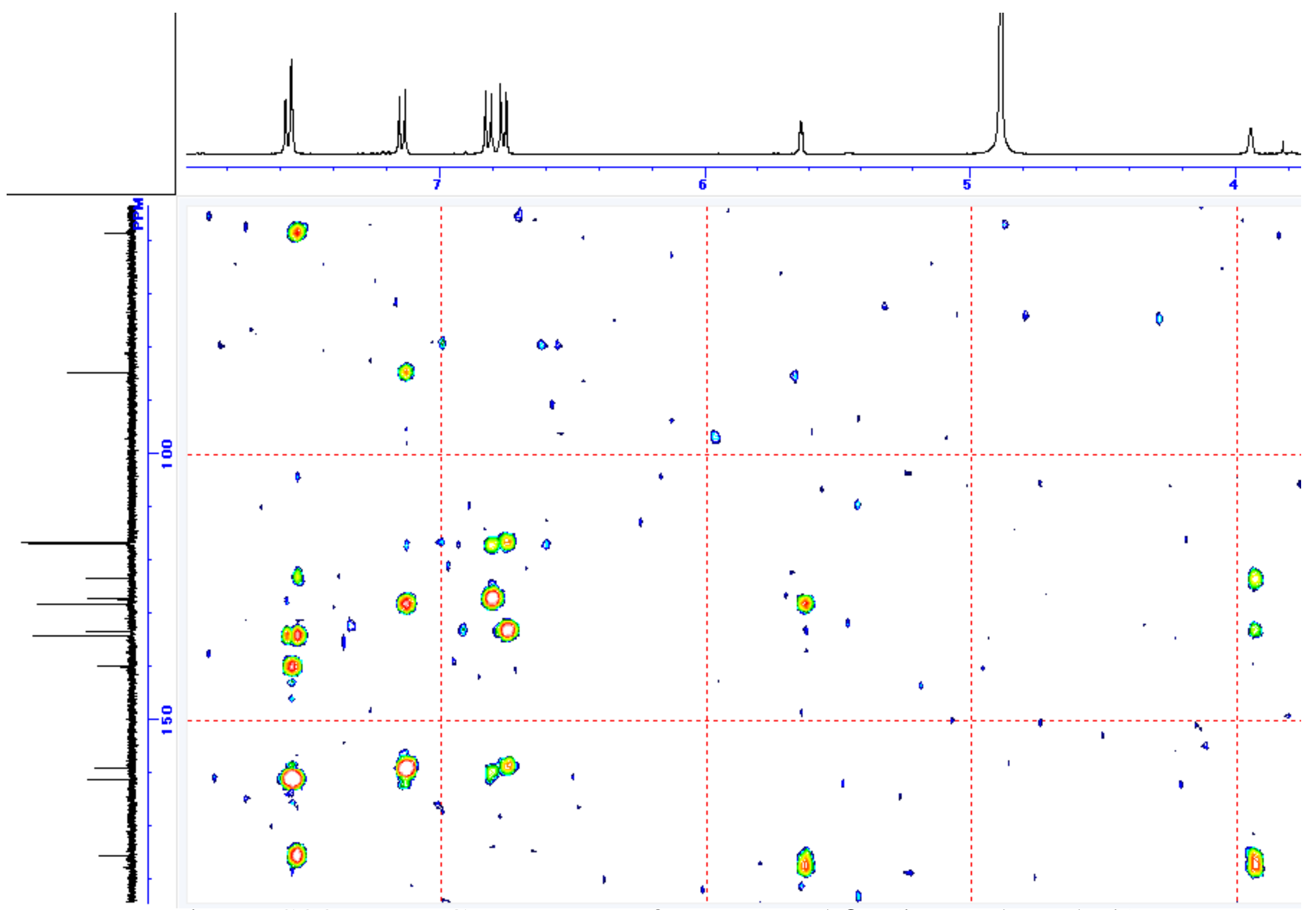

Figure S28. HMBC spectrum of compound 3a (in methanol- $d_{4}$ ) 
3b: (S)-PGME amide of $\mathbf{3}$

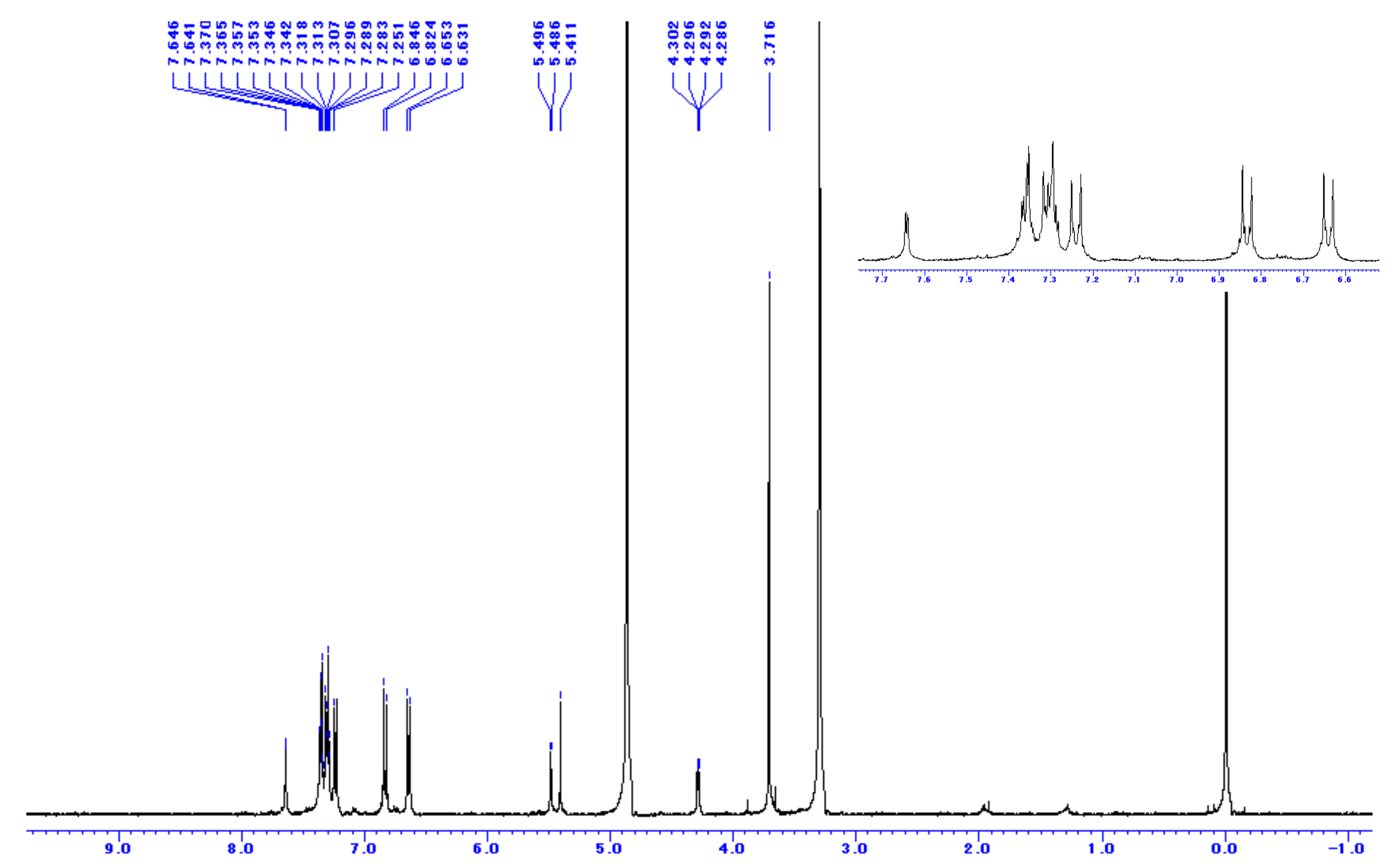

Figure S29. ${ }^{1} \mathrm{H}$ NMR spectrum of compound $\mathbf{3 b}$ (in methanol- $d_{4}$ ) 
3b: (S)-PGME amide of $\mathbf{3}$

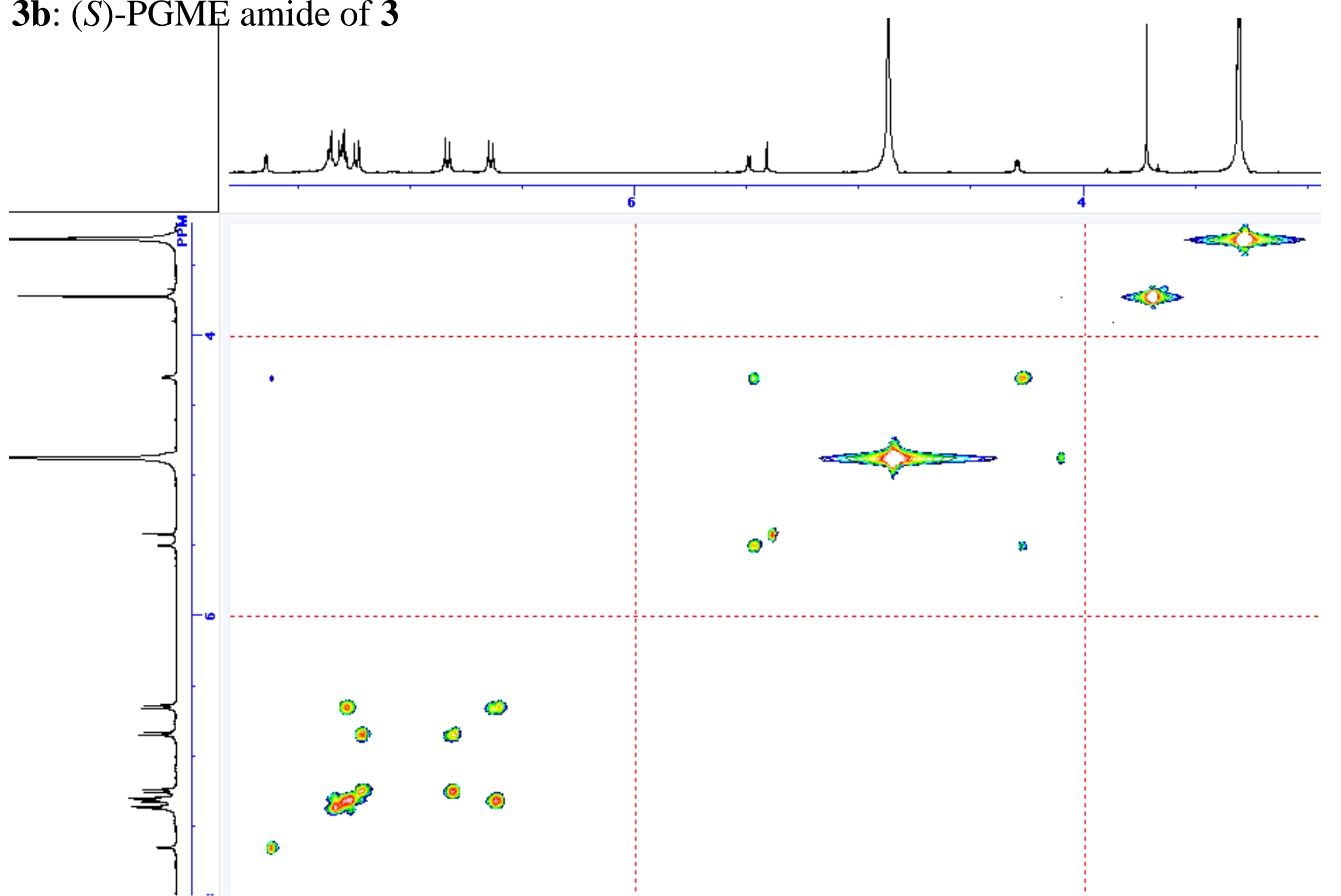

Figure $\mathrm{S} 30 .{ }^{1} \mathrm{H}-{ }^{1} \mathrm{H}$ COSY spectrum of compound $\mathbf{3 b}$ (in methanol- $d_{4}$ ) 
3c: $(R)$-PGME amide of $\mathbf{3}$

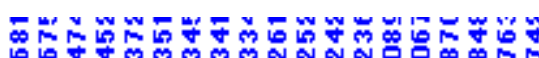

minnm

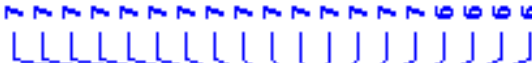

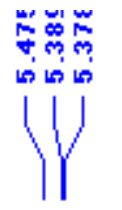
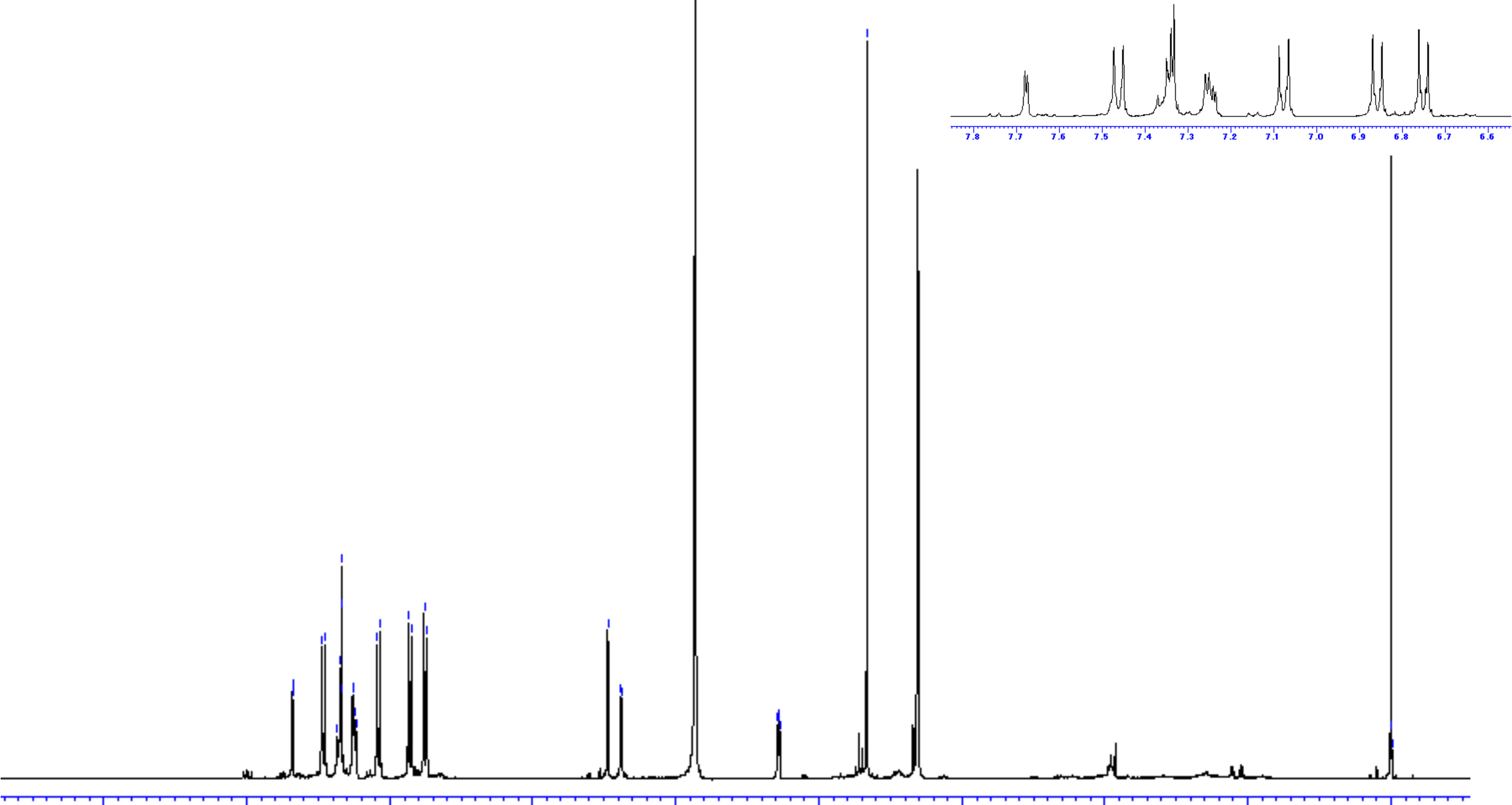

Figure S31. ${ }^{1} \mathrm{H}$ NMR spectrum of compound $3 \mathbf{c}$ (in methanol- $d_{4}$ ) 
3c: $(R)$-PGME amide of $\mathbf{3}$
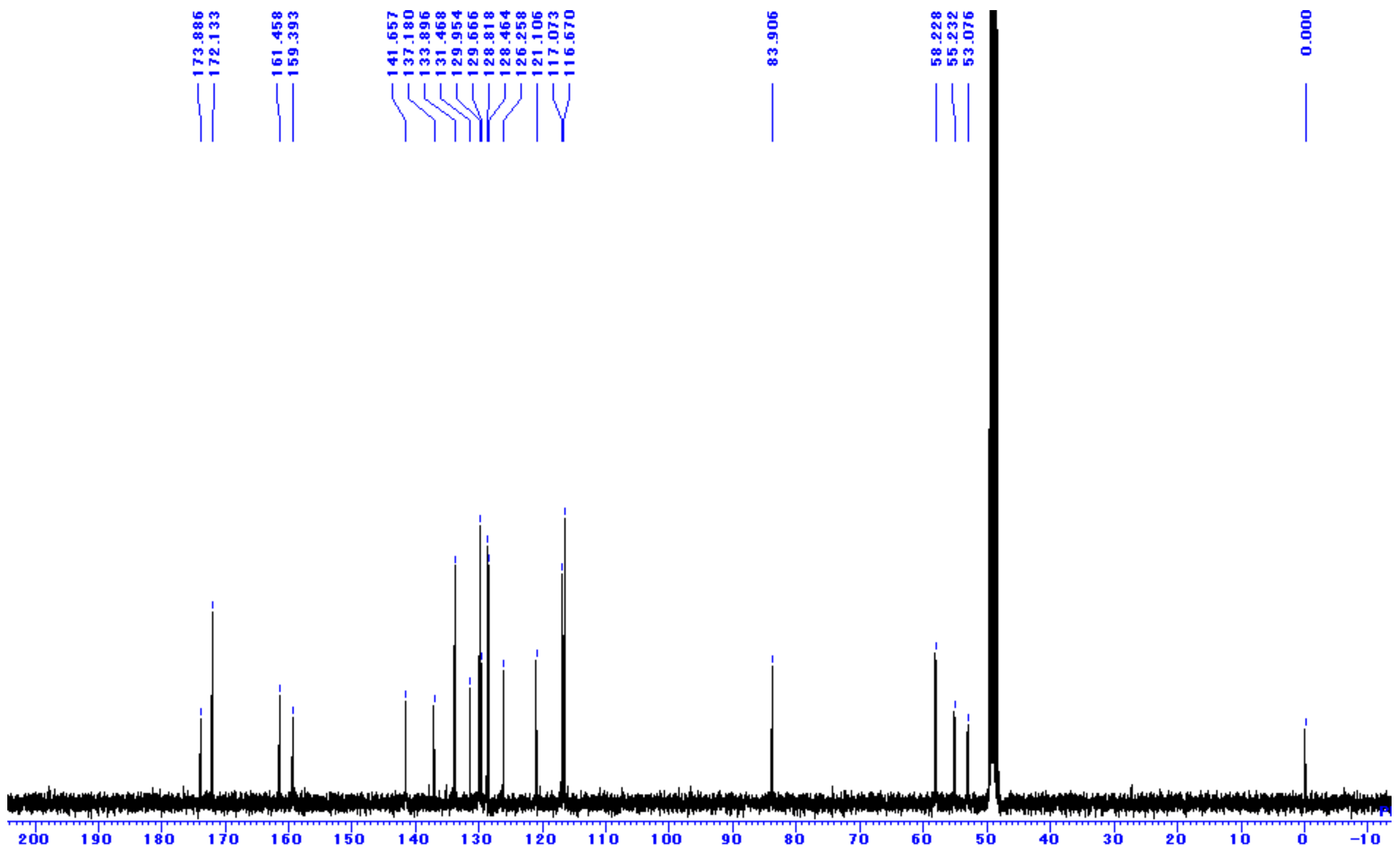

Figure S32. ${ }^{13} \mathrm{C}$ NMR spectrum of compound 3c (in methanol- $d_{4}$ ) 
3c: $(R)$-PGME amide of $\mathbf{3}$

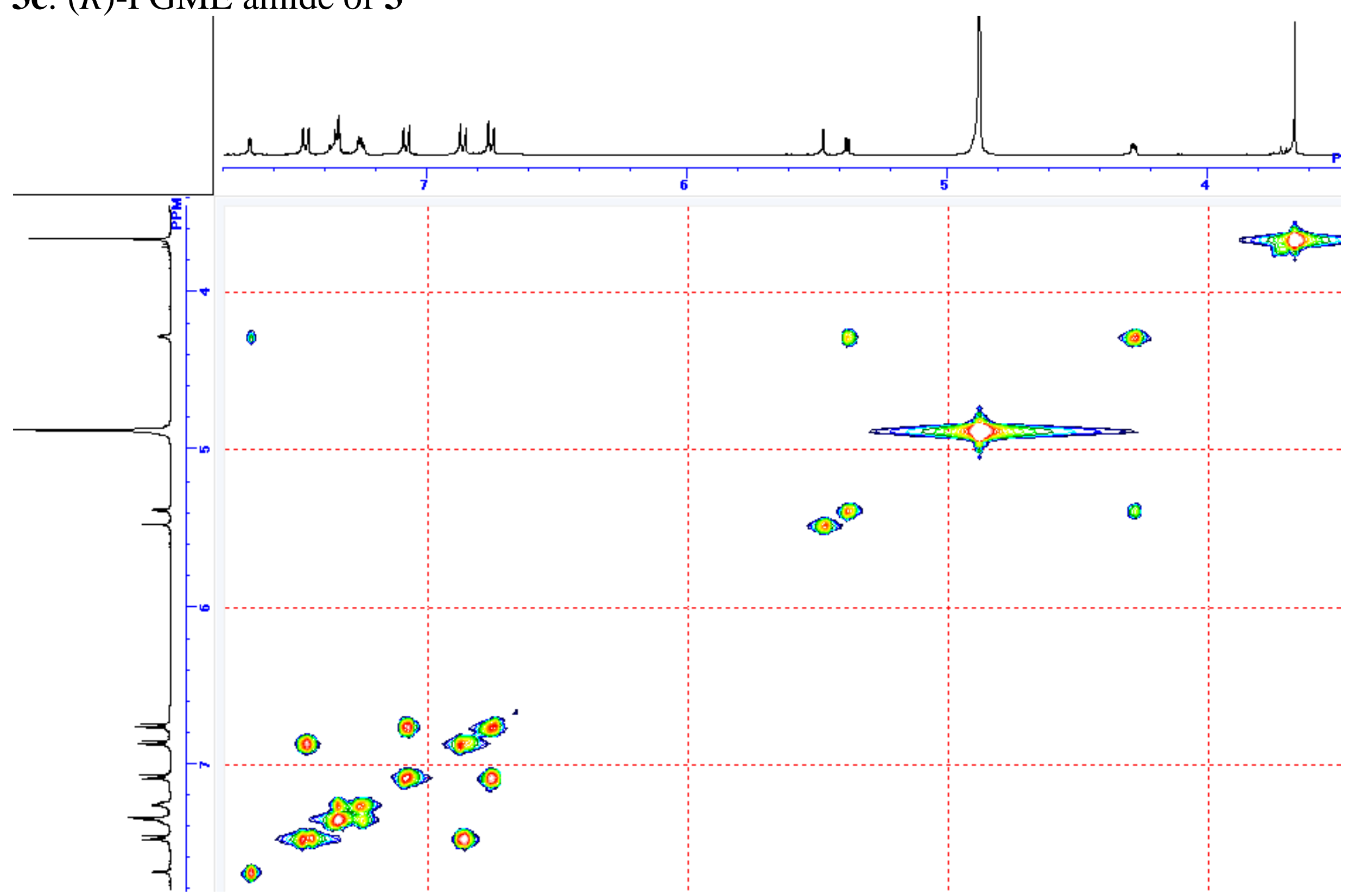

Figure S33. ${ }^{1} \mathrm{H}^{-1} \mathrm{H}$ COSY spectrum of compound $3 \mathbf{c}$ (in methanol- $d_{4}$ ) 
3c: $(R)$-PGME amide of $\mathbf{3}$

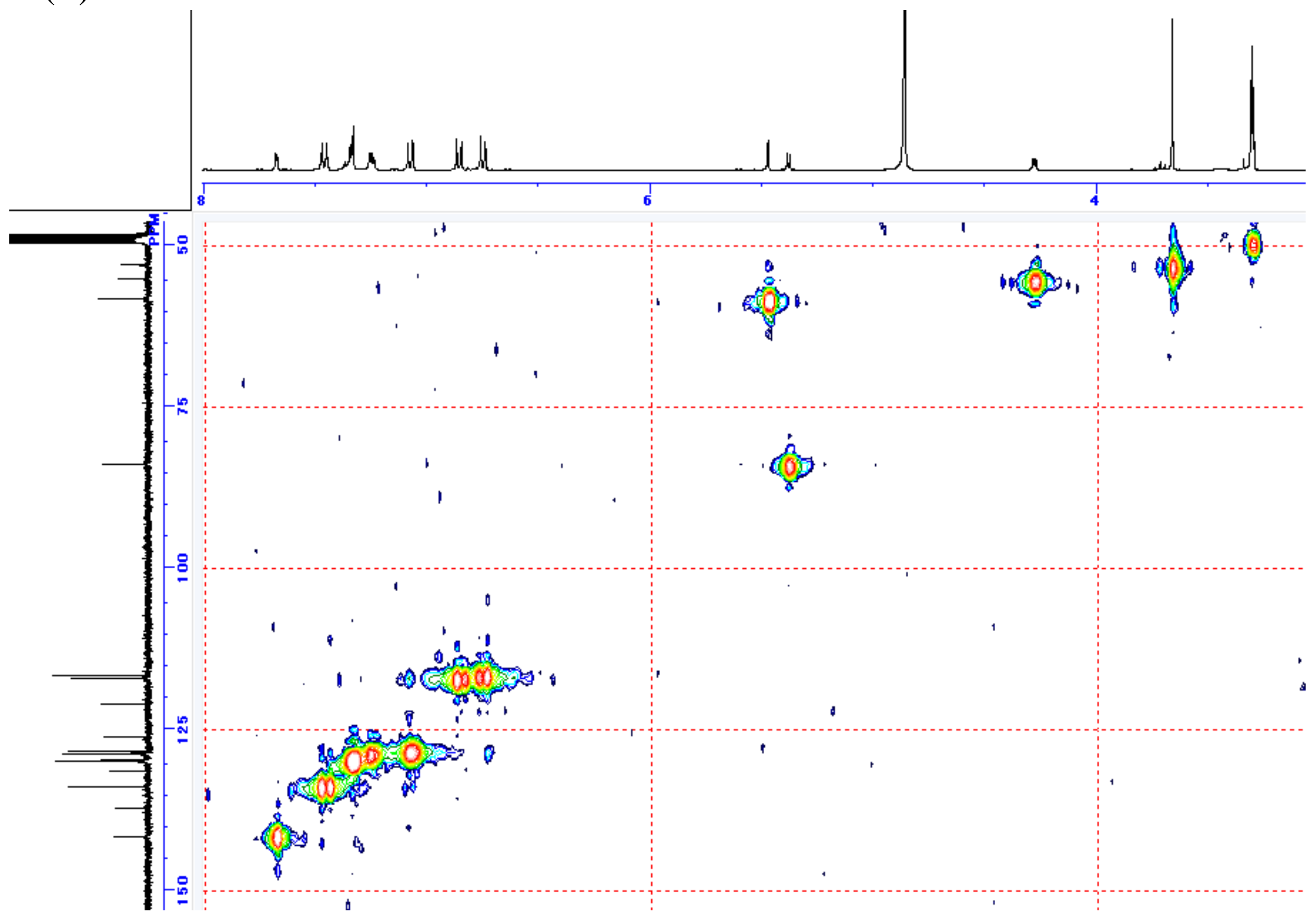

Figure S34. HMQC spectrum of compound $\mathbf{3 c}$ (in methanol- $d_{4}$ ) 


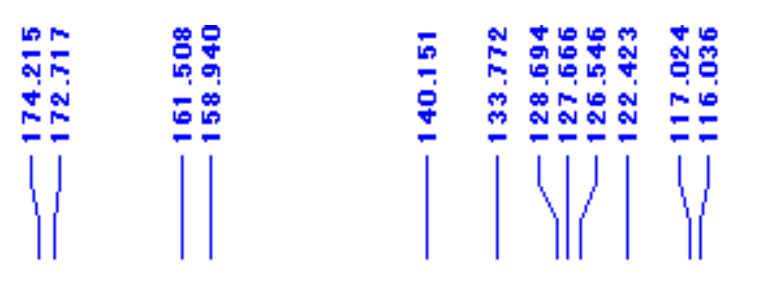

$$
\text { 象 }
$$
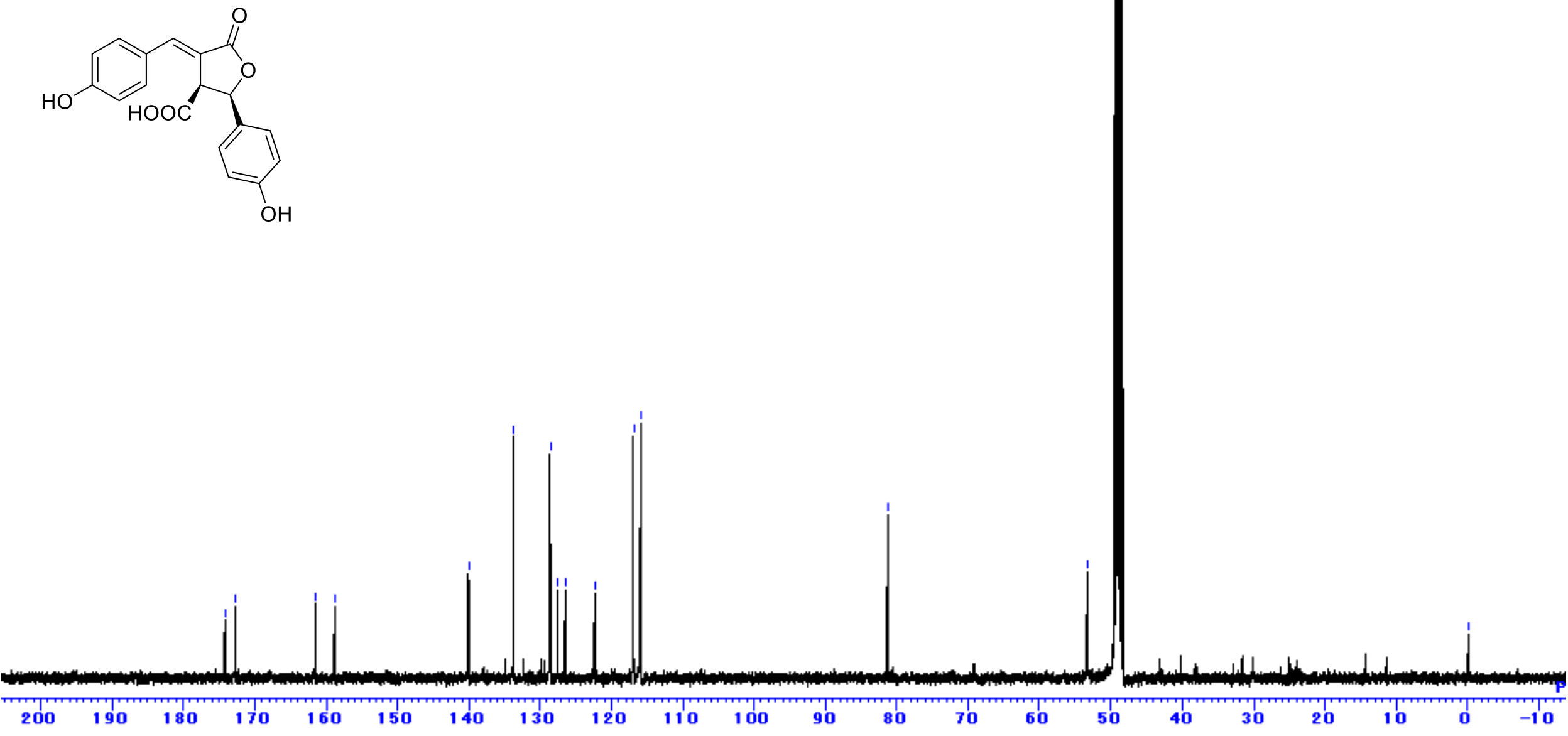

Figure S37. ${ }^{13} \mathrm{C}$ NMR spectrum of compound 4 (in methanol- $d_{4}$ ) 


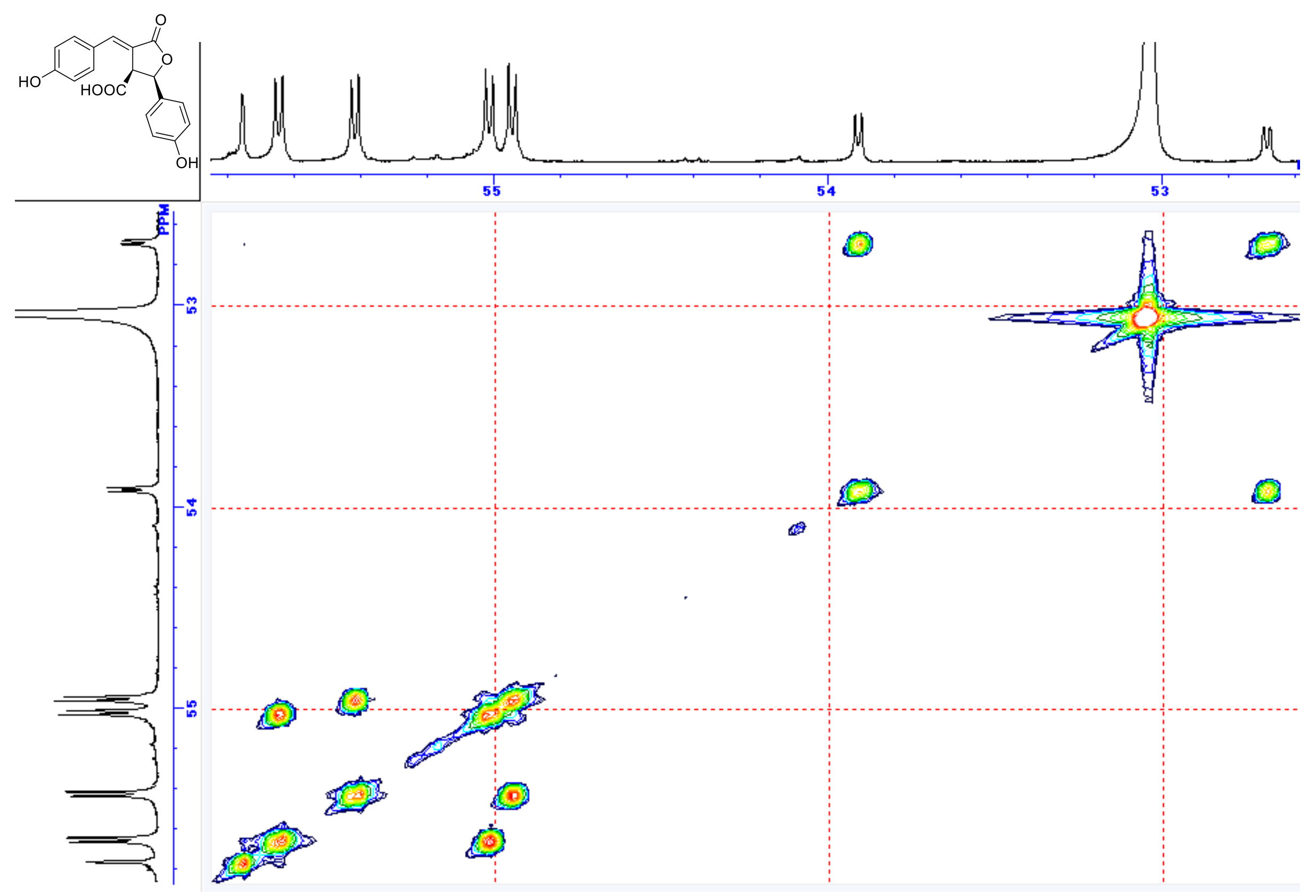

Figure S38. ${ }^{1} \mathrm{H}-{ }^{1} \mathrm{H}$ COSY spectrum of compound 4 (in methanol- $d_{4}$ ) 


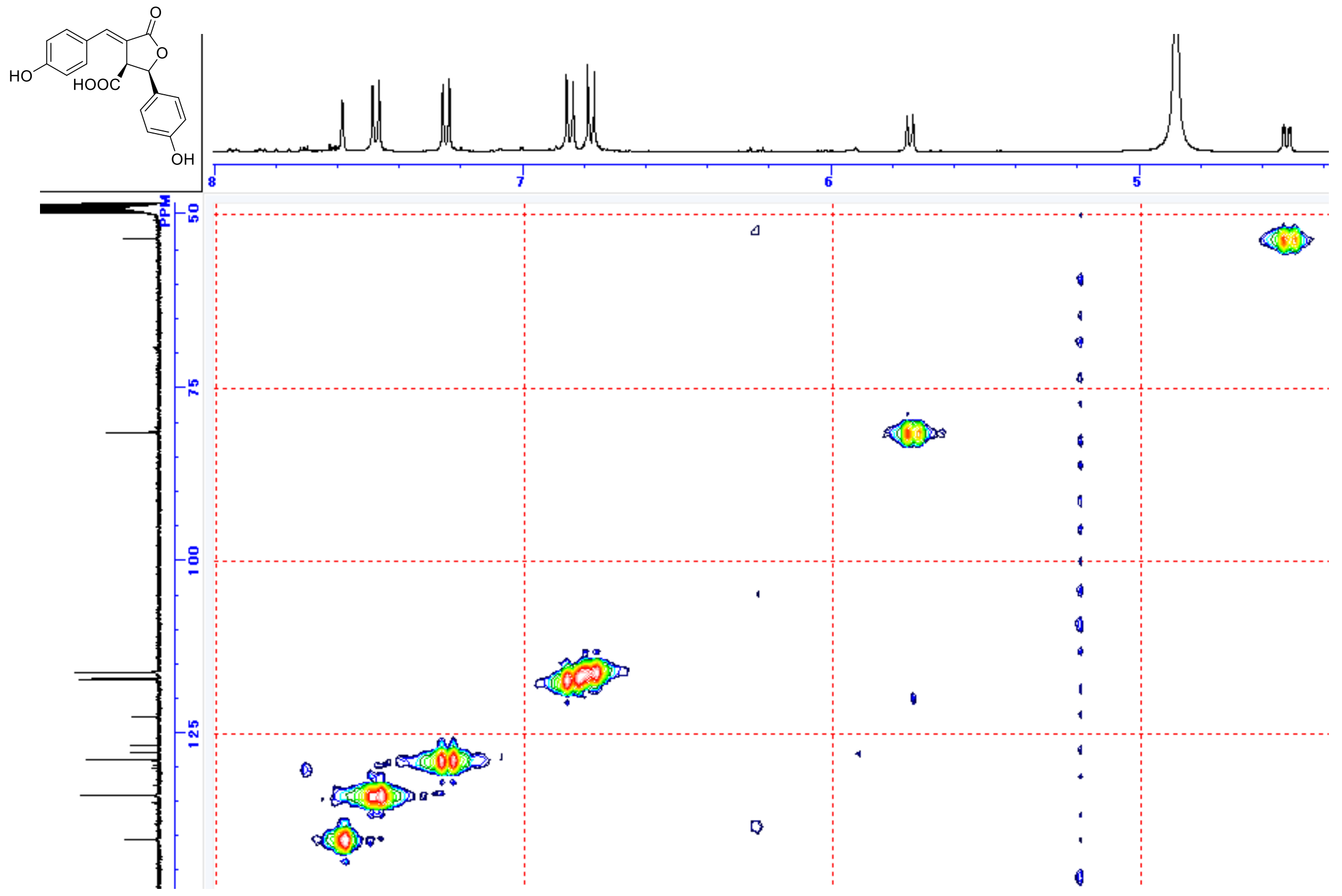

Figure S39. HMQC spectrum of compound 4 (in methanol- $d_{4}$ ) 


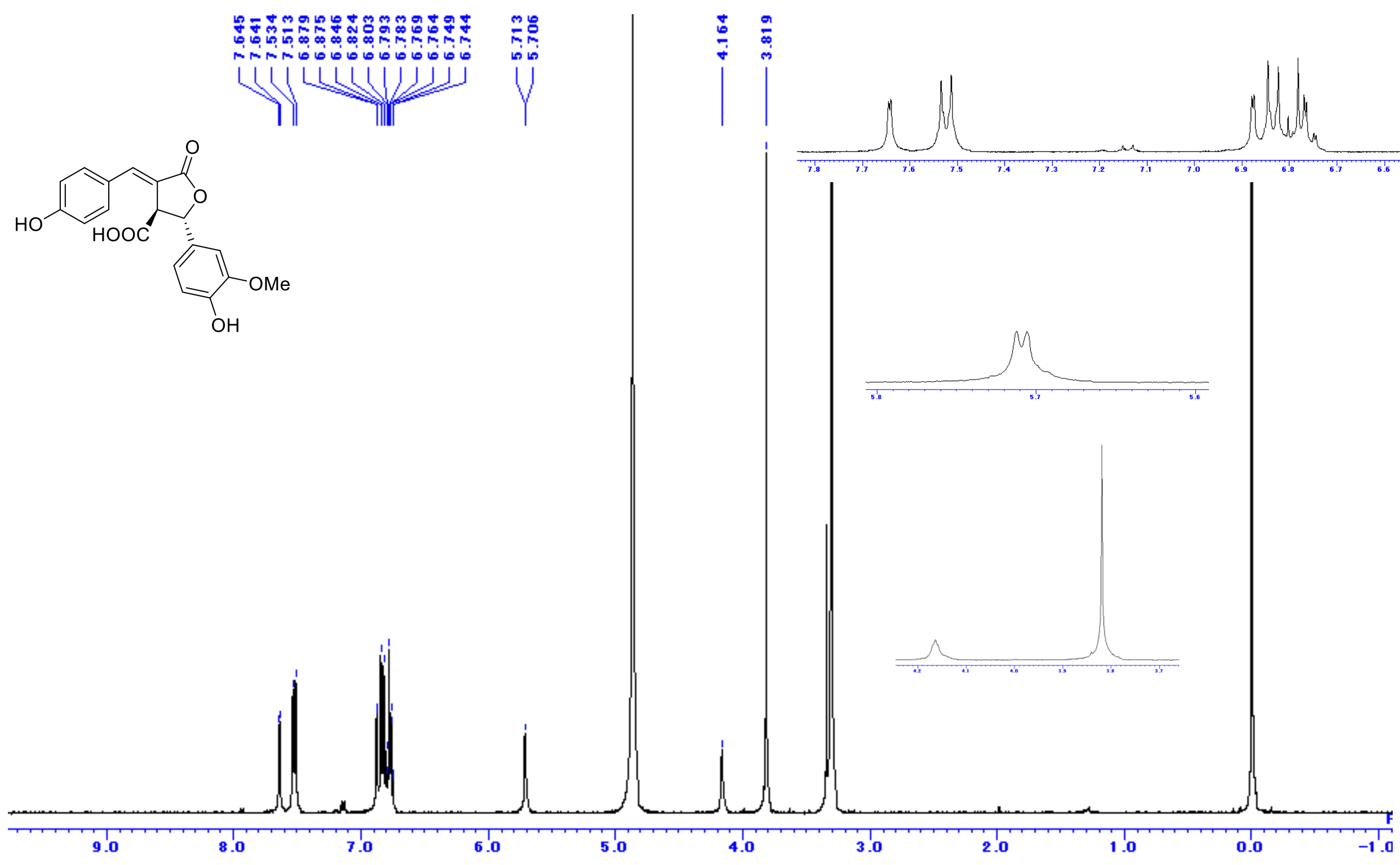

Figure S41. ${ }^{1} \mathrm{H}$ NMR spectrum of compound 5 (in methanol- $d_{4}$ ) 

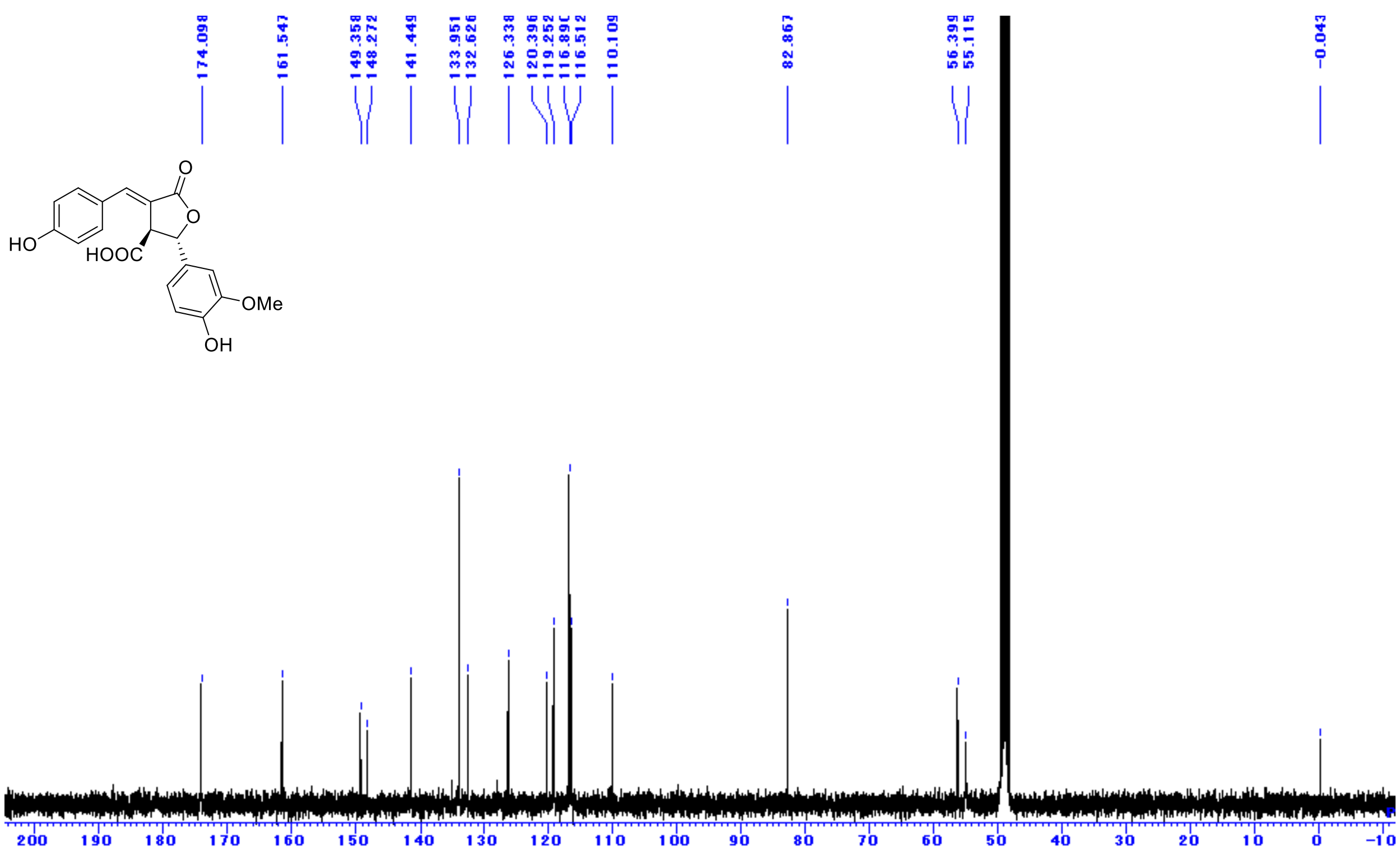

Figure S42. ${ }^{13} \mathrm{C}$ NMR spectrum of compound 5 (in methanol- $d_{4}$ ) 


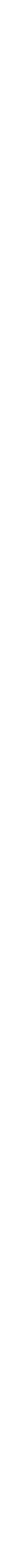

Figure S43. ${ }^{1} \mathrm{H}-{ }^{1} \mathrm{H}$ COSY spectrum of compound 5 (in methanol- $d_{4}$ ) 


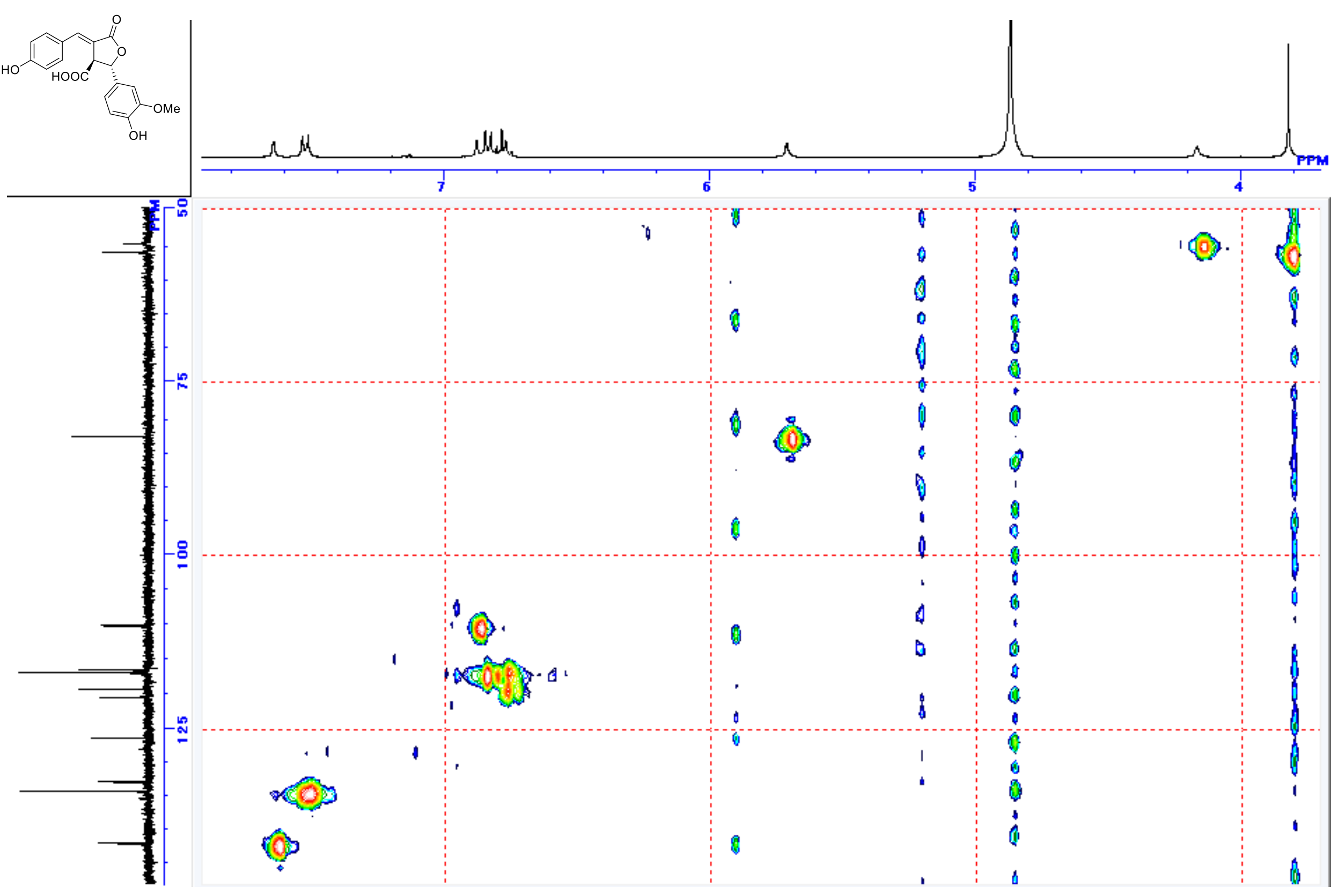

Figure S44. HMQC spectrum of compound 5 (in methanol- $d_{4}$ ) 


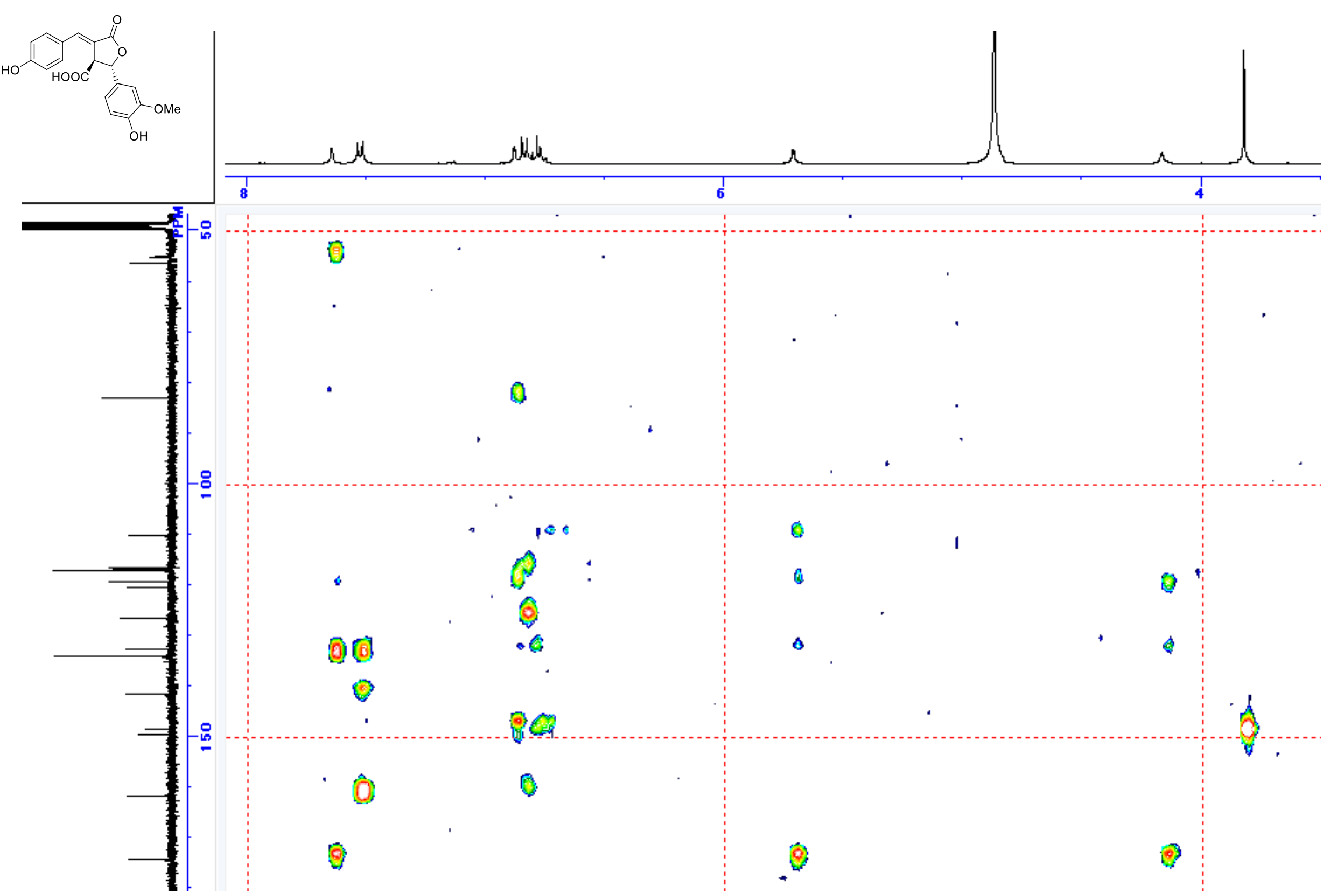

Figure S45. HMBC spectrum of compound 5 (in methanol- $d_{4}$ ) 


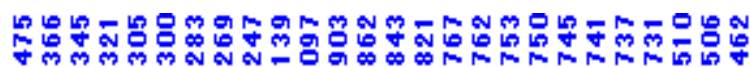

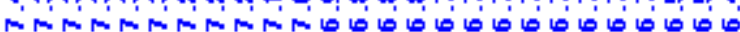

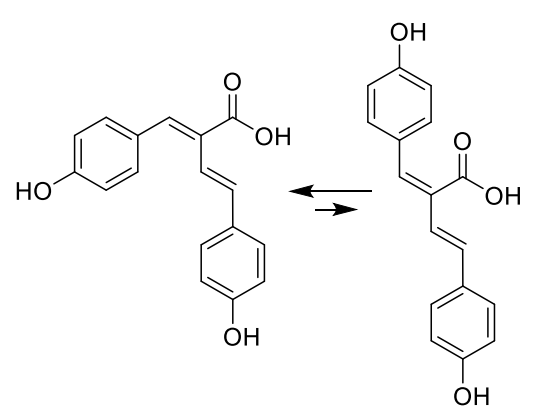

TाI Tा TाI $\|$
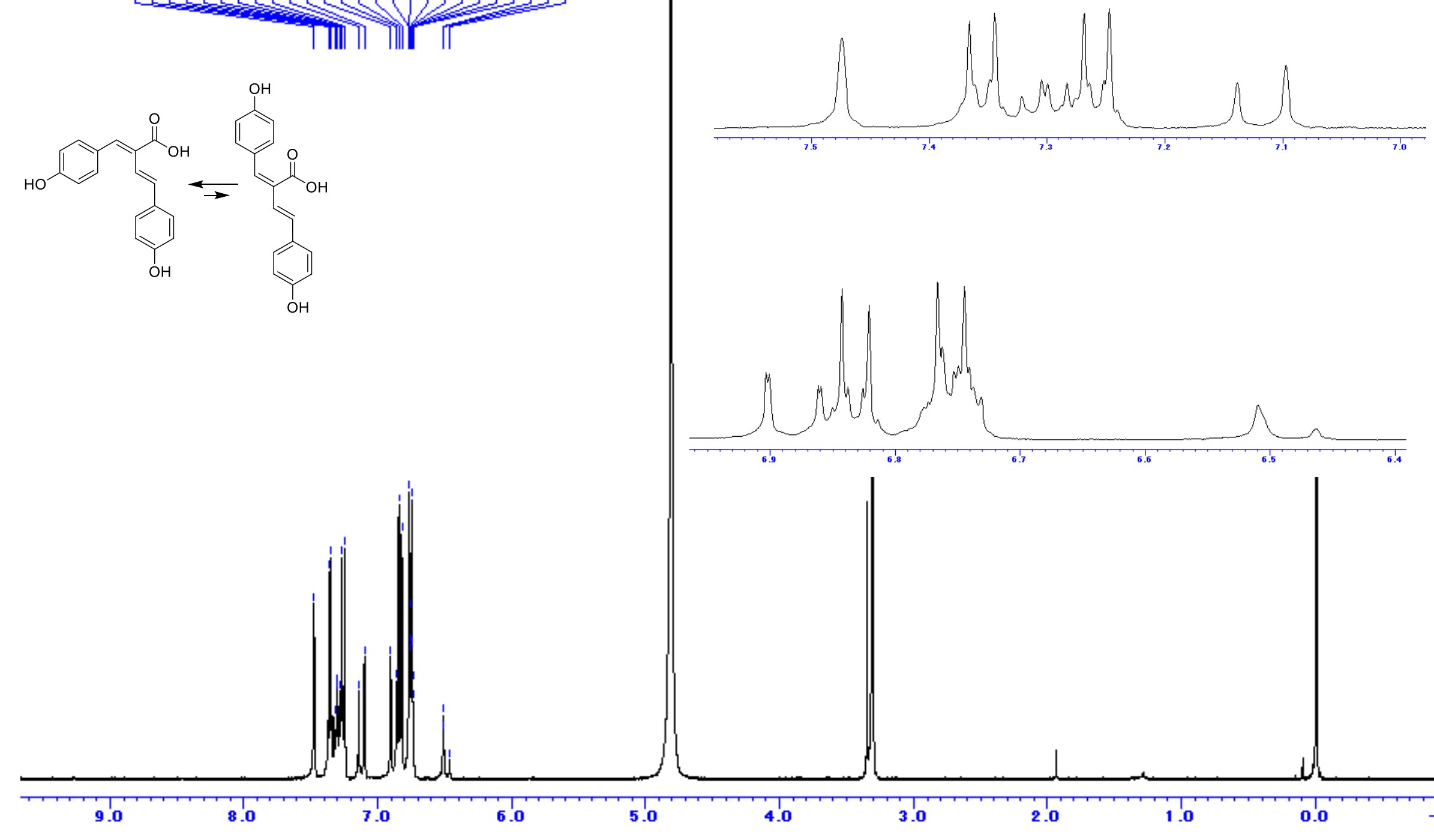

Figure S46. ${ }^{1} \mathrm{H}$ NMR spectrum of compound 6 (in methanol- $d_{4}$ ) 

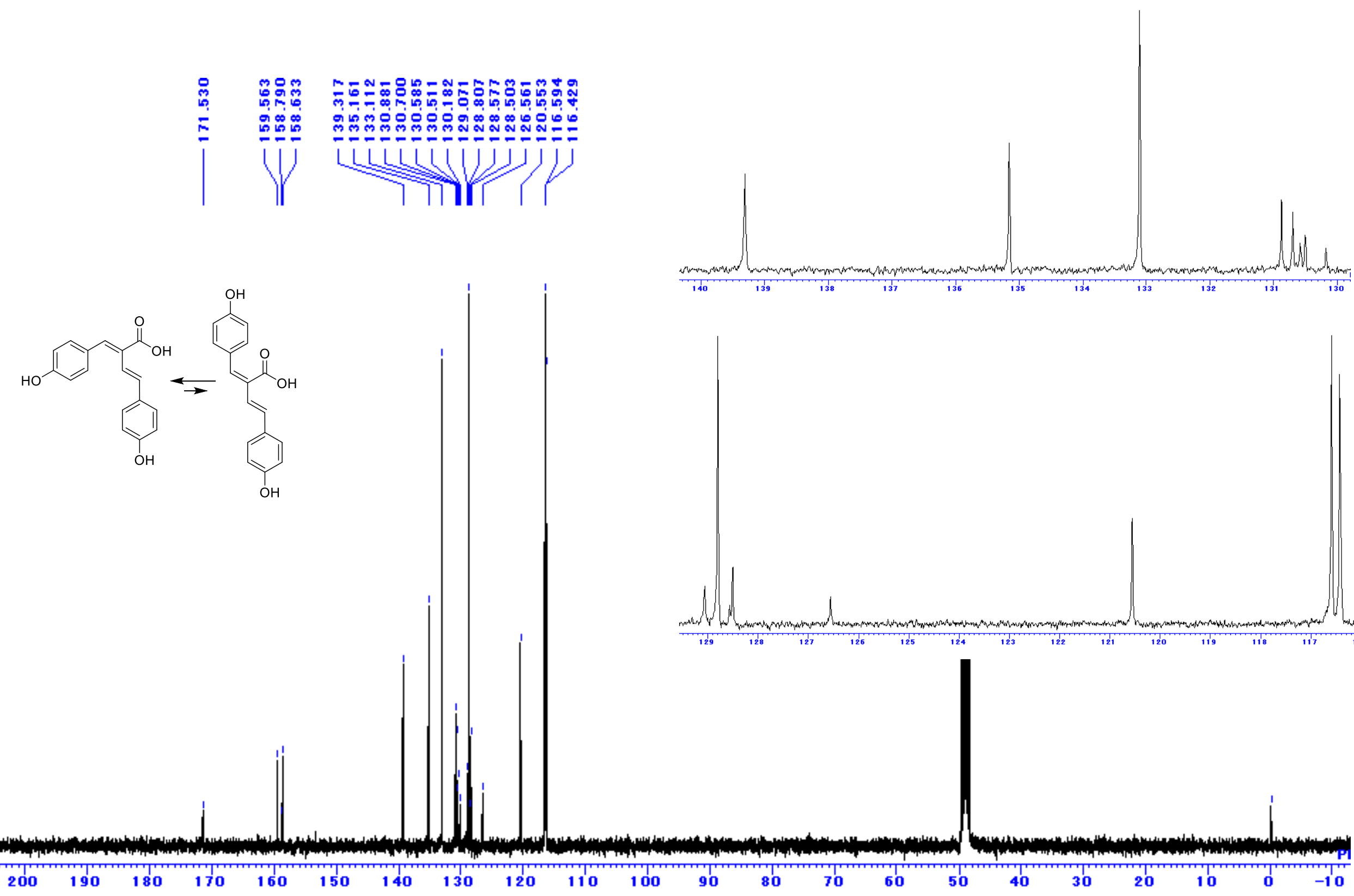

Figure S47. ${ }^{13} \mathrm{C}$ NMR spectrum of compound 6 (in methanol- $d_{4}$ ) 

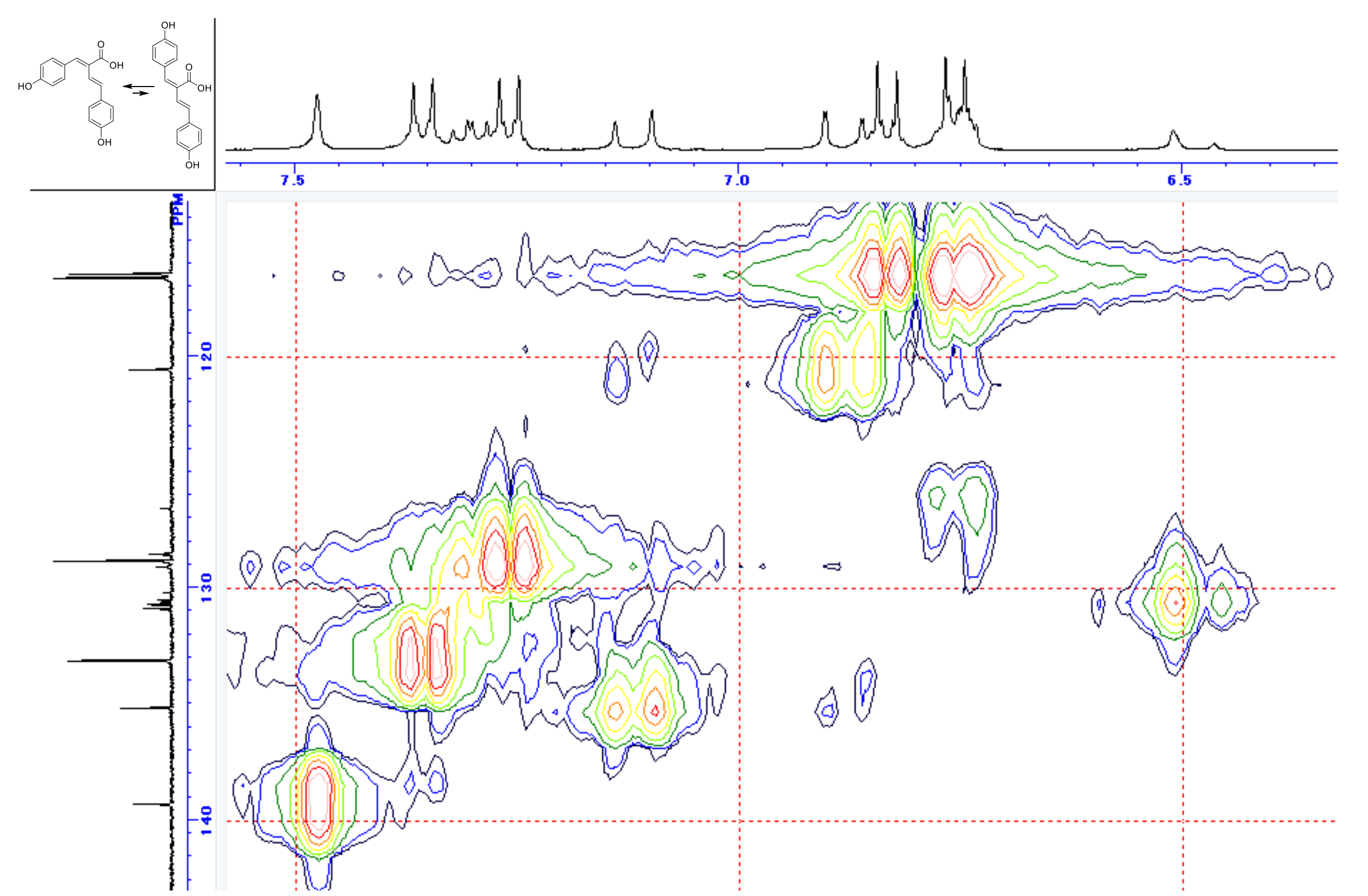

Figure S49. HMQC spectrum of compound 6 (in methanol- $d_{4}$ ) 


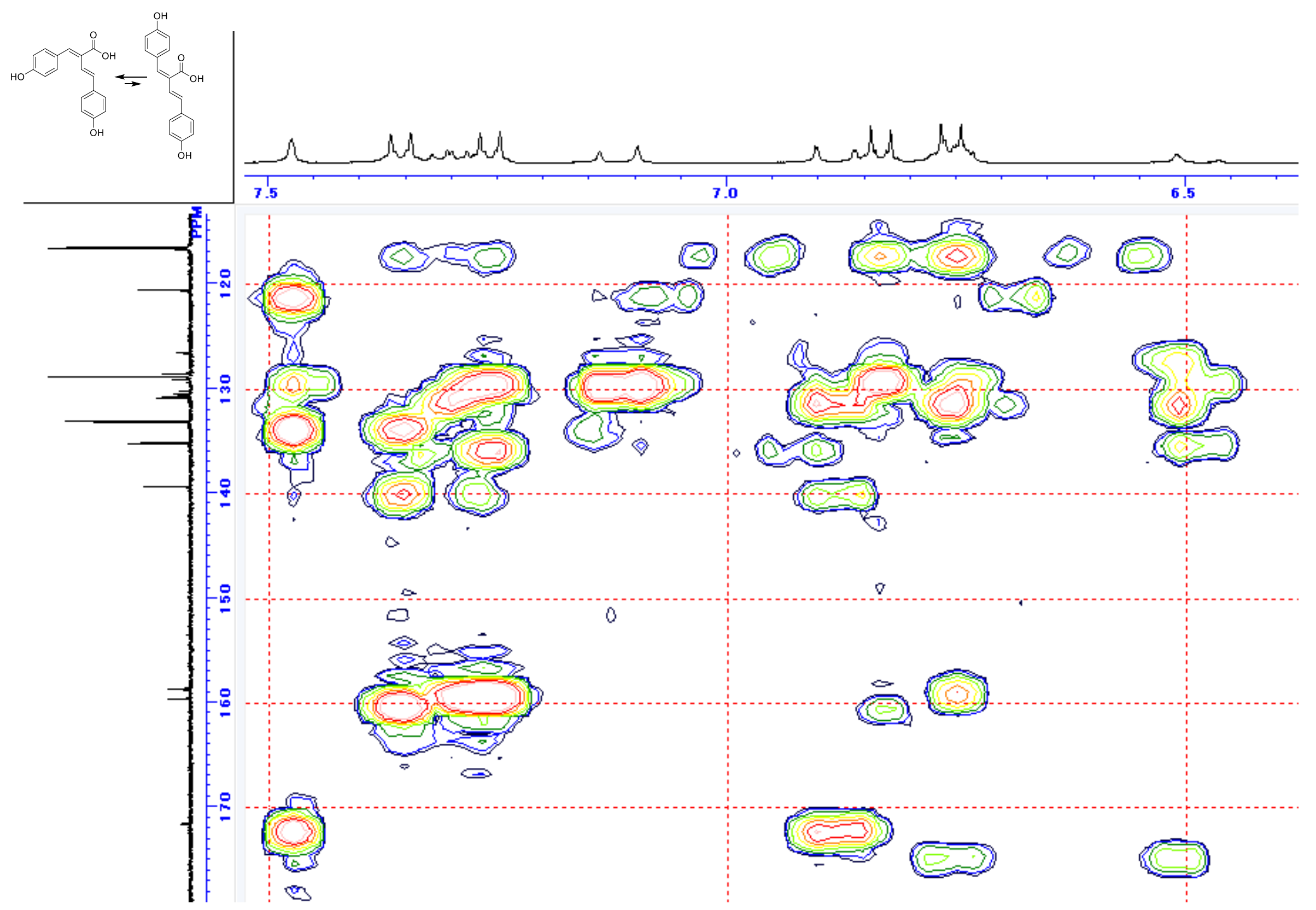

Figure S50. HMBC spectrum of compound 6 (in methanol- $d_{4}$ ) 

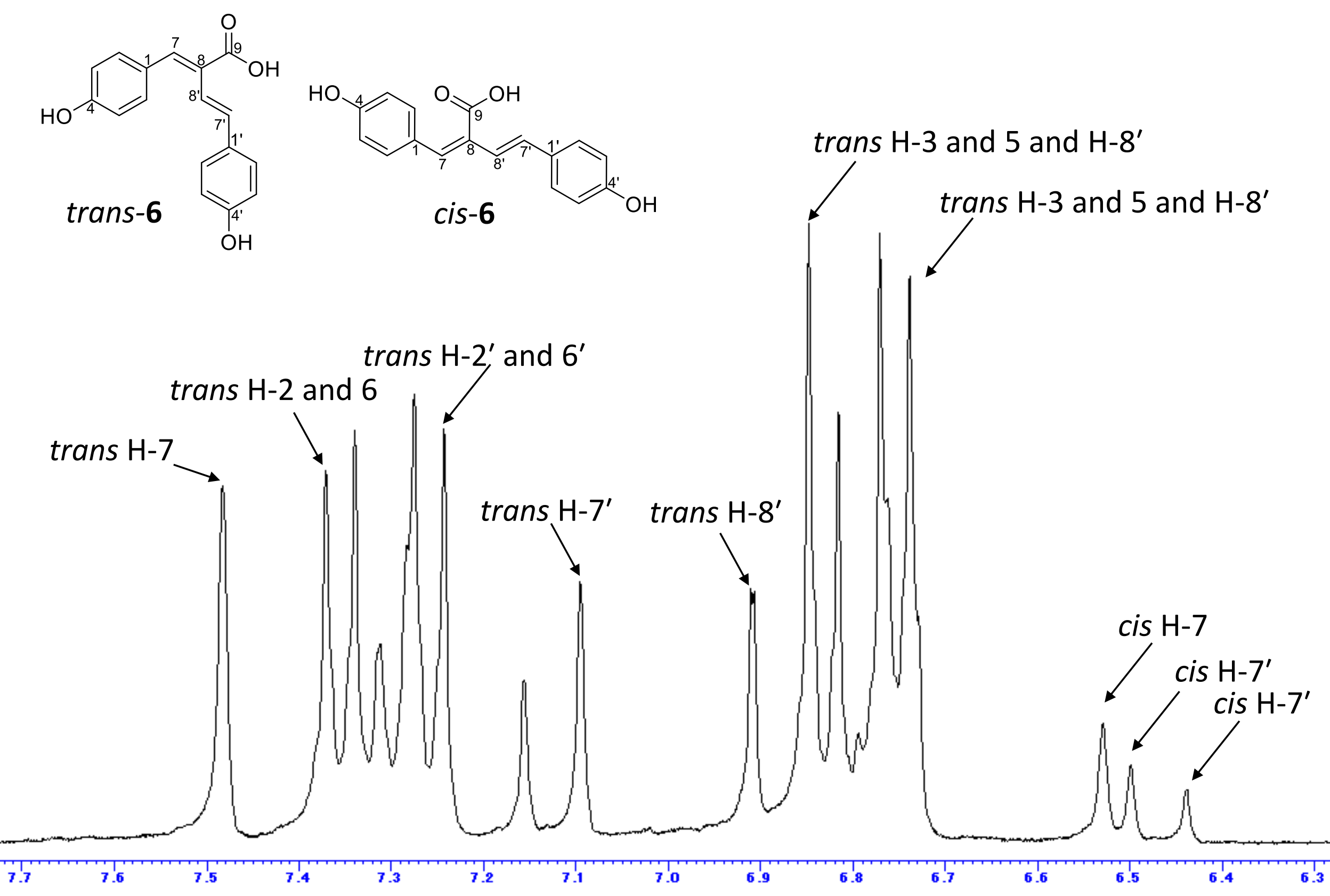

Figure S51. ${ }^{1} \mathrm{H}$ NMR spectrum for NOE of compound 6 (in methanol- $d_{4}, 270 \mathrm{MHz}$ S56 $_{56}$ 

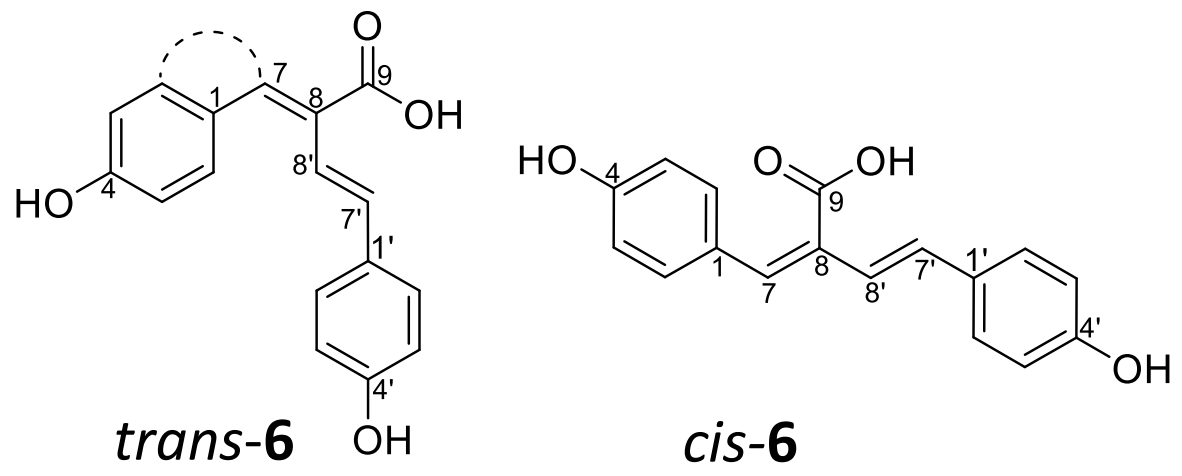

\section{trans $\mathrm{H}-2$ and 6}

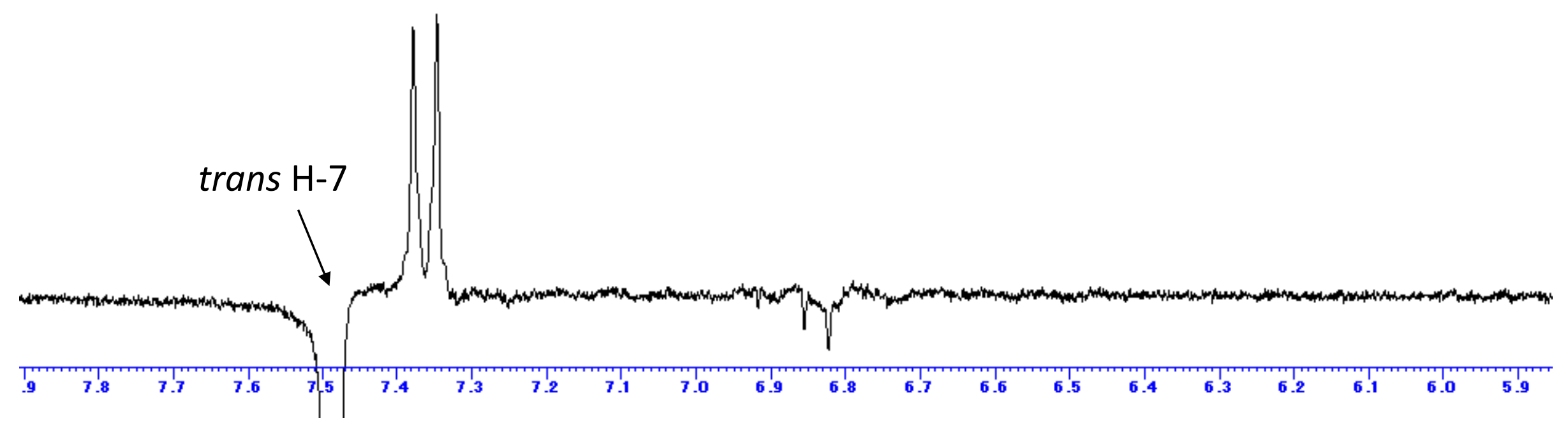

Figure S52. NOE spectrum of compound 6 (trans $\mathrm{H}-7$ ) 


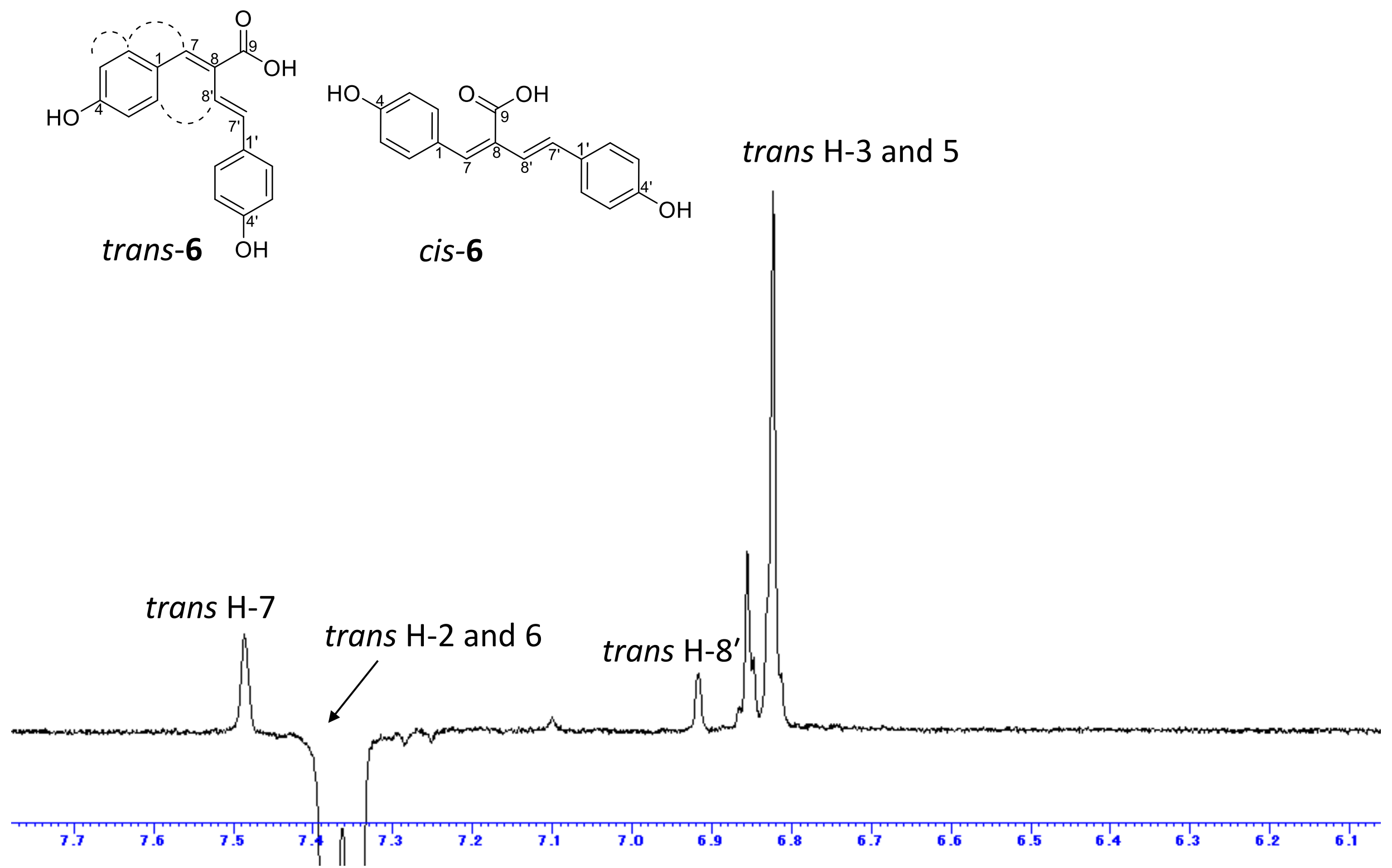

Figure S53. NOE spectrum of compound 6 (cis H-2 and 6) 


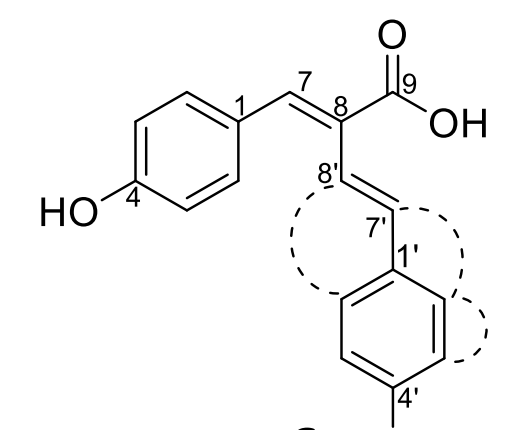

trans-6

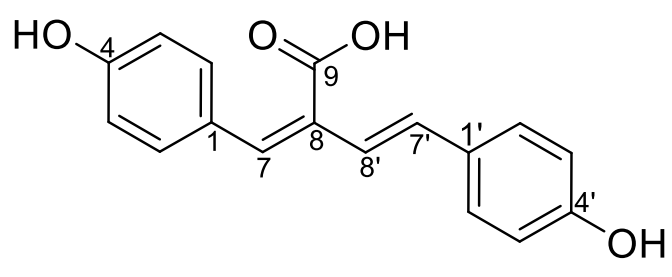

cis-6 trans $\mathrm{H}-3^{\prime}$ and $5^{\prime}$

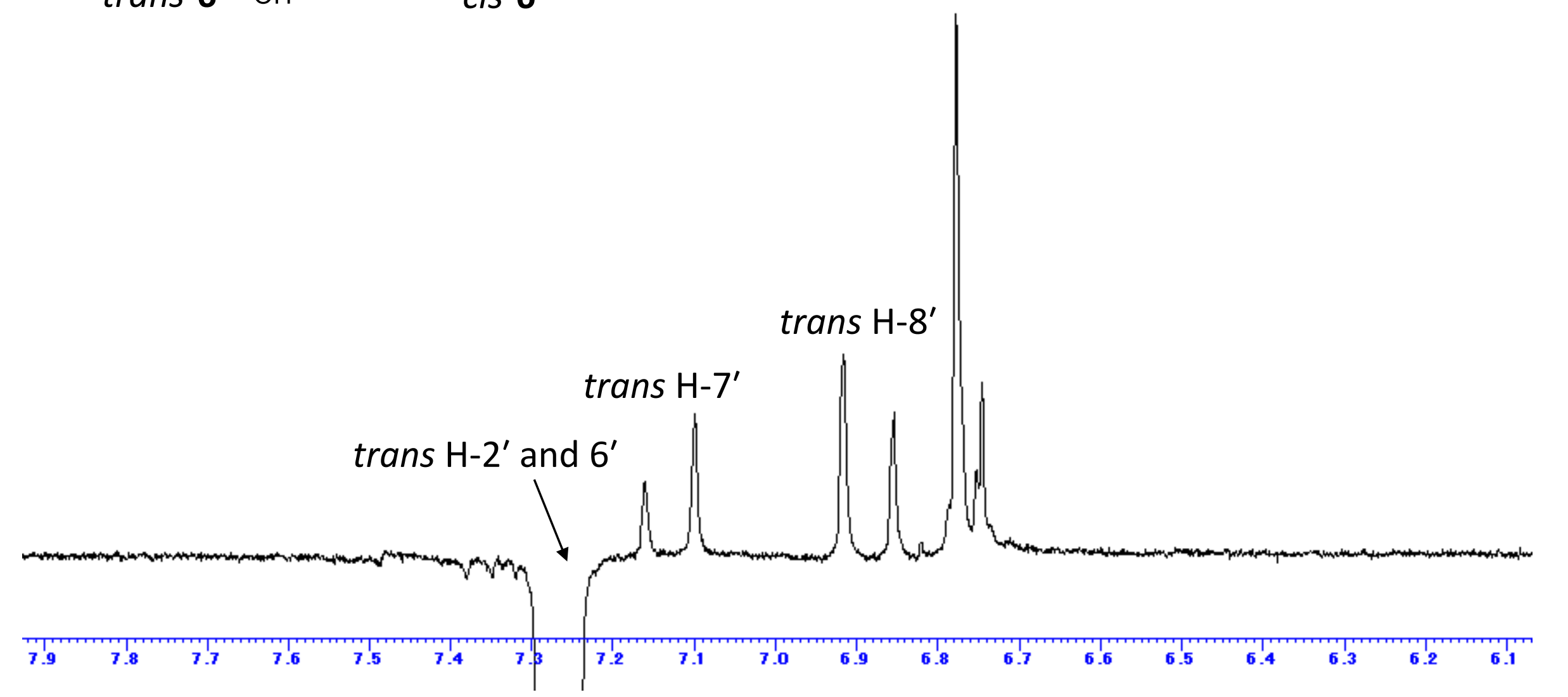

Figure S54. NOE spectrum of compound 6 (trans $\mathrm{H}-2^{\prime}$ and $6^{\prime}$ ) 


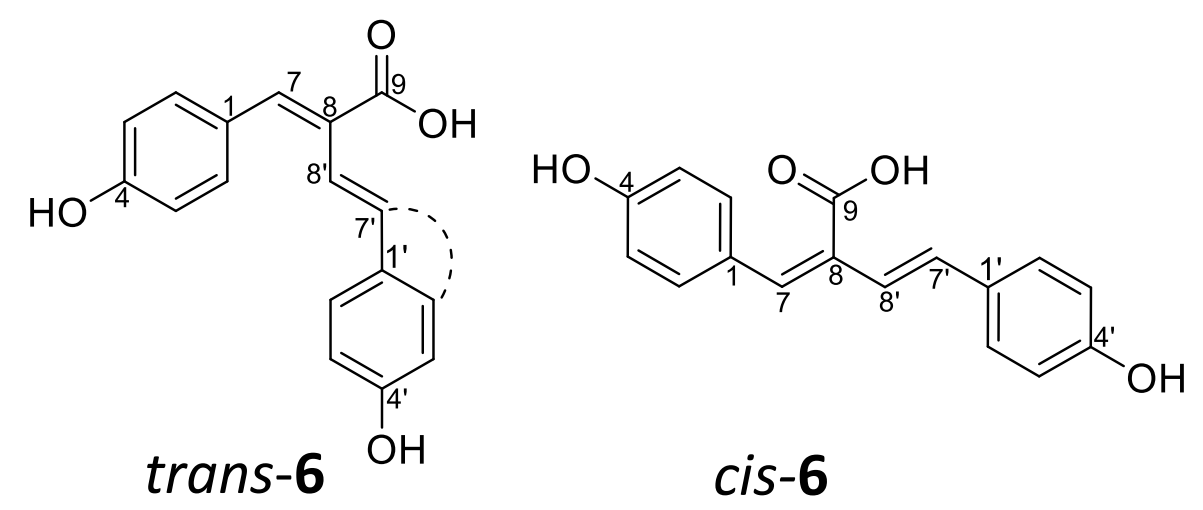

trans $\mathrm{H}-2^{\prime}$ and $6^{\prime}$

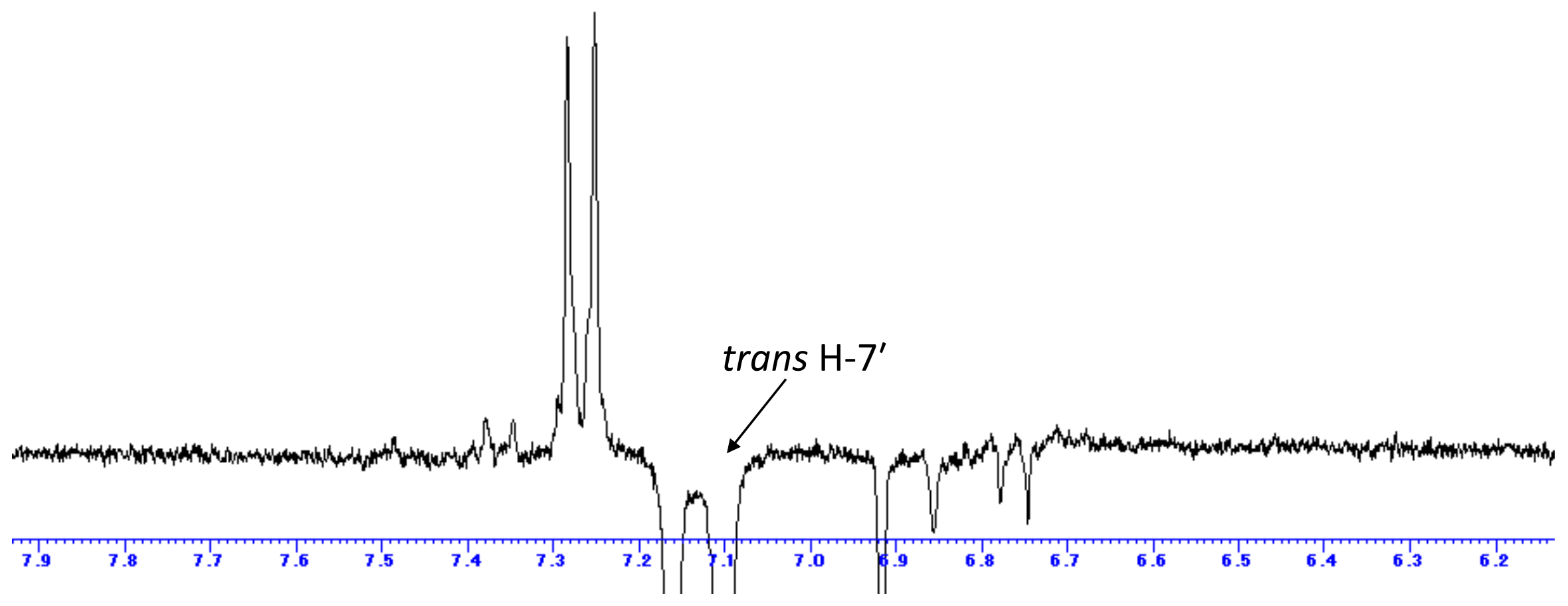

Figure S55. NOE spectrum of compound 6 (trans $\mathrm{H}-\mathbf{7}^{\prime}$ ) 

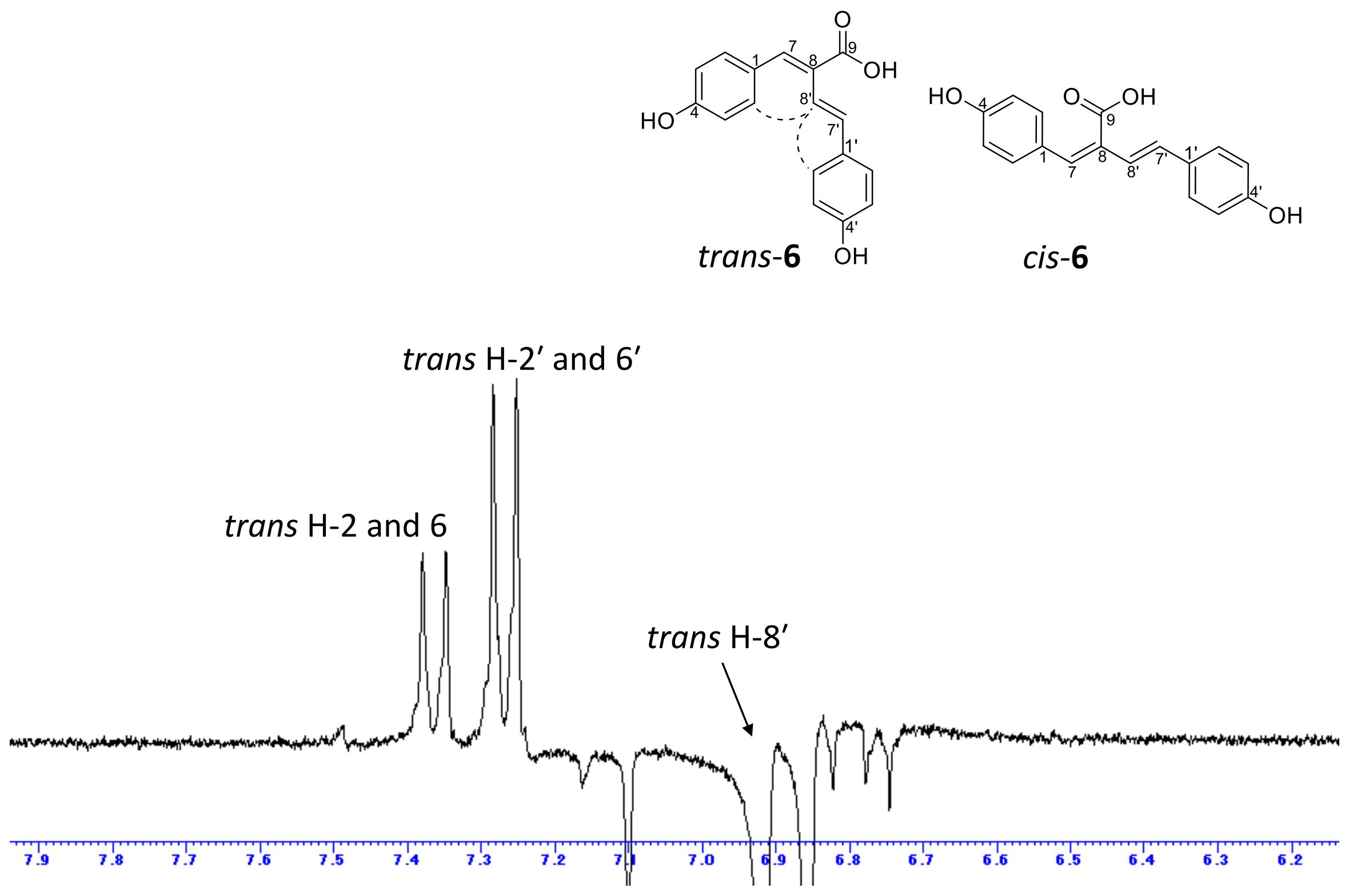

Figure S56. NOE spectrum of compound 6 (trans $\mathrm{H}-8^{\prime}$ ) 


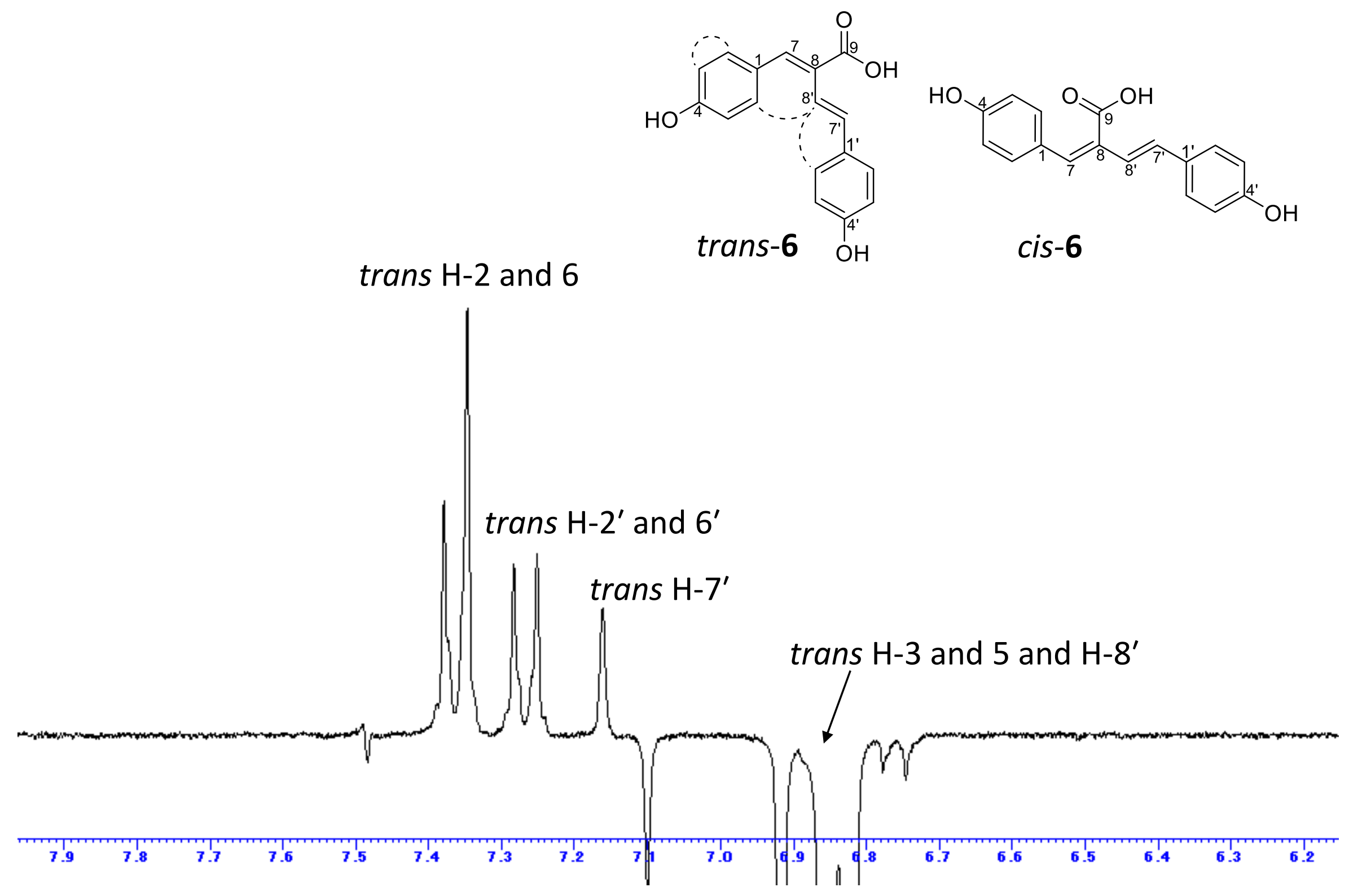

Figure S57. NOE spectrum of compound 6 (trans $\mathrm{H}-3$ and 5 and $\mathrm{H}-8^{\prime}$ ) 


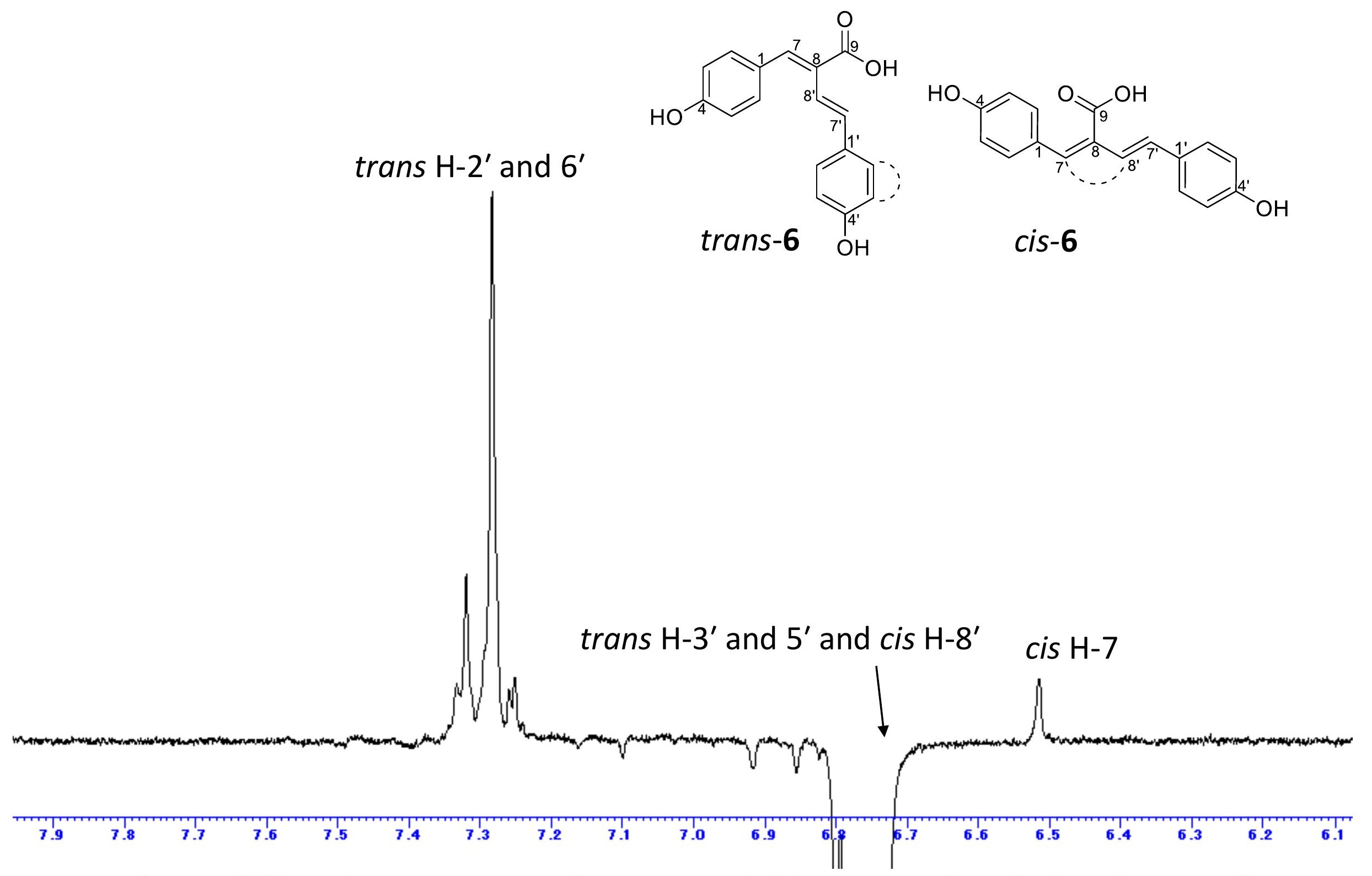

Figure S58. NOE spectrum of compound 6 (trans $\mathrm{H}-3^{\prime}$ and $5^{\prime}$ and cis $\mathrm{H}-8^{\prime}$ ) 

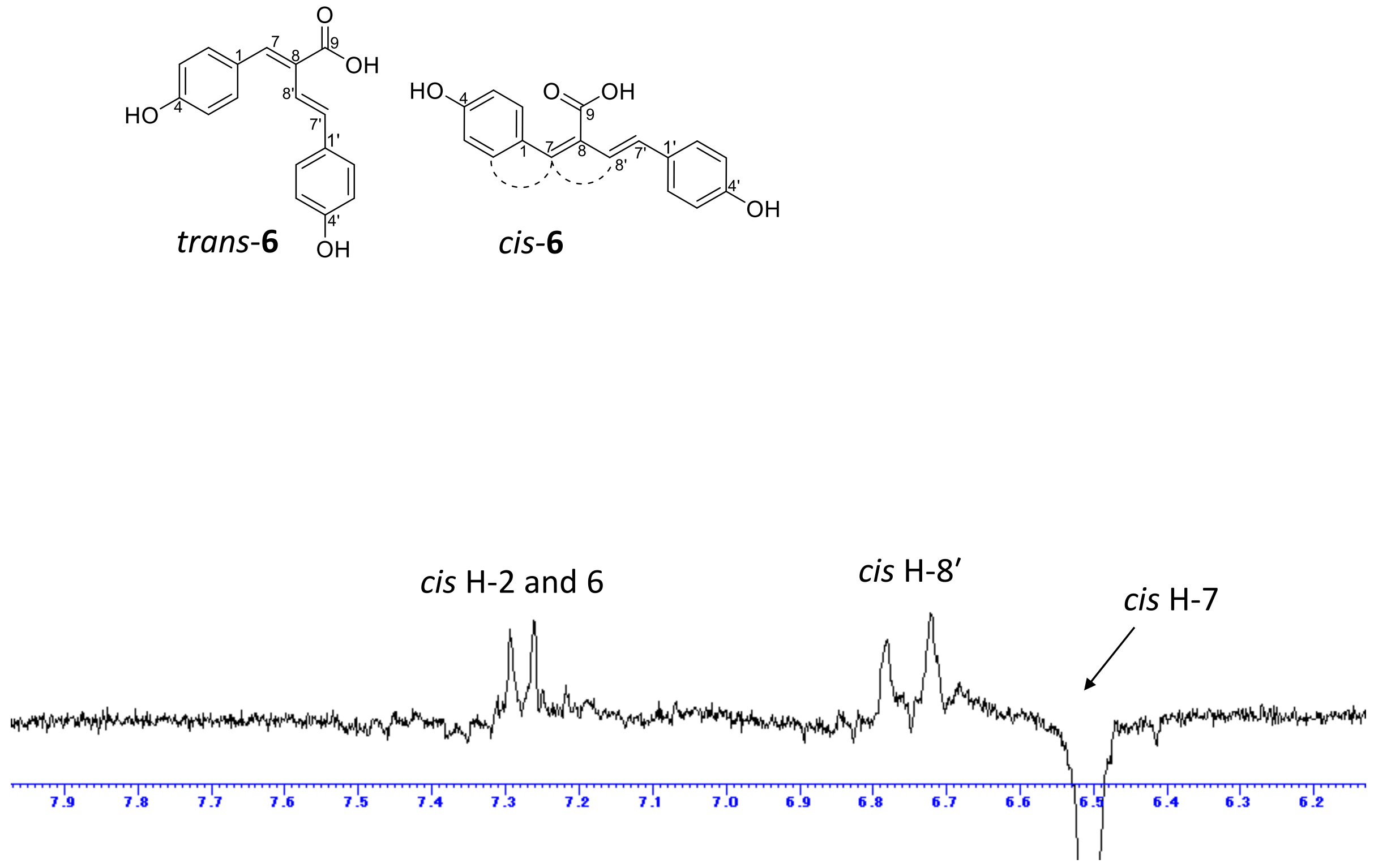

Figure S59. NOE spectrum of compound 6 (cis H-7) 


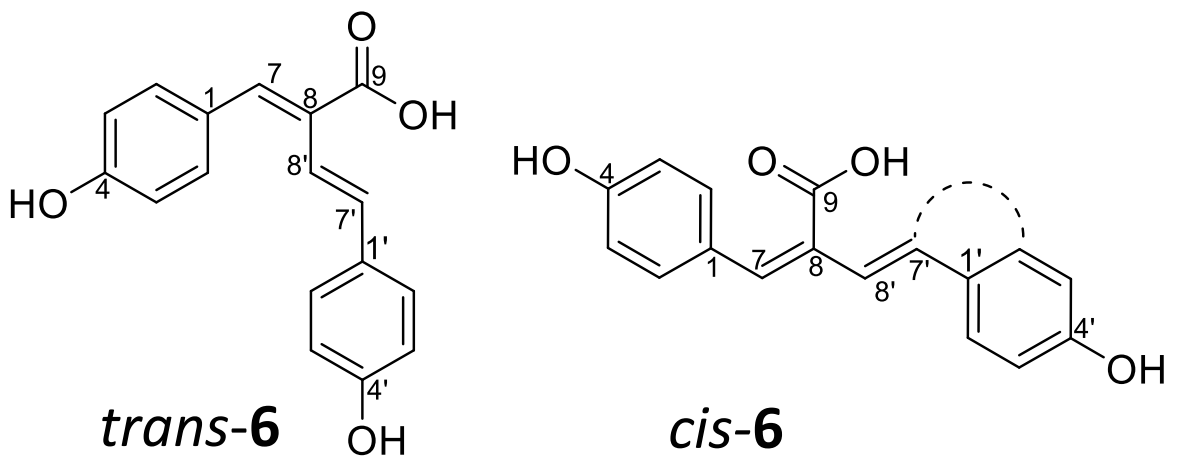

cis $\mathrm{H}-2^{\prime}$ and $6^{\prime}$

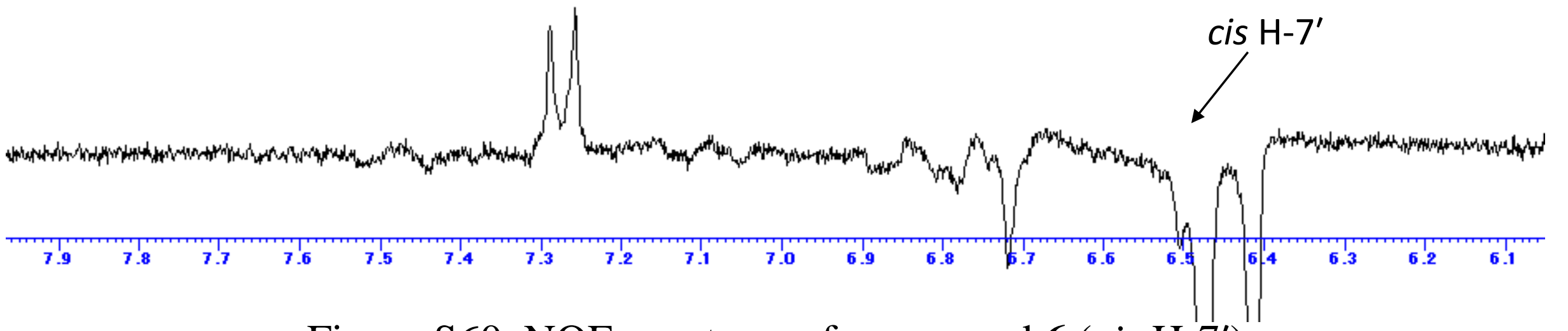

Figure S60. NOE spectrum of compound 6 (cis H-7') 


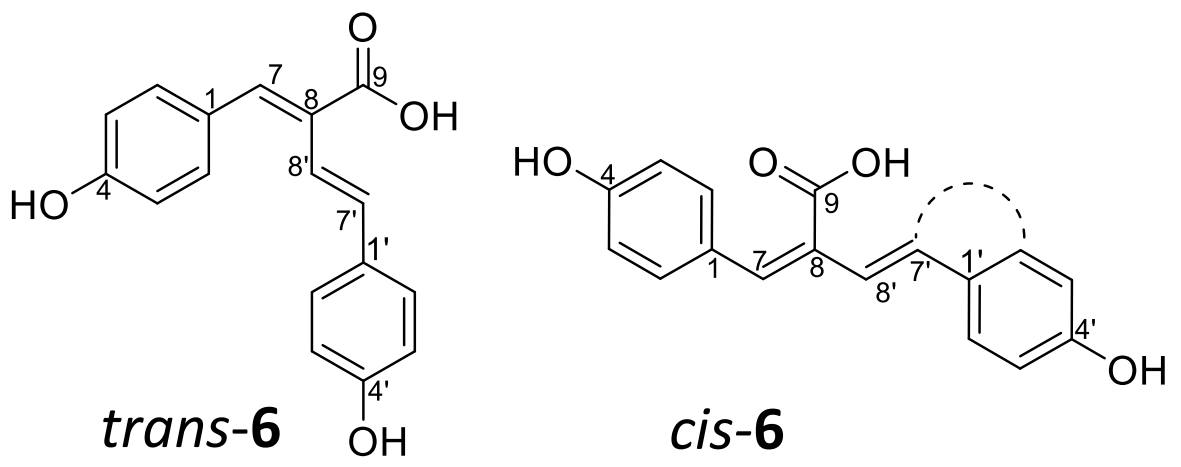

cis $\mathrm{H}-2^{\prime}$ and $6^{\prime}$

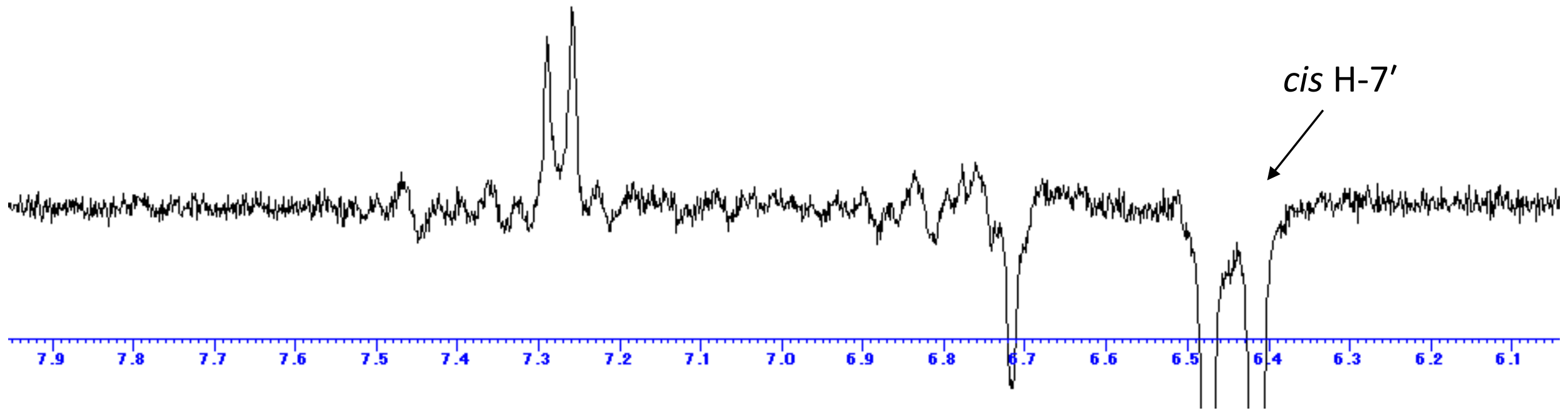

Figure S61. NOE spectrum of compound 6 (cis H-7') 